THE EDUCATION FOR JOBS (ExJ) INITIATIVE

El futuro del empleo y las competencias profesionales del futuro: la perspectiva de las empresas

MARÍA LUISA BLÁZQUEZ

ROGER MASCLANS

JORDI CANALS

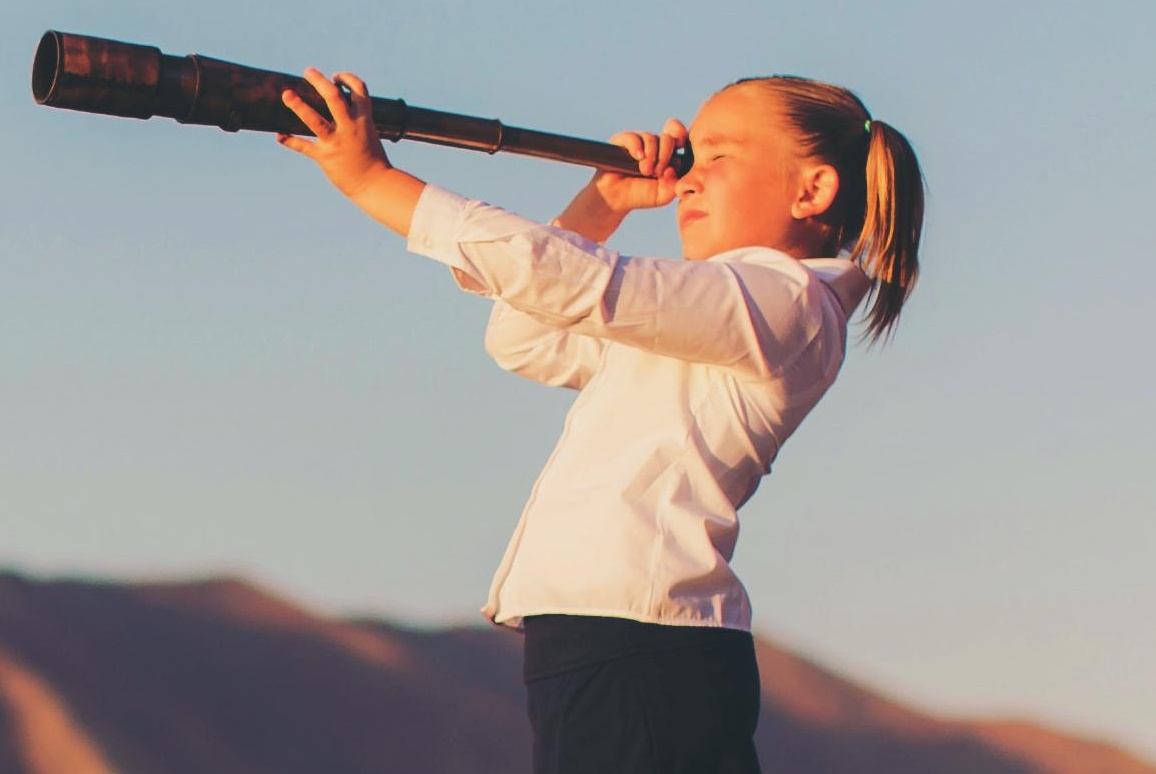



The Education for Jobs (ExJ) Initiative

\section{El futuro del empleo y las competencias profesionales del futuro: la perspectiva de las empresas}

Enero de 2019

MARÍA LUISA BLÁZQUEZ(1)

ROGER MASCLANS ${ }^{(2)}$

JORDI CANALS ${ }^{(3)}$ 



\section{Índice}

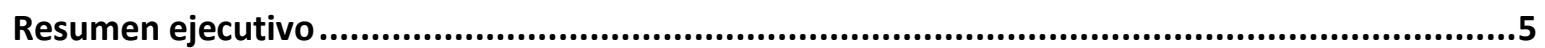

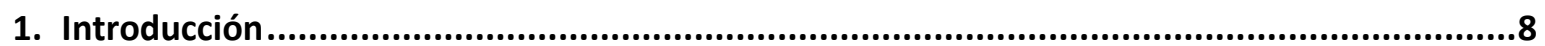

2. Empleo y desempleo en la Unión Europea. El caso especial de España ..............................9

3. El reto del empleo en la sociedad del siglo XXI .........................................................20

4. Nuevas competencias profesionales requeridas para los empleos del futuro ...................35

5. Educación para el desarrollo de competencias. El punto de vista de las empresas .............45

6. Un diagnóstico de conjunto sobre las competencias profesionales necesarias para el empleo desde la perspectiva de las empresas ...........................................69

7. Un plan de acción para promover la empleabilidad en el futuro.......................................76

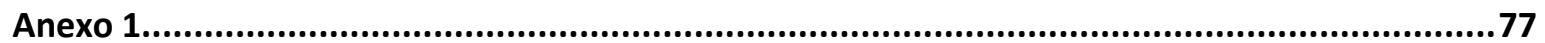

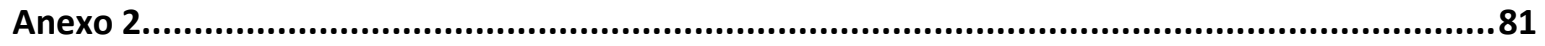

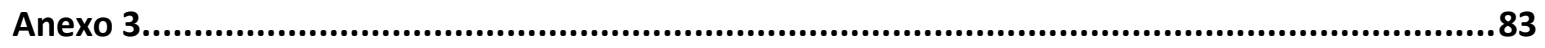

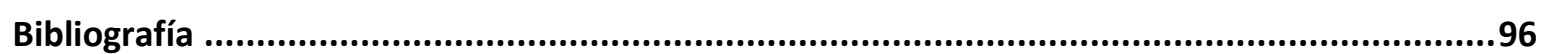





\section{Resumen ejecutivo}

El problema del desempleo es uno de los principales retos de España. Aunque la tasa de paro se ha reducido desde el 25,7\% registrado en diciembre de 2013 hasta el 14,5\% de diciembre de 2018 , nuestro país todavía presenta una tasa muy superior a la media de la UE $(6,6 \%$ en diciembre de 2018). El problema es especialmente grave entre los jóvenes, con una tasa de desempleo en menores de 25 años del 32,7\%, frente al 14,9\% de la media de la UE en diciembre de 2018.

La educación es uno de los principales factores que explican el empleo y el desempleo juvenil. Los trabajadores con niveles inferiores de formación sufren tasas de paro más altas que aquellos con niveles medios y, sobre todo, que los que tienen estudios de formación profesional superior o universitarios. En España, la diferencia en tasas de ocupación en septiembre de 2018 entre jóvenes con un nivel alto de estudios y aquellos con un nivel bajo es de 32 puntos porcentuales.

Este informe presenta la opinión y experiencia de 53 destacadas empresas que operan en España acerca de las perspectivas de creación de ocupación y las competencias profesionales requeridas por estas compañías para cubrir sus necesidades. A continuación, se presentan algunas conclusiones de interés.

1. El crecimiento económico sigue siendo importante a la hora de explicar la evolución del empleo y del desempleo. Sin embargo, algunas tendencias globales como la revolución digital, la automatización, la globalización, el envejecimiento demográfico o la expansión de la gig economy tienen un impacto específico sobre el volumen y la naturaleza del empleo, más allá del ciclo económico. Así, la creciente adopción de las nuevas tecnologías supondrá una mayor automatización de tareas y, por tanto, una determinada sustitución de puestos de trabajo por máquinas. La OCDE ha estimado que España tiene más de un $50 \%$ de empleos en riesgo alto o significativo de automatización, lo que supone claros desafíos desde el punto de vista del empleo y la formación.

2. En este contexto, nuestra sociedad necesita un sistema educativo de calidad, flexible y capaz de responder a las necesidades cambiantes de las empresas y de la propia sociedad. La expansión de las competencias profesionales requeridas se ha desarrollado a una velocidad muy superior a la adaptación del sistema educativo, lo que ha generado desajustes claros de capacidades requeridas para los puestos de trabajo ofrecidos. Según la OCDE, en el caso de España los desajustes de capacidades llegan a afectar a más del 33\% de los trabajadores. El futuro del empleo exige comprender los conocimientos y las capacidades que las empresas necesitarán en los próximos años. Estas son, en último término, las que crean empleo y juegan un papel fundamental en la definición de las competencias profesionales que deben desarrollarse para garantizar la empleabilidad de los jóvenes en el futuro.

3. El sistema educativo español no proporciona la respuesta adecuada a los cambios expuestos y a las necesidades reales de las empresas. El 72\% de las compañías entrevistadas encuentra problemas para cubrir los puestos de trabajo que ofrecen. Las dificultades se encuentran tanto a nivel de conocimientos como de capacidades y actitudes requeridas. La mejora de las competencias profesionales de los jóvenes es responsabilidad de todos los ciudadanos, no sólo de los centros educativos. De hecho, las familias y las empresas tienen un papel muy relevante en el desarrollo de las capacidades y actitudes profesionales y personales. 
4. Las empresas siguen apostando por contratar personas con formación universitaria de grado superior. El $67 \%$ de los puestos de trabajo actuales y el $57 \%$ de los ofrecidos en los últimos doce meses en las compañías entrevistadas están ocupados por personas con formación universitaria de grado superior. Asimismo, los puestos cubiertos por profesionales de formación profesional suponen el 17\% de los puestos de trabajo actuales y el $21 \%$ de las contrataciones realizadas en los últimos doce meses en las empresas entrevistadas. Sin embargo, las empresas siguen encontrando dificultades para contratar a personas preparadas con formación profesional. De hecho, España muestra un porcentaje de jóvenes con estudios de formación profesional del $24 \%$, muy por debajo de la media de la UE (36\%) o de países como Austria (59\%), Francia (48\%) o Alemania (51\%).

5. Las empresas consideran que las grandes tendencias antes descritas están teniendo un impacto muy alto en el cambio de perfiles profesionales requeridos. Así, un $72 \%$ de las empresas considera que la revolución digital tiene un impacto alto o muy alto en el cambio de perfiles requeridos. Un 56\% de las empresas piensa que el impacto de la automatización es alto o muy alto. En el caso de la automatización de los puestos de trabajo, el impacto esperado es mayor en niveles educativos inferiores y en funciones relacionadas con el área de Operaciones. Las empresas muestran gran preocupación por el cambio de competencias que supondrá la automatización y la revolución digital y la brecha de capacidades que generan.

6. Un $68 \%$ de las empresas detecta una importante brecha de conocimientos en tecnología y digitalización, en el caso de los graduados universitarios. Un $48 \%$ de las empresas detecta esta brecha en los graduados de formación profesional. Son cifras muy elevadas que muestran una insatisfacción con el sistema educativo. Asimismo, las compañías consideran que la brecha de conocimientos en áreas como big data, marketing digital, inteligencia artificial o blockchain será aún mayor dentro de cinco años, lo que agrava todavía más el problema del sistema educativo.

7. Las empresas también detectan una brecha relevante en las capacidades de las personas con formación universitaria. Un 56\% de las empresas entrevistadas no encuentra la capacidad de trabajo en equipo requerida para estos perfiles y un $52 \%$ de las empresas no encuentra la capacidad de comunicación necesaria. Un 52\% de las empresas no encuentra la capacidad requerida de comunicación y un $48 \%$ de las empresas no encuentra la capacidad requerida de trabajo en equipo en los graduados de formación profesional. Estos datos son relevantes, pues las empresas evolucionan hacia estructuras más planas y transversales, con modos de trabajar diferentes, que incorporan metodologías agile, trabajos por proyectos y métodos como design thinking. Estas tendencias requieren conocimientos y capacidades diferentes, con mayor énfasis en el trabajo en equipo, la comunicación, el liderazgo, la negociación o el sentido emprendedor.

8. La brecha en el ámbito de las actitudes profesionales y personales es también grande. Las empresas valoran especialmente la adaptabilidad, la resiliencia, el compromiso y la capacidad de trabajar en entornos inciertos. Un $72 \%$ de las empresas, sin embargo, no encuentra el nivel de adaptabilidad y resiliencia necesario en las personas procedentes de formación universitaria. Un 52\% de las empresas no encuentra estas actitudes en los graduados de formación profesional.

9. Para dar respuesta a las necesidades futuras y cubrir la brecha de conocimientos, capacidades y actitudes, las empresas necesitan, por parte del sistema educativo, una formación más completa, holística y práctica, con énfasis en los conocimientos, las capacidades y las actitudes necesarias en los próximos años. La percepción es que el sistema 
educativo no avanza en la dirección correcta ni a la velocidad adecuada, lo cual no ayuda a afrontar el reto del desempleo.

10. Con el objeto de promover la empleabilidad del futuro, es deseable una colaboración más intensa de los distintos actores. Un $87 \%$ de las empresas considera importante tener un papel más activo en la definición de los conocimientos y las capacidades necesarios, y su traslación a los planes de formación de los centros educativos. Las empresas también consideran necesaria una labor de orientación más profunda de los estudiantes sobre la realidad de la empresa y de la vida profesional. Resulta imprescindible que haya una colaboración más intensa entre empresas, universidades y otros centros educativos.

11. Por su parte, el gobierno central o los gobiernos autonómicos deberían impulsar esta colaboración entre empresas, universidades y centros educativos, flexibilizando el sistema para que las instituciones educativas puedan dar respuesta a las necesidades de las primeras, flexibilizando el contenido y la adaptación de los programas y módulos, y facilitando la creación de nuevos grados. Las formas de contratación de profesionales jóvenes y alumnos en prácticas en las empresas deberían tener un reconocimiento por parte de la sociedad, así como un tratamiento fiscal y laboral favorable. Estas fórmulas mixtas de estudio-trabajo, o prácticas hacia el final de un ciclo formativo o grado, son el mejor antídoto para luchar contra el desempleo y la mejor ayuda para preparar a los jóvenes para una trayectoria profesional satisfactoria. 


\section{Introducción ${ }^{1}$}

Pocas generaciones han vivido cambios tan drásticos como la actual: la globalización, los avances científicos y tecnológicos, la evolución de las comunicaciones y el transporte, y el crecimiento de las migraciones, entre otros factores, han contribuido a la desaparición o difuminación de muchas barreras geográficas, económicas y sociales. Estos cambios han generado incuestionables oportunidades en todos los campos, pero también retos y desafíos para los países, las empresas y la propia sociedad.

Uno de los principales retos que estos cambios plantean a los gobiernos y a toda la sociedad es cómo asegurar el empleo para sus ciudadanos. El desempleo tiene una incidencia directa en la exclusión social y la desigualdad y, lamentablemente, muchos países, entre ellos el nuestro, han sufrido en los últimos años los perniciosos efectos de unas elevadas tasas de paro.

Diversos factores influyen de forma decisiva en el empleo y el desempleo juvenil. En este informe pretendemos aportar una visión integradora que incluye el punto de vista de las empresas, las cuales deben tener un papel esencial en la definición de la educación para el futuro del empleo. En particular, en este documento queremos destacar que un factor decisivo sobre los niveles de empleo juvenil es la educación y el desarrollo de competencias profesionales necesarias para garantizar la empleabilidad.

En el proceso de definición de las competencias y capacidades que debe cubrir el modelo educativo para asegurar el empleo del futuro, las empresas deben tener un papel fundamental, ya que poseen el conocimiento de los perfiles y la formación que requerirán en el futuro. Limitar su función a la de meros empleadores de las personas que salen del sistema educativo es perder una contribución valiosísima para asegurar el necesario encaje entre el sistema educativo y las necesidades reales de las organizaciones.

Este trabajo está estructurado del siguiente modo. En el apartado 2 ofrecemos una síntesis de la evolución del empleo y desempleo en la Unión Europea (UE). En el apartado 3 presentamos brevemente las fuerzas que mueven el empleo y el desempleo en el mundo del siglo XXI. En el apartado 4 describimos la metodología utilizada en este informe. El apartado 5 ofrece los resultados de las entrevistas realizadas a 53 empresas (véase el Anexo 1). En el apartado 6 ofrecemos, a partir de los resultados de las encuestas y entrevistas realizadas, un diagnóstico sobre las competencias profesionales necesarias para el empleo. Finalmente, en el apartado 7 presentamos algunas ideas para un plan de acción.

\footnotetext{
${ }^{1}$ Los autores desean agradecer a los profesores Antonio Argandoña, Sandalio Gómez, Alfredo Pastor y José Ramón Pin los muy útiles comentarios que han efectuado sobre este informe. También desean agradecer el compromiso y tiempo que los directivos de las 53 empresas entrevistadas han dedicado a este proyecto (véase el Anexo 1): sin su participación este informe no habría sido posible. Finalmente, agradecen al equipo de Academic Material del IESE el magnífico trabajo de edición de este informe.
} 


\section{Empleo y desempleo en la Unión Europea. El caso especial de España}

La creación de empleo es uno de los principales retos de los países avanzados y ha sido, durante las últimas décadas, uno de los problemas más serios en España. Durante la última crisis económica, desde 2008 hasta finales de 2013, se destruyeron casi cuatro millones de empleos en nuestro país. A partir de entonces, iniciamos una senda de crecimiento económico que se ha traducido, entre otras cosas, en un aumento significativo del número de ocupados y la reducción de la tasa de paro desde el 25,7\% de 2013 hasta el 14,5\% de diciembre de 2018 (véase la Figura 1).

\section{Figura 1}

\section{Evolución del número de ocupados y de la tasa de paro en España, 1990-2018}

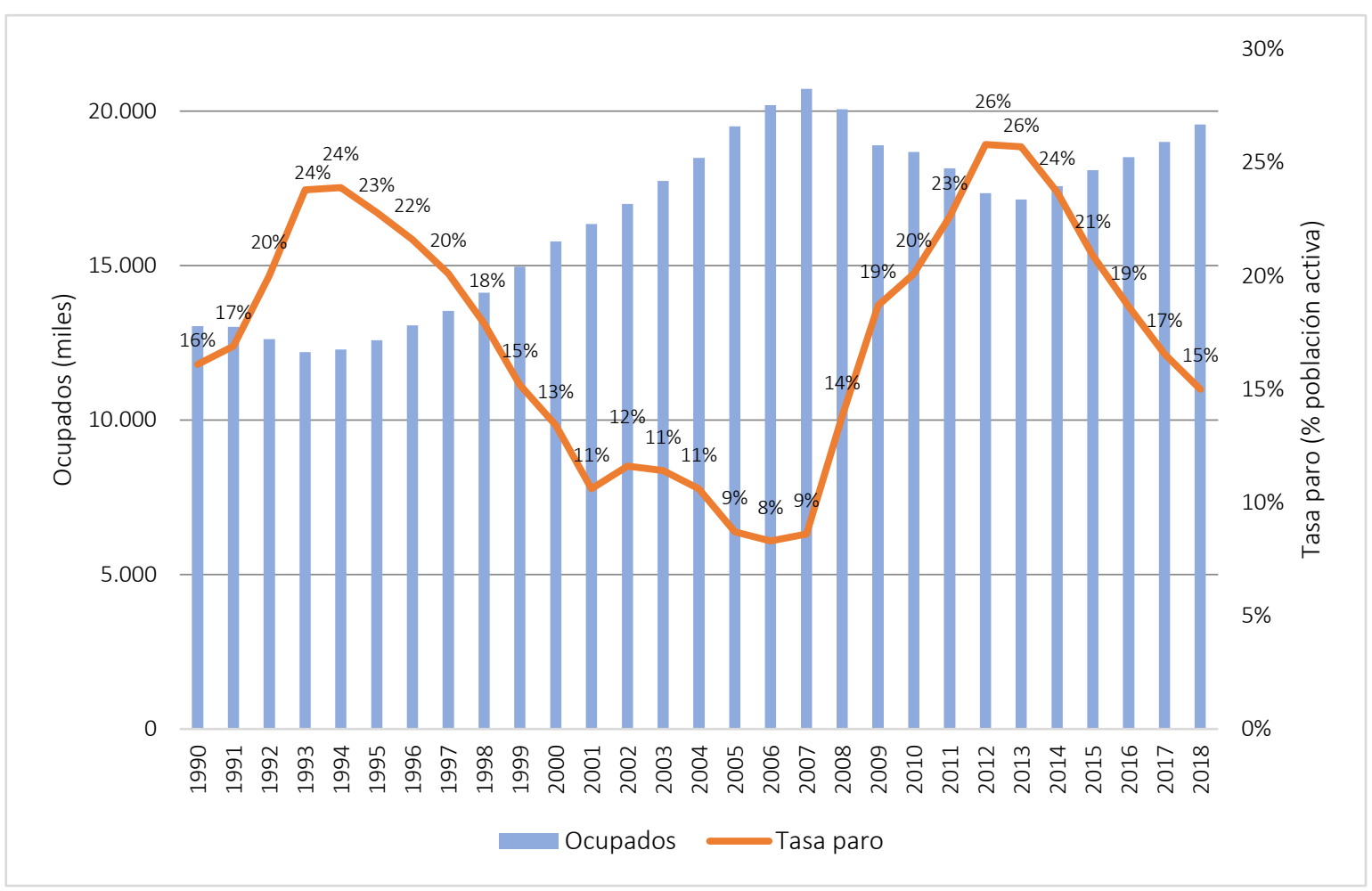

Fuente: Instituto Nacional de Estadística (2019), Encuesta de Población Activa.

Sin embargo, aunque la tendencia es incuestionablemente positiva, nuestro país tiene una tasa de paro muy superior a la media de la UE, que se sitúa en el 6,6\% en la UE-28, a finales de 2018. El problema en España es especialmente grave entre los jóvenes. La tasa de desempleo en menores de 25 años alcanza el 32,7\% de la población activa, frente al 14,9\% de media en la UE-28 registrada en diciembre de 2018 (véase la Figura 2). Esto genera graves consecuencias económicas, pero también a nivel social, como la desconfianza, la exclusión social y la fuga de talento, además de lastrar la capacidad competitiva a medio y largo plazo de nuestro país. 
Figura 2

Desempleo en la UE-28, diciembre de 2018 (\% sobre población activa)

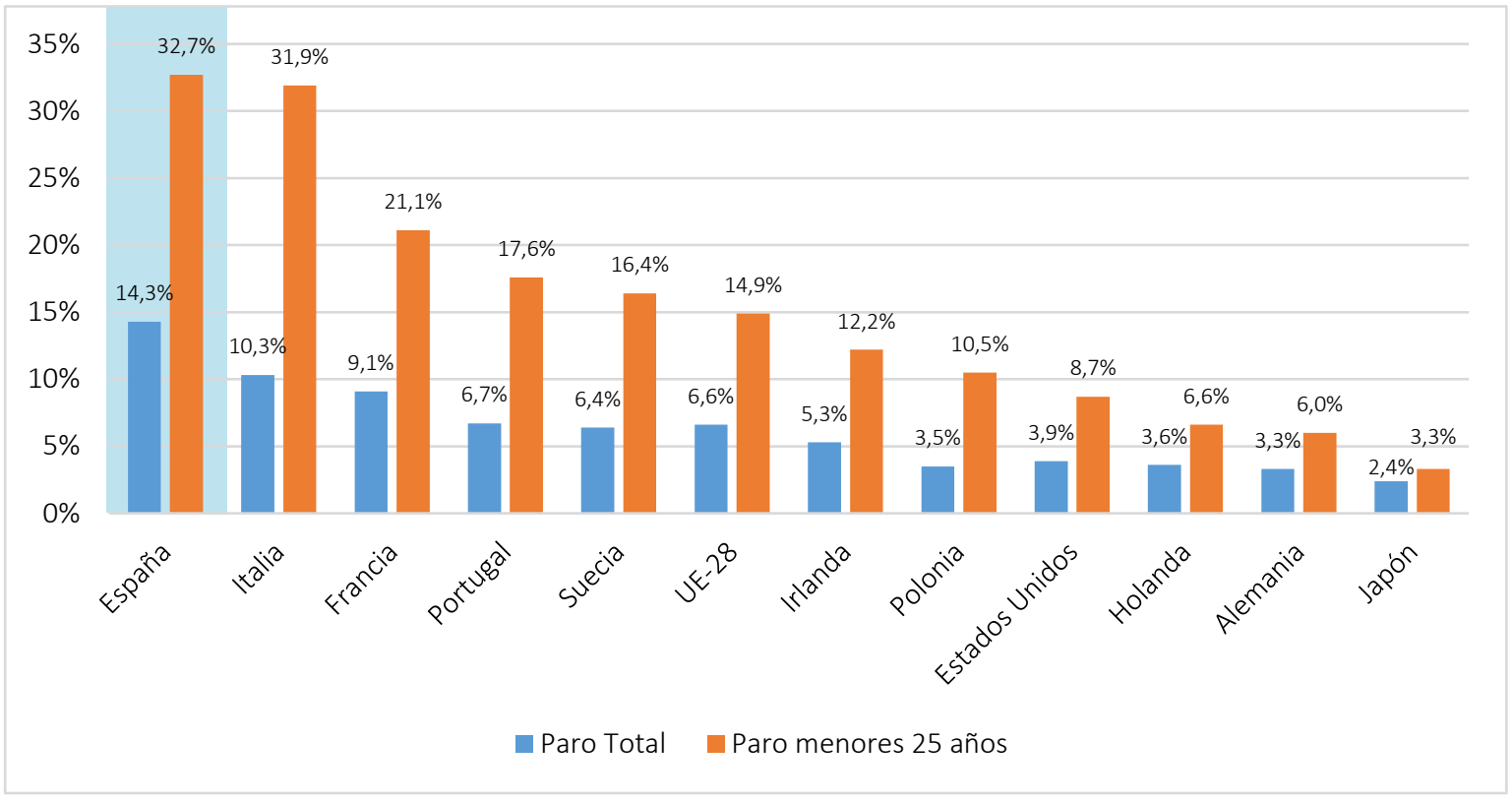

Fuente: Eurostat (2019), Unemployment Statistics.

El problema de desempleo juvenil, si bien tiene características estructurales - como el resto del desempleo-, ha alcanzado proporciones realmente alarmantes en los años de la crisis, llegando la tasa de paro a niveles cercanos al 60\% de los jóvenes en 2013, tal y como muestra la Figura 3. Como puede observarse, desde dicha fecha, las tasas de ocupación entre los jóvenes, tanto hombres como mujeres, se han recuperado y ha descendido drásticamente la tasa de paro, aunque sigue manteniéndose en niveles muy elevados.

\section{Figura 3}

\section{España: tasas de actividad, ocupación y paro de los jóvenes}

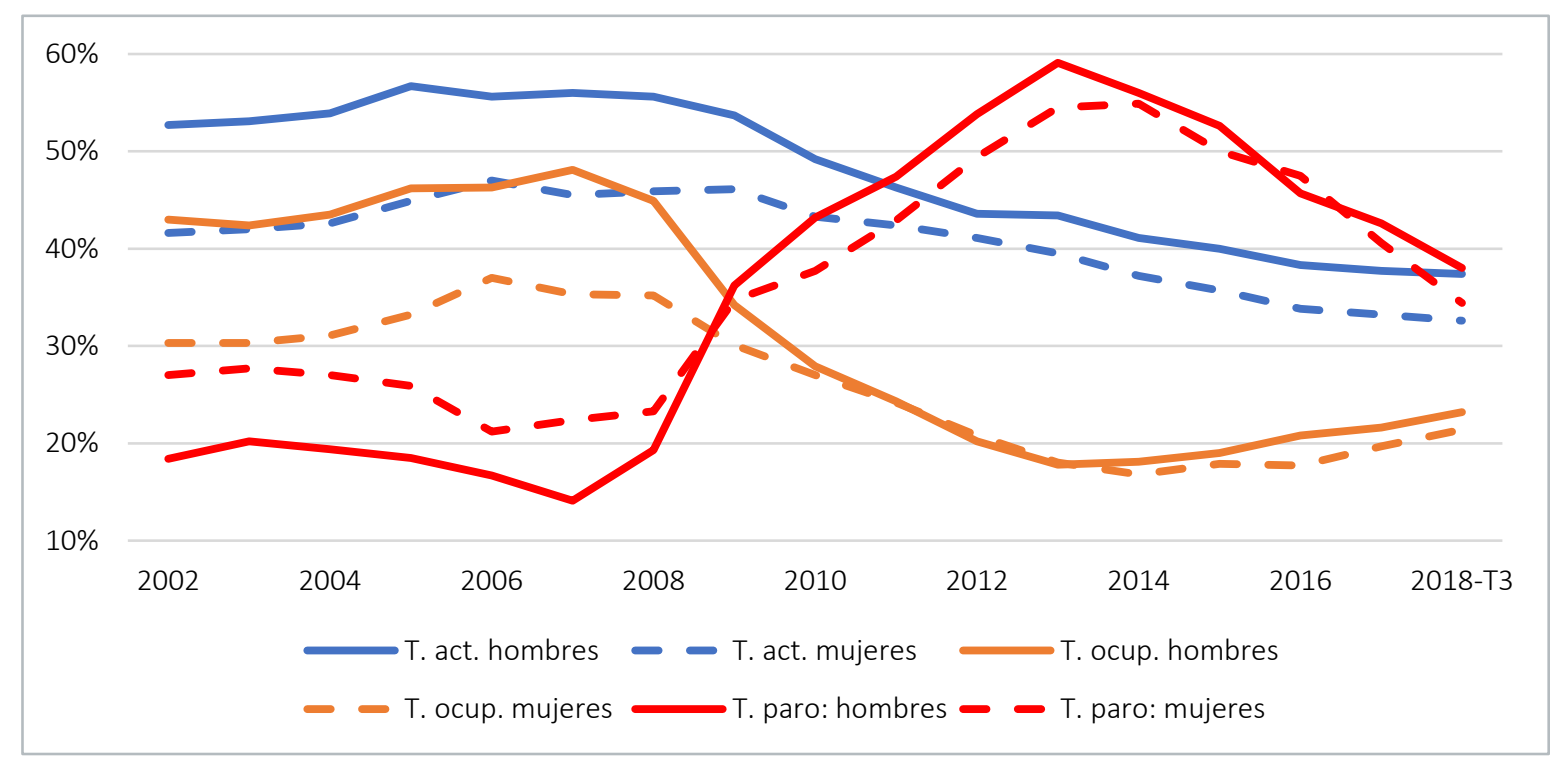

Fuente: Instituto Nacional de Estadística (2018a), Encuesta de Población Activa. 
El sistema laboral en nuestro país presenta, además, otras características preocupantes de dualidad y polarización, que se expresa en la elevada tasa de temporalidad, superior al 26\%, y trabajo a tiempo parcial, por encima del 16\% (Banco de España, 2018a), con la peculiaridad, además, de que en la mayoría de los casos ambas características son no deseadas por los trabajadores. Hay que tener en cuenta, por otro lado, que España es una economía de servicios (suponen casi el 70\% del producto interior bruto [PIB]), con un peso importante de sectores como el turismo y la agricultura, que tienen un carácter estacional, lo que impulsa la temporalidad del trabajo.

En el caso de los jóvenes, estos problemas se agravan. La temporalidad en menores de 25 años se situaba, en 2017, en el 69\% en nuestro país, destacando claramente sobre el resto de los de la UE, según datos de Eurostat. Además, en más del $70 \%$ de los casos se trata de una temporalidad no deseada, frente a países como Eslovenia u Holanda, que, si bien también cuentan con tasas muy altas de temporalidad, en su caso esta es buscada por los trabajadores jóvenes. El Banco de España, en su último informe anual, alerta sobre una menor duración de los nuevos contratos temporales en el periodo reciente, con las consecuencias que ello tiene sobre el aumento de la rotación y la disminución de la productividad (Banco de España, 2018b).

En el caso del trabajo a tiempo parcial en menores de 25 años, España presenta una tasa menor, alrededor del $38 \%$, y más cercana a la media de la UE. Pero, también en más de la mitad de los casos $(53,4 \%)$, esta modalidad es no deseada por los empleados, a diferencia de países como Dinamarca u Holanda, en los que los jóvenes buscan, en más del $90 \%$ de los casos, el empleo a tiempo parcial. (Véanse las Figuras 4 y 5).

\section{Figura 4}

Tasas de temporalidad y temporalidad no deseada en menores de 25 años en la UE, 2017

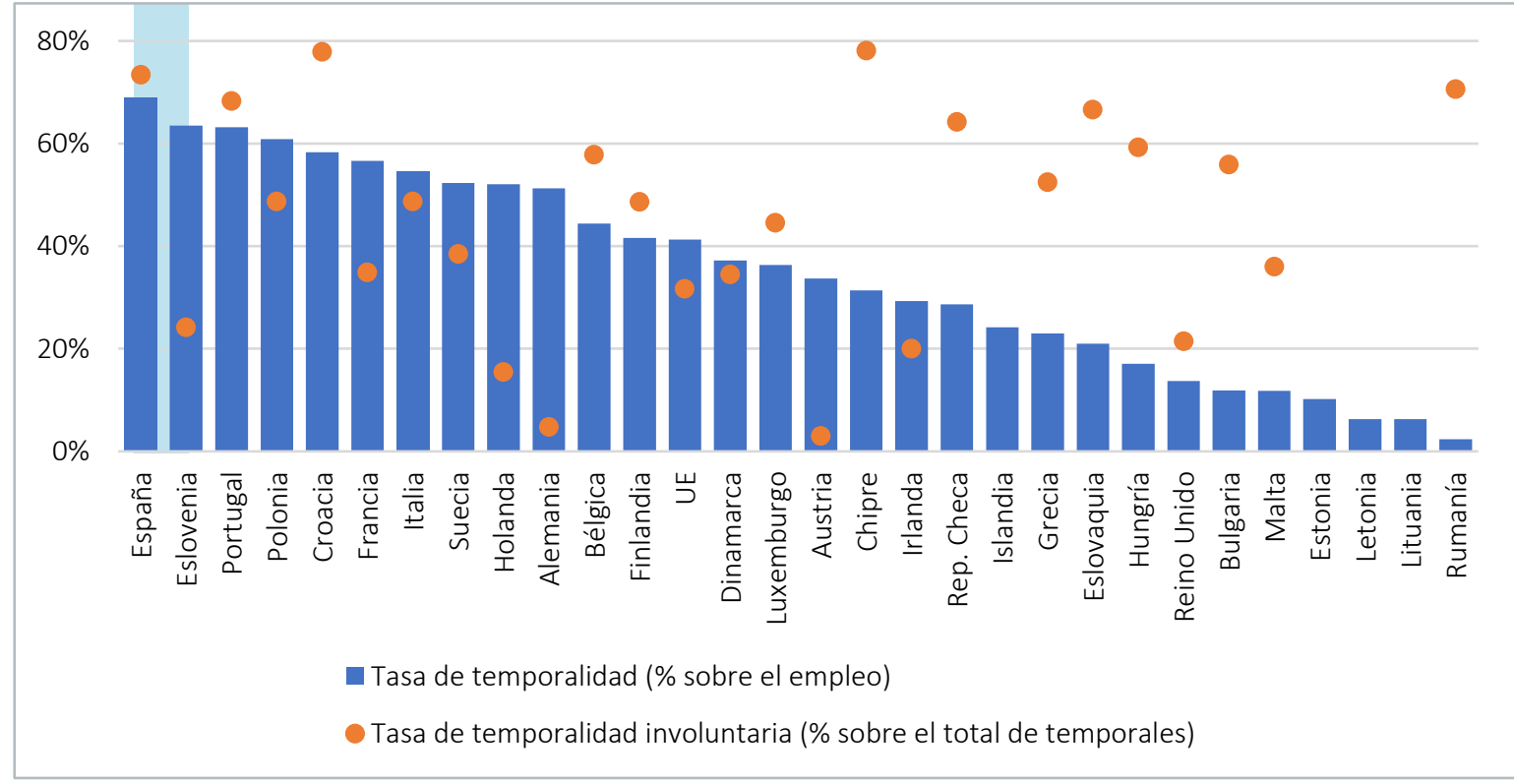

Fuente: Eurostat (2018b), Employment Statistics. 
Figura 5

Tasas de trabajo a tiempo parcial voluntario e involuntario (menores de 25 años en Europa)

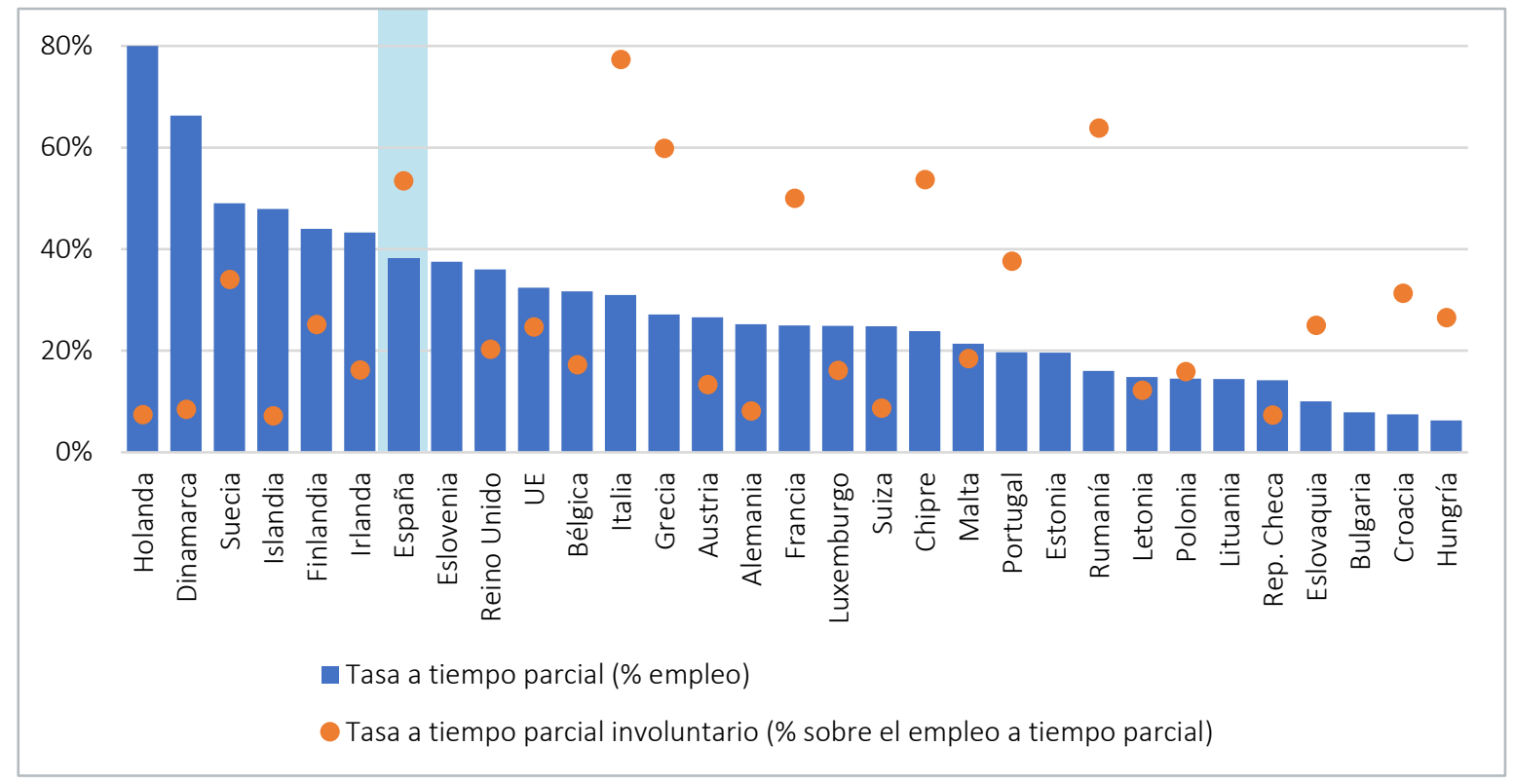

Fuente: Eurostat (2018b), Employment Statistics.

\subsection{El desempleo: la importancia de la educación}

Las causas que contribuyen al problema del elevado desempleo y, en particular, del desempleo juvenil en España son diversas ${ }^{2}$. Este informe no pretende hacer un análisis exhaustivo de un problema tan complejo, sino subrayar algunos aspectos relacionados con la educación y la evolución futura de las competencias profesionales que las empresas demandarán, y proponer un punto de vista enfocado en la educación del futuro para afrontar estas necesidades.

Uno de los factores relacionados con los altos niveles de desempleo es la calidad de la educación (Dolado et al., 2013). En la mayoría de los países europeos, las tasas de paro juvenil están ligadas a los niveles de estudio. Los trabajadores con niveles inferiores de estudio sufren tasas más altas de paro que aquellos con niveles medios y, sobre todo, que los que tienen estudios de formación profesional superior o universitarios. Así, en el caso de España, el paro entre trabajadores de 25-34 años que solo cuentan con la educación secundaria es del 28\%, mientras que baja al $14 \%$ en el caso de personas con estudios universitarios o de formación profesional de grado superior. El mismo patrón se observa en el resto de países europeos. Por ejemplo, en Francia, la tasa de paro varía entre el $26 \%$ de los jóvenes que solo cursaron la educación obligatoria y el $6 \%$ de los que cuentan con un grado universitario o formación profesional de grado superior (véase la Figura 6).

\footnotetext{
2 Bentolila, Dolado y Jimeno (2008) han tratado los condicionantes históricos de la falta de flexibilidad y la dualidad en el mercado laboral español. Bentolila, García-Pérez y Jansen (2017) han analizado en profundidad la persistencia en España del desempleo de larga duración, demostrando la incidencia de la falta de formación en habilidades en el desempleo de larga duración y el mayor riesgo de permanecer en este para personas mayores de 45 años con poca experiencia o que reciben prestaciones de desempleo. Dolado et al. (2013) analizan extensamente las causas del desempleo juvenil en España. La CEOE (2017) en su informe "La educación importa: libro blanco de los empresarios españoles", hace énfasis en la necesidad de mejora del sistema educativo.
} 


\section{Figura 6}

\section{Tasa de paro por nivel de estudios, 2017 (25-34 años)}

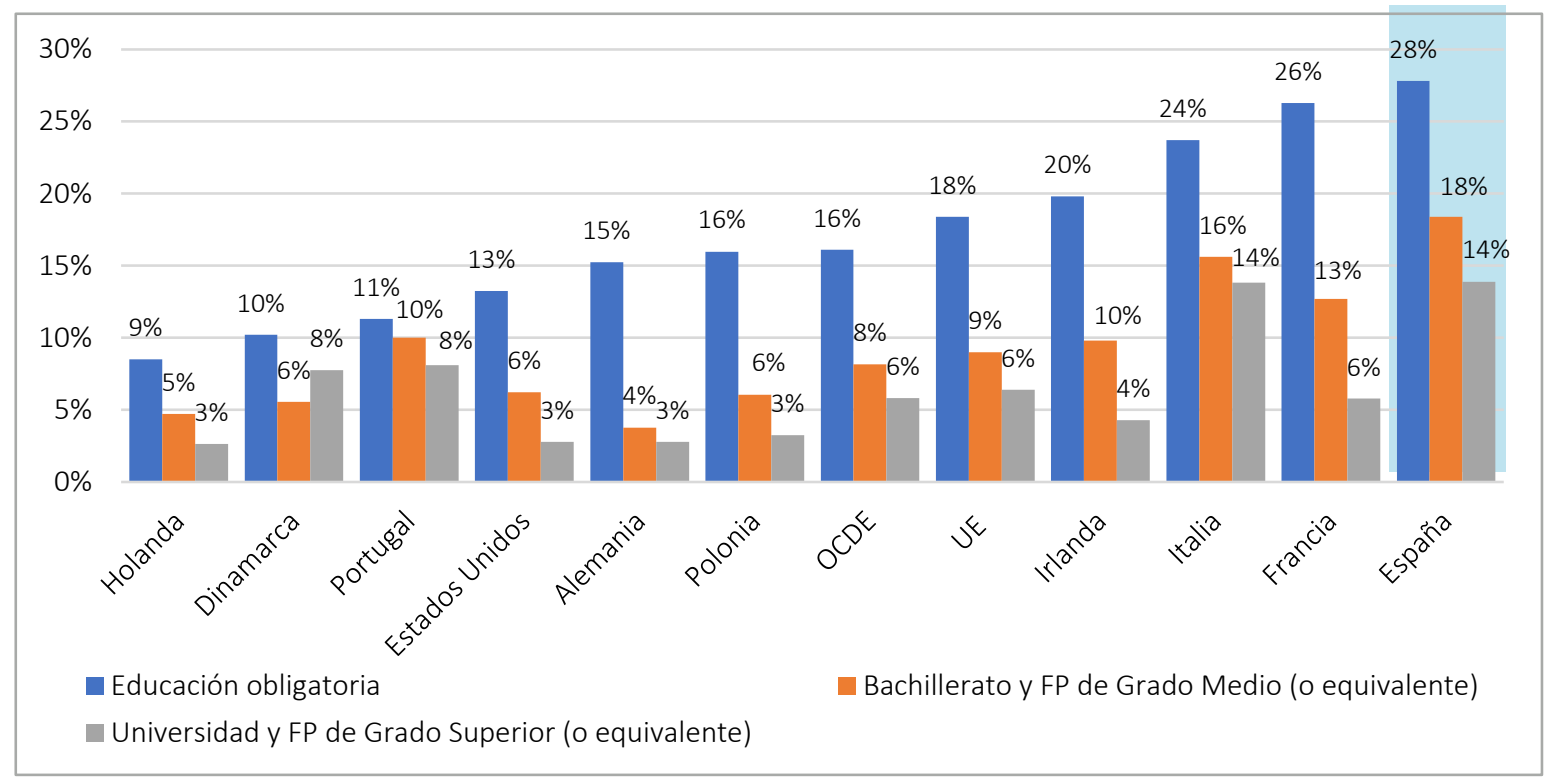

Fuente: OCDE (2018a), Education at a Glance 2018: OECD Indicators, OECD Publishing, París.

En el caso de España, la brecha de ocupación según el nivel de estudios es clara y se ha intensificado con la crisis económica. Así, en 2007 la tasa de ocupación ya era más alta para jóvenes con un nivel alto de estudios (59\%) que para jóvenes con un nivel medio $(38,6 \%)$ o bajo $(41,8 \%)$. Pero en 2018 la diferencia en tasas de ocupación entre jóvenes con un nivel alto y jóvenes con un nivel medio de estudios es de 27 puntos porcentuales, y si se comparan las tasas de ocupación de jóvenes con un nivel alto de estudios con los de un nivel bajo, la tasa de ocupación muestra una diferencia de 32 puntos porcentuales (véase la Figura 7).

Figura 7

Tasa de ocupación de jóvenes (16-24 años, \% sobre la población, según el nivel de estudios)

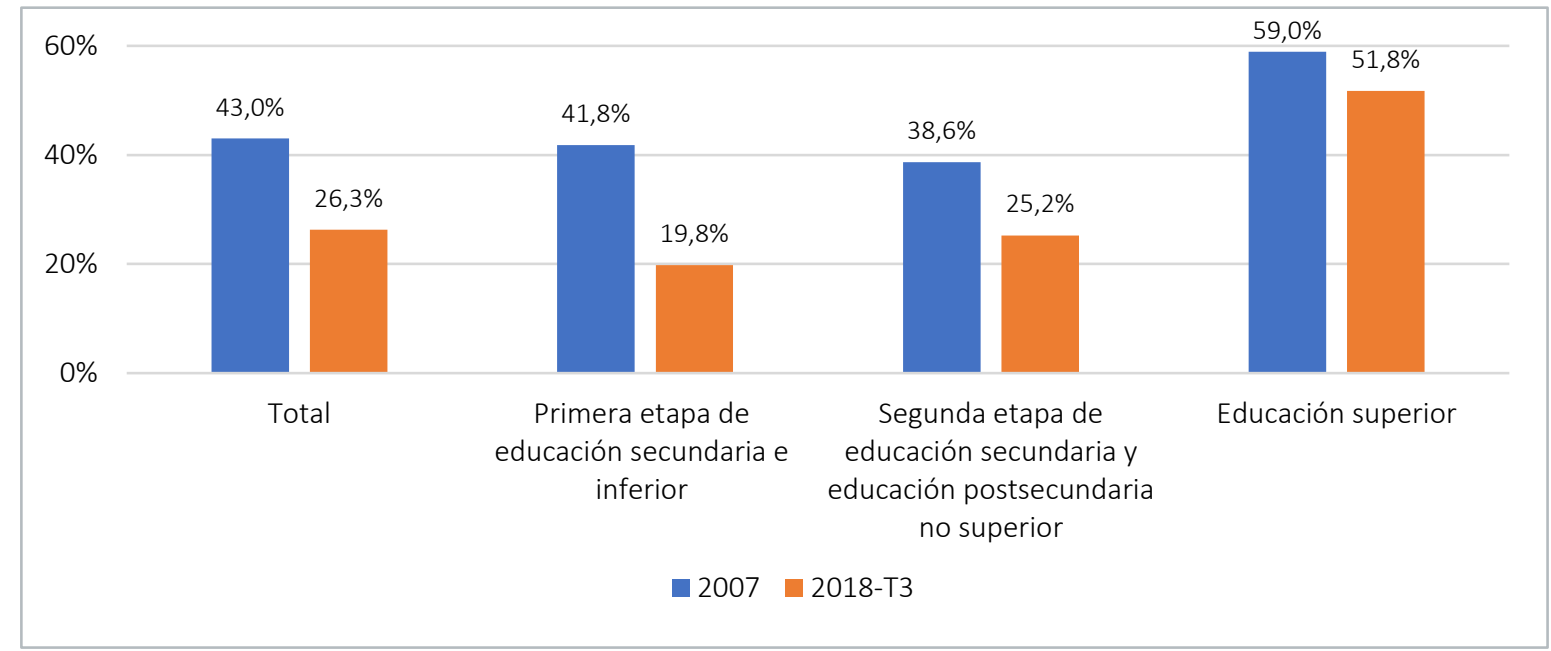

Fuente: Instituto Nacional de Estadística (2018a), Encuesta de Población Activa. 
Los niveles de abandono escolar en jóvenes de entre 18 y 24 años (18,3\%), de nuevo están muy por encima de la media de la UE, que se sitúa en el 10,6\% (véase la Figura 8). Aunque se ha hecho un esfuerzo claro en la disminución de esta brecha con buenos resultados desde 2007, el margen de mejora todavía es muy relevante.

\section{Figura 8}

\section{Tasa de abandono escolar temprano (18-24 años)}

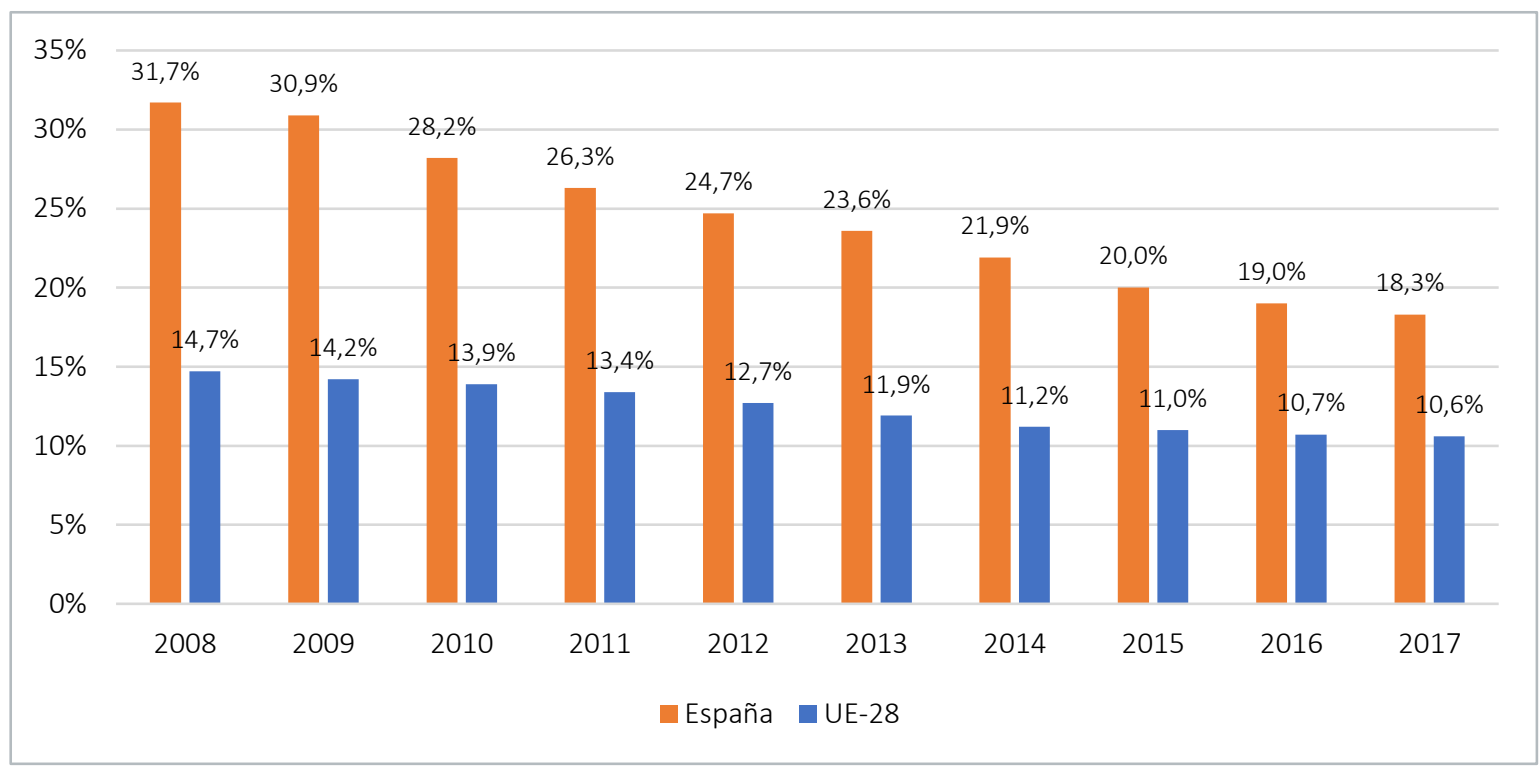

Fuente: Eurostat (2018a), Early Leavers from Education and Training.

En este sentido, si comparamos el nivel máximo de estudios alcanzados por los jóvenes, la diferencia entre España y otros países europeos es clara. La Figura 9 muestra que, en nuestro país, el 35\% de la población de entre 25 y 34 años en 2018 solo ha cursado la Educación Obligatoria (ESO), comparado con porcentajes como el $8 \%$ en Suiza, el 10\% en Austria y el 13\% en Francia y Alemania. Esto, unido a la baja penetración de la formación profesional en España, hace que casi la mitad de nuestros jóvenes de 25 a 34 años no hayan pasado del nivel de Bachillerato, porcentaje muy superior al del resto de países incluidos en la muestra. 


\section{Figura 9}

\section{Comparación del nivel máximo de estudios alcanzado, 2015 (\% de población de 25 a 34 años)}

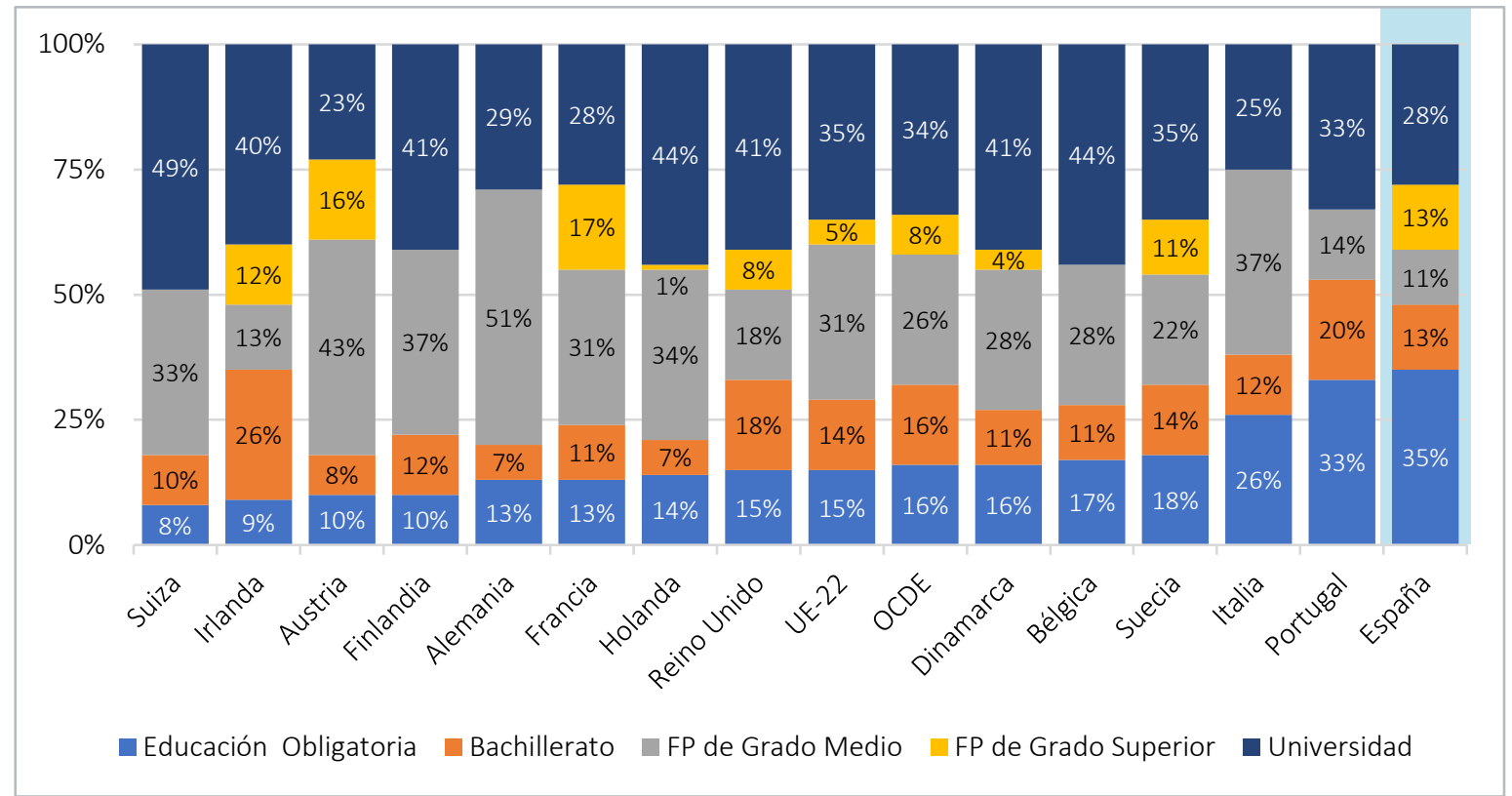

Fuente: OCDE (2016), Education at a Glance 2016: OECD Indicators, OECD Publishing, París.

\subsection{Algunas iniciativas para combatir el desempleo juvenil en la UE}

La Estrategia Europa 2020 aborda los problemas de desempleo y educación, y fija el marco de referencia en el que se desarrollan programas más específicos. Algunos de los objetivos de Europa 2020 están muy en línea con los problemas mencionados: por ejemplo, asegurar trabajo para el $75 \%$ de las personas de entre 24 y 64 años, reducir la tasa de abandono escolar por debajo del $10 \%$ o lograr que al menos el $40 \%$ de las personas de entre 30 y 34 años tengan estudios superiores finalizados.

Algunos de los programas implantados para lograr estos objetivos son Oportunidades para la Juventud, Tu primer trabajo EURES (2012) (para fomentar la movilidad ayudando a jóvenes a encontrar empleo o prácticas en otros países de la UE) o el fondo de Garantía Juvenil (2013), que trata de conseguir que jóvenes de hasta 25 años consigan una buena oferta de empleo, educación continua o prácticas en los cuatro meses siguientes a terminar su formación o quedarse en paro. En aplicación de este último programa, España puso en marcha en junio de 2014 el Plan Nacional de Implantación de la Garantía Juvenil, ampliándolo en 2015 para personas de hasta 30 años. Asimismo, diversas empresas han llevado a cabo iniciativas para tratar de aportar soluciones al problema del desempleo juvenil. El Anexo 2 incluye una breve descripción de algunas de estas iniciativas.

Como indica el informe "Jóvenes y mercado de trabajo", n.o 17 de la Subsecretaría de Trabajo, Migraciones y Seguridad Social (2018b), el principal indicador que se utiliza para seguir el éxito del programa es la tasa de "ninis" (porcentaje de jóvenes de entre 15 y 24 años que ni estudian ni trabajan). Pues bien, en nuestro país, si bien la tasa sigue por encima de la media de la UE, se ha reducido desde el 18,6\% de 2013 hasta el 13,3\% de 2017. 
En España, dos tipos de contratos facilitan el acceso de los jóvenes al mercado de trabajo: los contratos para la formación y el aprendizaje y los contratos en prácticas ${ }^{3}$. Los dos aportan bonificaciones e incentivos de contratación para las empresas y se han venido utilizando de forma más intensiva en los últimos años (véanse las Figuras 10 y 11 ).

\section{Figura 10}

\section{Número de contratos en prácticas (jóvenes de 16 a 29 años)}

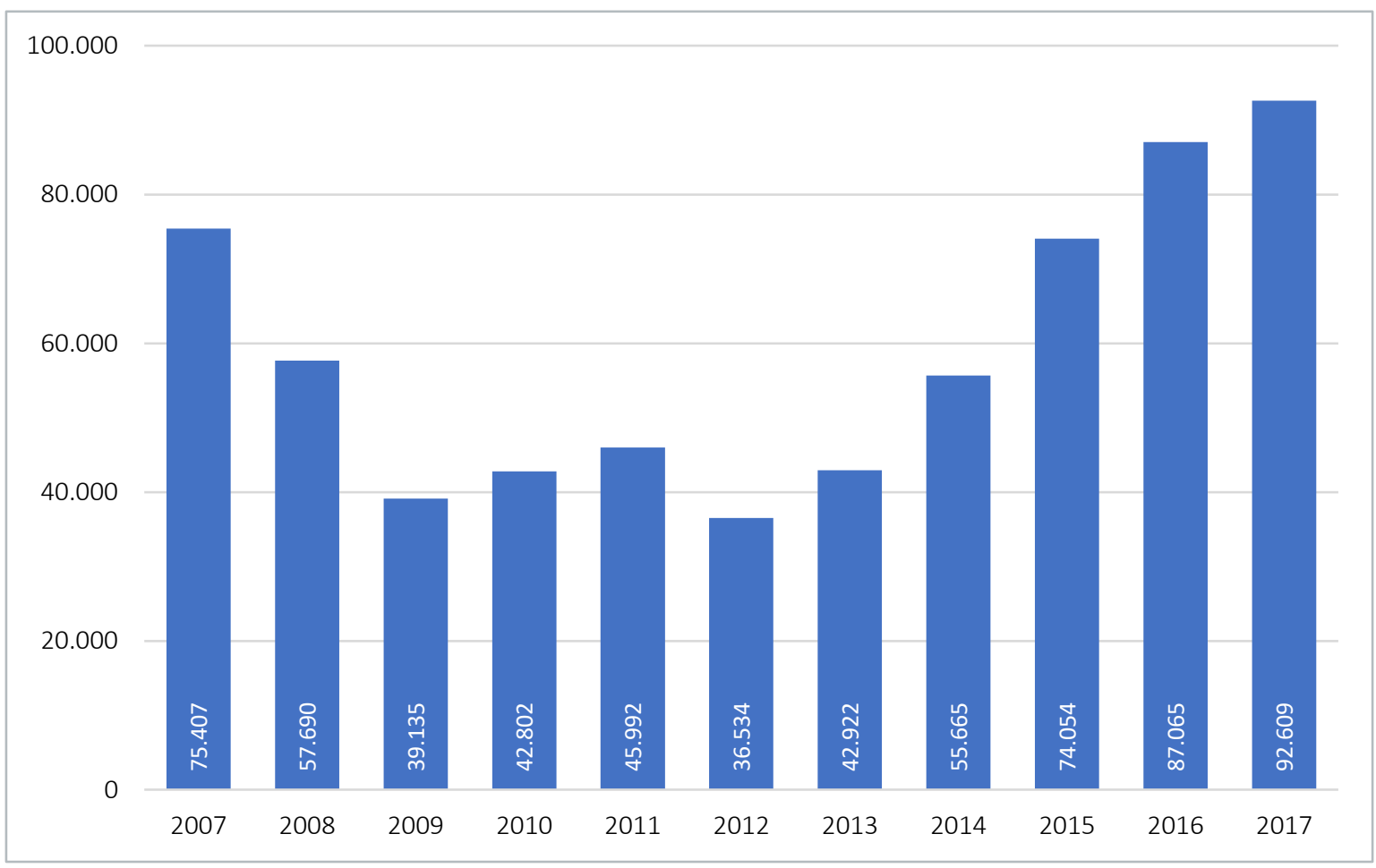

Fuente: Subsecretaría de Trabajo, Migraciones y Seguridad Social (2018b), “Jóvenes y mercado de trabajo”, n.o 17, p. 34.

\footnotetext{
${ }^{3}$ De acuerdo con el Servicio Público de Empleo Estatal (SEPE), del Ministerio de Trabajo, Migraciones y Seguridad Social, el contrato para la formación y el aprendizaje tiene por objeto la cualificación profesional de los trabajadores, en un régimen de alternancia de actividad laboral retribuida en una empresa, con actividad formativa recibida en el marco del sistema de formación profesional para el empleo o del sistema educativo. Está dirigido a jóvenes de entre 16 y 25 años (ampliado a menores de 30 años, hasta que la tasa de desempleo se sitúe por debajo del 15\%) y la duración mínima es de 1 año, y la máxima, de 3.

El contrato en prácticas tienen una duración de entre seis meses y dos años y su objeto es la obtención, por parte del trabajador, de la práctica profesional adecuada al nivel de estudios cursados. No se trata únicamente de adquirir experiencia en un trabajo determinado, sino también de que esa experiencia verse sobre los estudios cursados. Se puede concertar con quienes tengan título universitario o de formación profesional de grado medio o superior, o títulos oficialmente reconocidos como equivalentes, si no han transcurrido más de cinco años desde la terminación de los estudios. Si el trabajador es menor de 30 años, no se tiene en cuenta la fecha de terminación de los estudios.
} 


\section{Figura 11}

\section{Número de contratos para la formación y el aprendizaje (jóvenes de 16 a 29 años)}

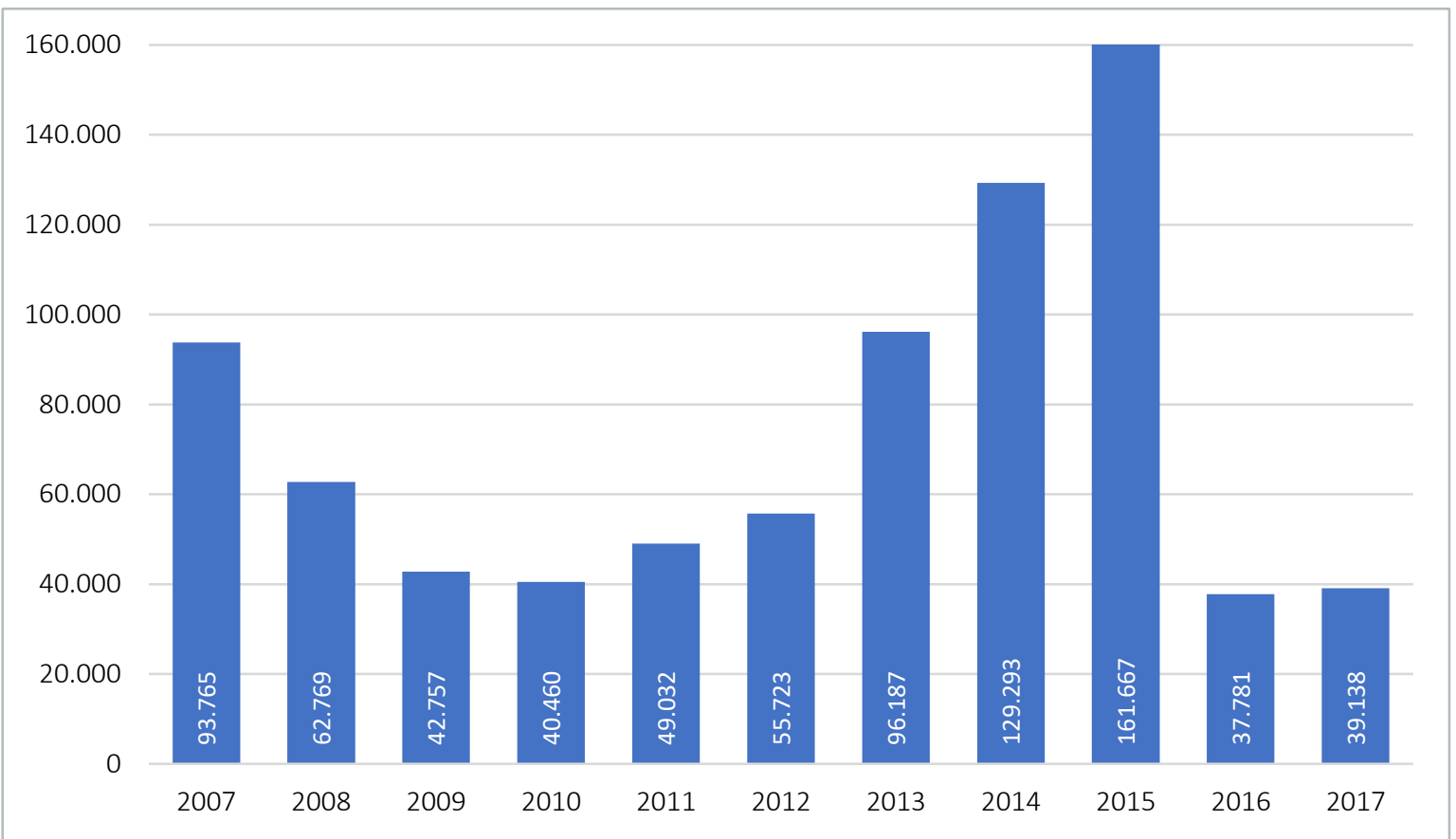

Fuente: Subsecretaría de Trabajo, Migraciones y Seguridad Social (2018a), “Jóvenes y mercado de trabajo”, n.o 16, p. 15.

Los contratos para la formación y el aprendizaje, además, son importantes para promover y facilitar la formación profesional dual, que sigue estando muy por debajo de los niveles deseables, tal como veremos a continuación ${ }^{4}$.

\subsection{Formación profesional y formación profesional dual en España}

Ante el grave problema del desempleo juvenil y del desajuste existente entre el sistema educativo y las demandas del mercado laboral, gobiernos ${ }^{5}$, empresas e instituciones coinciden en señalar la formación profesional como una de las vías de mejora de la empleabilidad. Se han sucedido en los últimos años iniciativas con el objeto de impulsarla, y los datos son un reflejo claro de ese esfuerzo. Así, desde el curso 2010-2011 hasta el curso 2017-2018, el número de alumnos en formación profesional ha aumentado un 38\%, superando los 804.000 el pasado curso. El aumento se debe, sobre todo, a la categoría de formación profesional básica, seguida por la superior, mientras que la media apenas aumenta (véase la Figura 12).

\footnotetext{
${ }^{4}$ El descenso brusco de contratos para la formación y el aprendizaje en los años 2016 y 2017 se debe al cambio regulatorio que se introdujo para asegurar que se cumplían los estándares de calidad de esta tipología.

5 El marco legislativo español define un reparto de competencias en materia educativa entre el gobierno central y el gobierno de cada comunidad autónoma. En este informe nos referimos a ambos gobiernos, central y autonómico, sin considerar sobre quien recae la competencia regulatoria específica. Tampoco realizamos una valoración sobre el impacto que dicho reparto pueda tener en la educación de los alumnos, y, en último término, en el empleo y desempleo juvenil.
} 
Figura 12

Evolución del alumnado en formación profesional entre los cursos 2010-2011 y 2017-2018 (2017-2018: datos estimados)

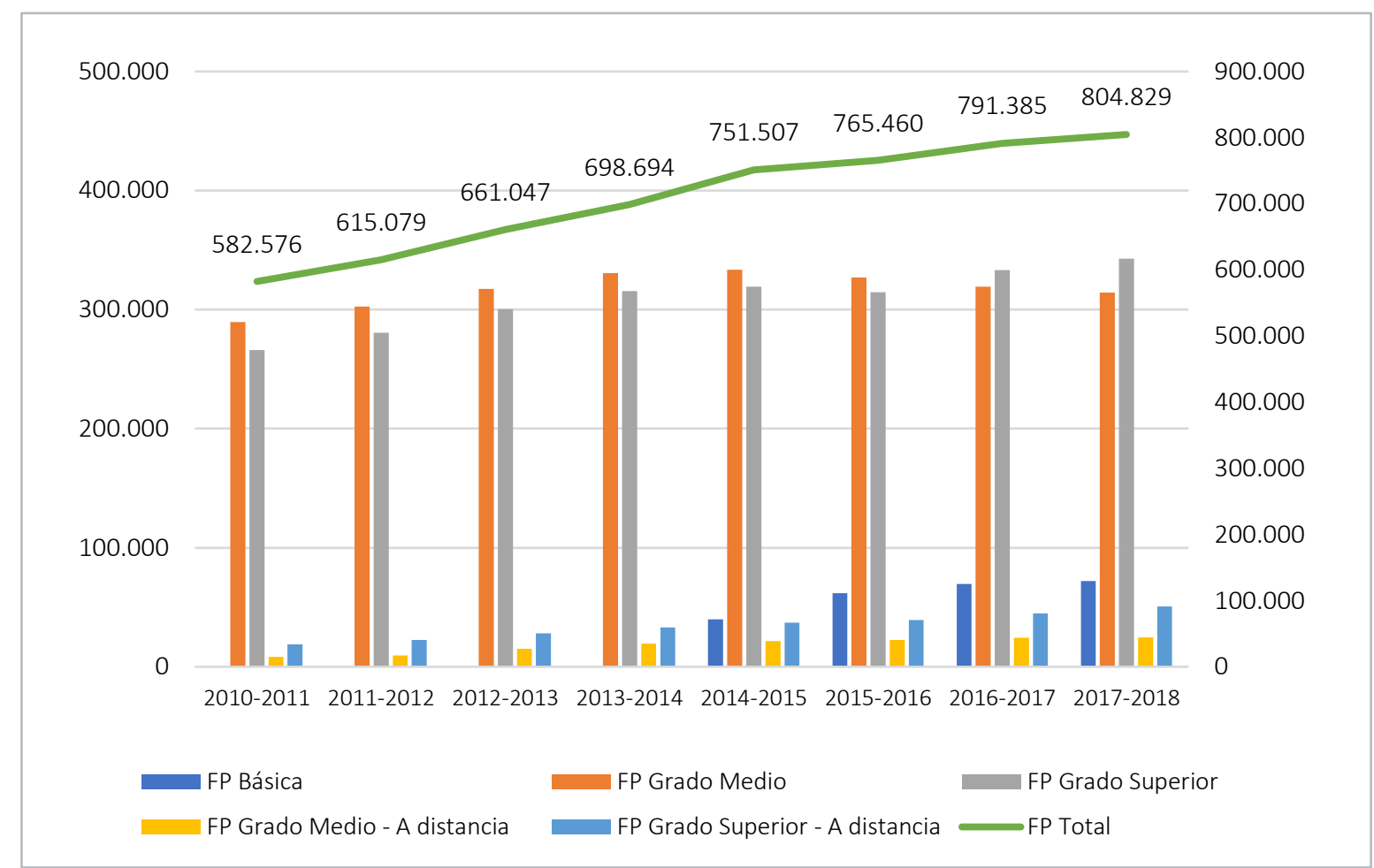

Fuente: Subdirección General de Estadística y Estudios del Ministerio de Educación y Formación Profesional (2018), Estadisticas de las Enseñanzas no universitarias.

Estas cifras, si bien presentan una evolución positiva, están muy lejos de las que encontramos en otros países europeos. Diferentes estudios han analizado las causas de la baja penetración de la formación profesional en España y de las acciones necesarias para impulsarla, como el elaborado por la Fundación ATRESMEDIA, la Fundación MAPFRE y el IESE (2018). Este trabajo destaca, por ejemplo, la necesidad de prestigiar la formación profesional, de dotar a los centros de la autonomía necesaria y de flexibilidad en sus programas o de fomentar la relación de los centros con las empresas.

Es, además, muy significativa, la baja penetración en nuestro país de la formación profesional dual, que solo alcanzaba en 2016 a 24.000 alumnos, si bien se multiplicó por cinco en cuatro años, poco después de la publicación del Real Decreto que estableció su base legal en España. Este tipo de formación obtiene resultados muy positivos en términos de empleabilidad y salarios. Un reciente estudio de Jansen y Troncoso-Ponce (2018) muestra que los graduados de formación profesional dual en la Comunidad de Madrid acumularon un 27\% más de días de trabajo durante los primeros doce meses que los graduados en formación profesional presencial, y un diferencial de ingresos del 32\%. Además, las probabilidades de acceder a un contrato indefinido al final del segundo o tercer año de contrato para la formación y el aprendizaje se situaban entre el $25 \%$ y el $35 \%$, mientras que en los contratos temporales de la misma duración la probabilidad es de solo el $1 \%$.

Parece, por tanto, necesario, seguir impulsando la formación profesional y, en concreto, la dual, tanto desde los gobiernos como desde las instituciones educativas y la empresa. 


\subsection{Algunas reflexiones}

El problema del desempleo, y del desempleo juvenil en concreto, presenta características preocupantes en Europa y, sobre todo, en España. Su elevada tasa, su evolución y el alto porcentaje de temporalidad y tiempo parcial no deseados son algunas de ellas. Diversas causas contribuyen a estos resultados, como el bajo nivel educativo de los jóvenes, la falta de flexibilidad y de movilidad o la ineficiencia de las políticas activas. En este estudio, el foco es la importancia de la educación para el empleo.

Al tratar el fenómeno del desempleo es importante entender que el encaje entre la oferta y demanda de trabajo se produce a nivel de sectores, regiones y empresas. En último término, estas últimas son las que determinan la demanda en cada uno de los segmentos, por lo que es vital conocer su opinión sobre qué capacidades, actitudes y conocimientos buscan y valorar si, por el lado de la oferta, el sistema educativo está siendo capaz de responder a dichas demandas. Además, las empresas son las que perciben y definen las nuevas competencias profesionales requeridas, ante los cambios estructurales de la economía, desencadenados por la disrupción tecnológica, la globalización, el off-shoring de actividades productivas o el movimiento de las migraciones.

En momentos de rápida transformación, resulta vital anticipar las capacidades y los conocimientos, y tomar las medidas necesarias para asegurar el futuro del empleo en nuestro país. En los próximos apartados abordaremos estas cuestiones vitales. 


\section{El reto del empleo en la sociedad del siglo XXI}

\subsection{Algunas macrotendencias con impacto en el empleo y el desempleo juvenil}

Después de un primer diagnóstico del empleo y el desempleo en la UE y en España, en este apartado destacaremos algunas tendencias económicas y tecnológicas globales que tienen un impacto relevante sobre el empleo y el desempleo, y que amplifican los problemas diagnosticados en el apartado anterior. En particular, nos referimos a la revolución tecnológica y la automatización, la globalización, el envejecimiento demográfico, la evolución de la productividad, los nuevos formatos de contratación temporales y el aumento del número de trabajadores autónomos.

\subsubsection{Revolución tecnológica y automatización}

Si la tercera revolución industrial supuso la amplia disponibilidad de tecnologías digitales, la cuarta revolución industrial o Industria 4.0 supone la integración e interconectividad digital de personas y empresas. La creciente interconectividad y disponibilidad de datos aumentan la eficiencia de las operaciones, mejoran la calidad de vida y la sostenibilidad de las ciudades e, indudablemente, cambiarán el modo en el que trabajamos, nos comunicamos y vivimos.

Numerosos avances tecnológicos se han abierto camino en los últimos años: data analytics, Internet of Things, inteligencia artificial, blockchain, impresión 3D, robótica, etc. Tal y como muestra la Figura 13, el grado de adopción de muchas de estas tecnologías está siendo exponencial. El World Economic Forum (2018a), en su informe "The Future of Jobs Report 2018" estima, por ejemplo, que en cuatro años un $45 \%$ de las empresas utilizará tecnologías blockchain; un $58 \%$, realidad aumentada y virtual; un $72 \%$, cloud computing; y un $85 \%$, data analytics 6 . El impacto de la adopción de estas tecnologías es directo sobre las capacidades y los conocimientos requeridos. No solo harán falta conocimientos específicos sobre las distintas aplicaciones tecnológicas, sino que los trabajadores y las organizaciones deberán desarrollar las capacidades necesarias para incorporarlas, adaptarlas a su actividad diaria y sacarles el máximo provecho.

\footnotetext{
${ }^{6}$ Estudio realizado a partir de encuestas realizadas a trescientos directivos de empresas.
} 


\section{Figura 13}

Tecnologías según la proporción de empresas que probablemente las adoptarán para 2022

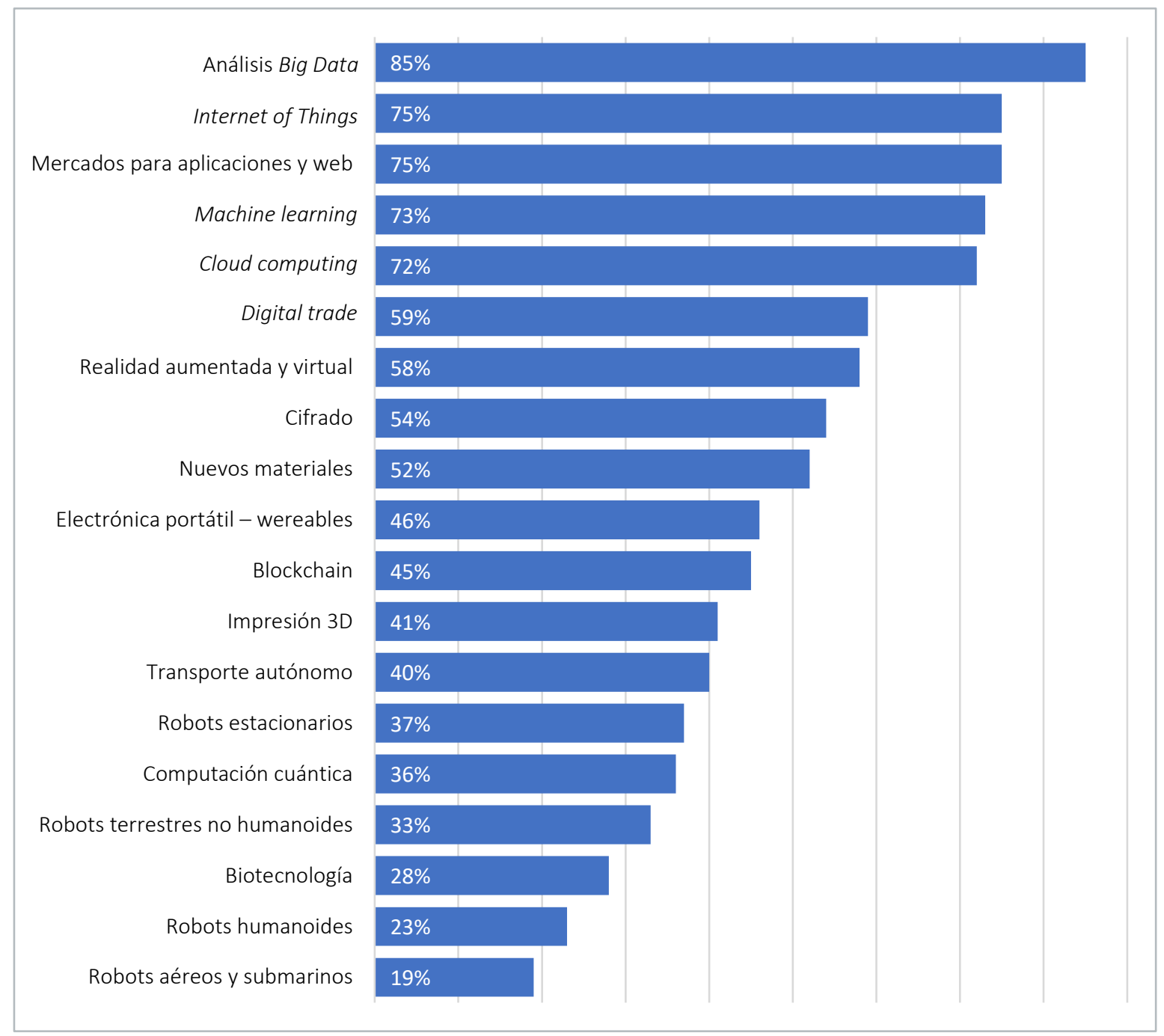

Fuente: World Economic Forum (2018a), "The Future of Jobs Report 2018”, p. 7. 
La adopción de estas tecnologías conllevará también una mayor automatización de tareas y, por tanto, cierta sustitución de personas por máquinas o robots en los puestos de trabajo, con el consecuente impacto sobre el empleo y los salarios (Acemoglu y Restrepo, 2017). Según el World Economic Forum (2018a), en 2022, tareas como el procesamiento de información y datos podrían llegar a estar realizadas en un $62 \%$ por máquinas en vez de por personas, frente al $47 \%$ actual; $y$ tareas de administración estarán realizadas por máquinas en un $44 \%$, frente al 28\% de 2018 (véase la Figura 14).

\section{Figura 14}

\section{Ratio de horas de personas-máquinas, 2018 vs. 2022}

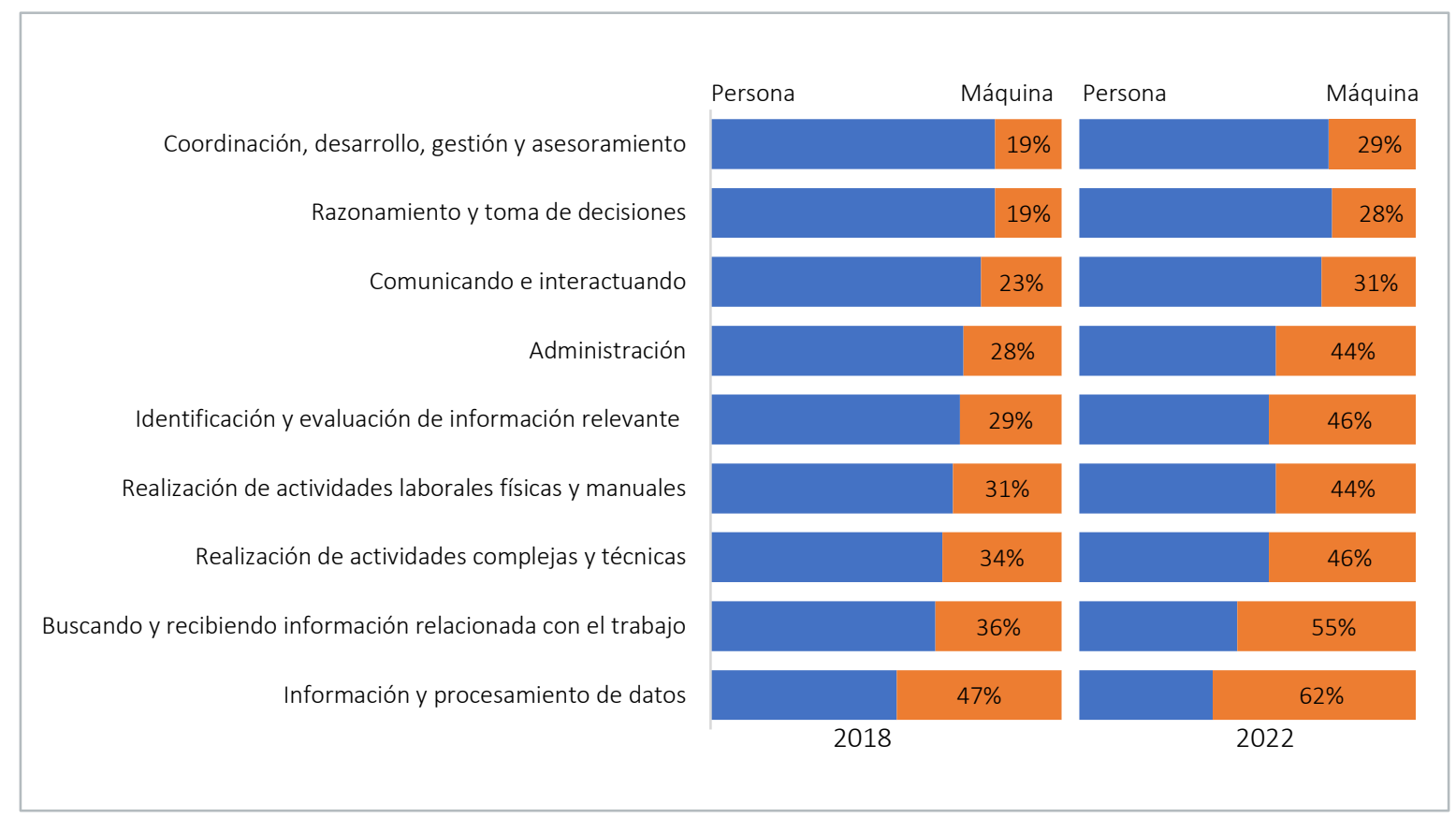

Fuente: World Economic Forum (2018a), "The Future of Jobs Report 2018”, p. 11.

El impacto de la automatización sobre el empleo es obvio, pero difícil de medir. Nedelkoska y Quintini (2018) han estimado el porcentaje de puestos de trabajo con riesgo alto o significativo de automatización. Como puede observarse en la Figura 15, España tiene más de un 50\% de empleos en riesgo alto o significativo de automatización, por encima de la media de la OCDE. Esto, como señala el informe, no depende de la estructura sectorial de los distintos países, sino de la organización del trabajo o del tipo de tareas que se realizan, en particular, si son más manuales o poseen un mayor valor añadido. 


\section{Figura 15}

\section{Porcentaje de empleos con riesgo de automatización significante y elevado, por país}

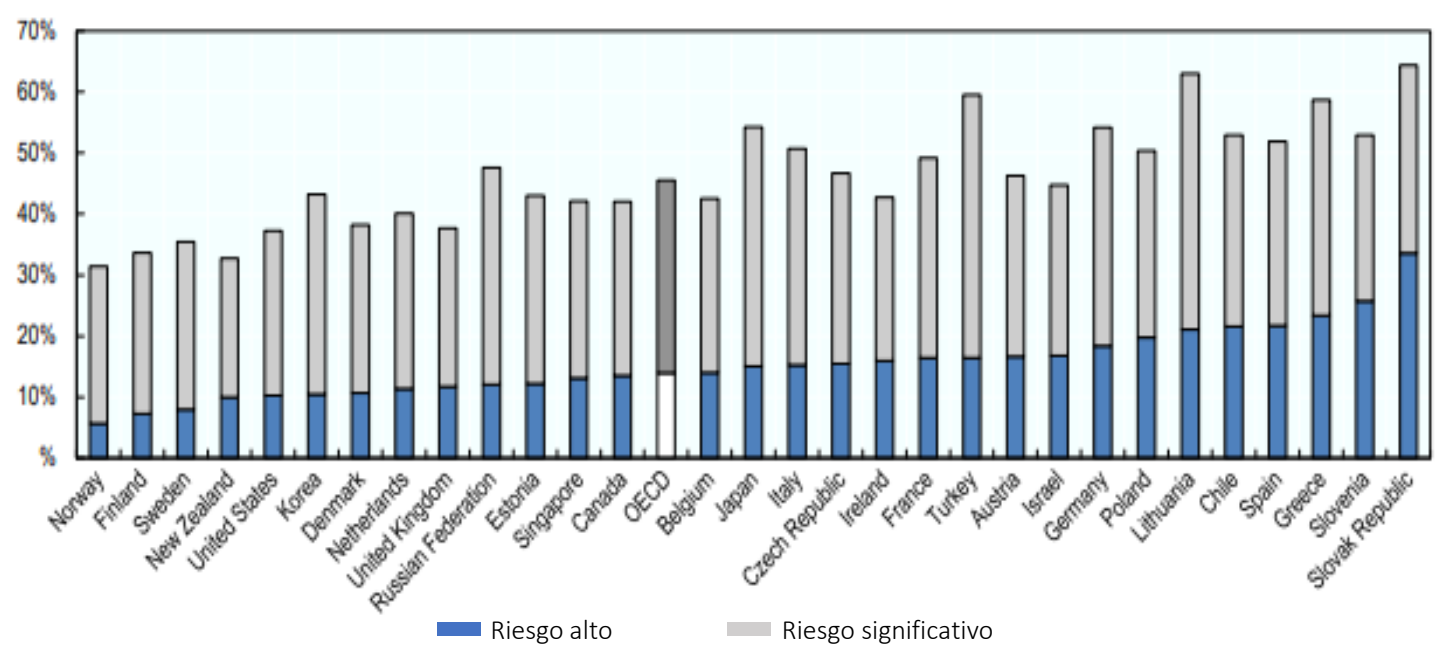

Fuente: Nedelkoska, L. y G. Quintini (2018), “Automation, Skills Use and Training”, OECD Social, Employment and Migration Working Papers, n.o 202, OECD Publishing, París, p. 49.

Nota: "Riesgo alto" se refiere a empleos con un riesgo del 70\% o superior de ser automatizados. "Riesgo significativo" refleja el porcentaje de empleados cuyos trabajos tienen unas posibilidades de entre el $50 \%$ y el $70 \%$ de ser automatizados.

Si bien el impacto de la automatización implica claros desafíos desde el punto de vista del empleo y la formación, constituye también una oportunidad para empujar a las empresas a enfocarse en tareas de mayor valor añadido y a mejorar la formación, los conocimientos y las capacidades de sus trabajadores.

\subsubsection{Globalización}

La globalización es otro de los fenómenos que ha cambiado el panorama mundial. La creciente internacionalización y apertura iniciada tras la Segunda Guerra Mundial e impulsada por los acuerdos comerciales surgidos a partir de 1947 bajo el paraguas del GATT (General Agreement on Tariffs and Trade) y, posteriormente, de la Organización Mundial del Comercio (OMC), hicieron crecer de modo exponencial el comercio y las transacciones financieras internacionales. Ello, unido al desarrollo tecnológico y al avance de las comunicaciones y el transporte, ha impulsado la creación de un mundo interconectado y con menos barreras. La creciente guerra arancelaria desatada por la Administración norteamericana puede ralentizar este proceso, pero difícilmente lo detendrá.

La globalización ha afectado al comercio, la inversión directa, la regulación, la cultura y los hábitos de vida, así como a la dinámica de la ocupación y el empleo en los diversos países. El fenómeno de la globalización y su impacto sobre el empleo suscita un debate encendido entre defensores y detractores. La deslocalización de grandes multinacionales a países menos desarrollados que suponen una oportunidad de abaratar costes ha generado empleo y desarrollo en los países de destino, pero, en los países de origen, se ha producido en ocasiones oposición a estos movimientos por la pérdida de puestos de trabajo locales que supone. No hay acuerdo en cuanto a la pérdida de empleo que ha supuesto la globalización y deslocalización en los países desarrollados. Algunos autores, como Autor, Dorn y Hanson (2013), llegaron a señalar que las importaciones de China durante los años 2000 comportaron la pérdida de cerca de dos millones y medio de empleos en Estados Unidos. Si bien los 
economistas señalan la deslocalización y especialización de los países como algo beneficioso que redunda en una mayor eficiencia, competitividad y, a la postre, crecimiento económico (y, por tanto, más empleo a largo plazo), este debate ha generado una profunda tensión social en algunos países y el retorno a políticas más proteccionistas, como ha sucedido en Estados Unidos.

Las implicaciones de la globalización sobre el empleo son complejas y no constituyen el objeto de este informe, pero está claro que el mercado de talento hoy en día es global y las personas deben competir en ese ámbito por los puestos de trabajo. Esto supone una oportunidad y, a la vez, un desafío. En el caso de las empresas, la oportunidad de encontrar el talento que necesitan en un mercado mucho más amplio, pero también la necesidad de esforzarse en formar y retener a sus trabajadores frente a crecientes oportunidades a nivel global. En el caso de los trabajadores, se abren oportunidades en muchas más empresas y países, pero también encuentran competencia de talento internacional en sus países de origen. Por su parte, gobiernos e instituciones educativas se enfrentan al desafío de promover planes educativos que aseguren la competitividad futura del país y que generen talento capaz de competir en un mundo global.

Al mismo tiempo, la necesidad de trabajar en un entorno global ha generado un cambio en las competencias que deben fomentarse a nivel educativo. Aspectos como la resiliencia, la capacidad de adaptación a entornos en continuo cambio, la capacidad de trabajo en contextos multiculturales y multidisciplinares o un buen nivel de idiomas adquieren una importancia vital y pueden generar, si no se fomentan adecuadamente, un desajuste de capacidades que afecte a la capacidad de encontrar empleo.

\subsubsection{Envejecimiento demográfico}

El envejecimiento demográfico es un fenómeno que afecta de modo claro a Europa y, en concreto, a España. La mejora de la sanidad y las condiciones de vida han alargado sensiblemente la esperanza de vida. Al mismo tiempo, las tasas de natalidad en muchos países desarrollados han descendido notablemente, lo que desemboca en el mencionado envejecimiento de la población. La Figura 16 muestra la evolución de la población de más de 65 años (en porcentaje sobre el total de población) desde 1970 para diversos países. Como puede observarse, la evolución es claramente ascendente para España y la UE, aunque sin llegar a los elevados niveles de Japón. 
Figura 16

Población de más de 65 años (en \% sobre la población total),1970-2014

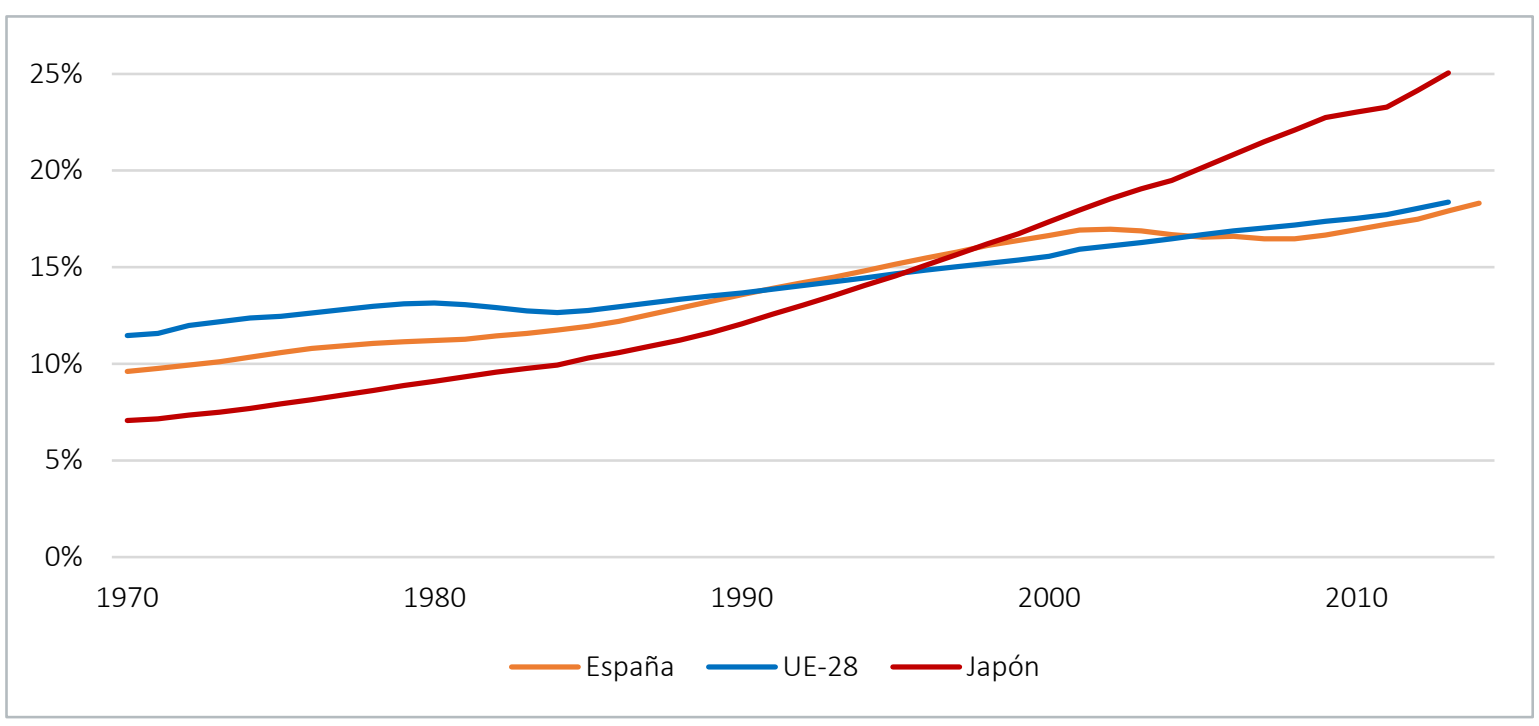

Fuente: OCDE (2018d), Labour Force Statistics.

Las proyecciones sobre la pirámide de población en nuestro país para 2030 y 2050 son preocupantes. En 2018, la mayor parte de la población se concentraba entre los 30 y los 55 años. Sin embargo, en las proyecciones para 2030 ya se observa cómo en ese rango de edad, así como en la población infantil, la pirámide se estrecha sensiblemente, y la tendencia se agudiza más en 2050 (véase la Figura 17).

\section{Figura 17}

\section{Pirámide de población en España}

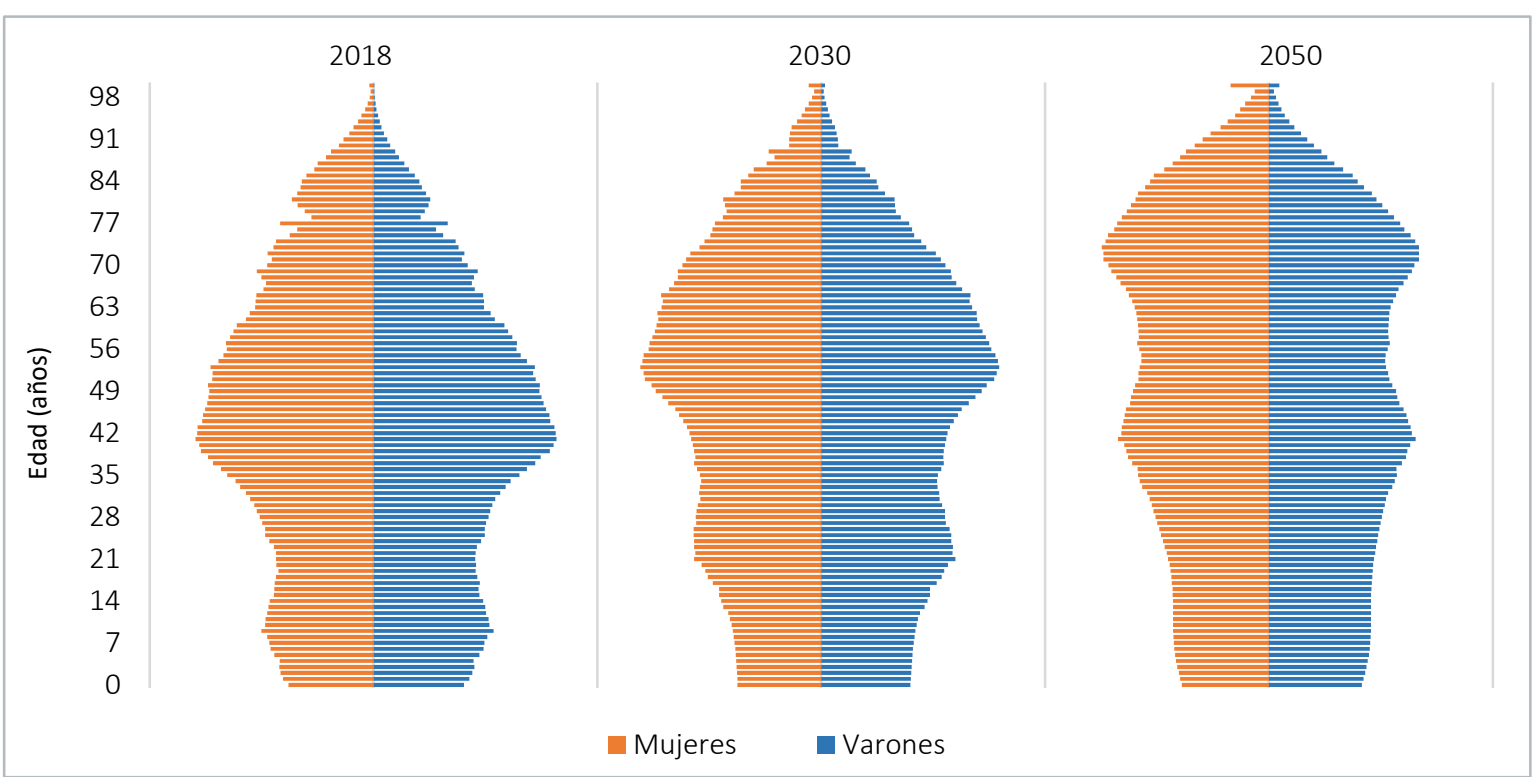

Fuente: Instituto Nacional de Estadística (2018b), Proyecciones de población. 
La fuerza laboral creció en décadas pasadas en países desarrollados como consecuencia de la incorporación de la generación del baby boom de la década de 1960 y la incorporación de la mujer al mercado de trabajo. Ahora, estos dos fenómenos han quedado atrás. Estos factores tienen implicaciones claras sobre el menor consumo, la capacidad de pago de las pensiones, la presión de gasto adicional para el sistema sanitario y el impacto en la deuda pública, entre otros aspectos.

Por otro lado, el envejecimiento de la población plantea desafíos, como el de un importante grupo de personas adultas que, si bien no están en edad de trabajar, tienen un talento y una experiencia valiosos que la sociedad debería ser capaz de aprovechar.

\subsubsection{Productividad}

La productividad es uno de los mejores indicadores de la prosperidad a largo plazo de los países. El World Economic Forum (2018b) define la competitividad como "el conjunto de instituciones, políticas y factores que determinan el nivel de productividad de un país. El nivel de productividad, a su vez, fija el nivel de prosperidad sostenible que puede alcanzar la economía".

En términos generales, la productividad se ha estancado en las últimas tres décadas en muchos países occidentales. España sigue manteniendo un diferencial negativo en cuanto a productividad del trabajo respecto de la eurozona y países como Alemania o Estados Unidos (véase la Figura 18).

\section{Figura 18}

\section{PIB por hora trabajada}

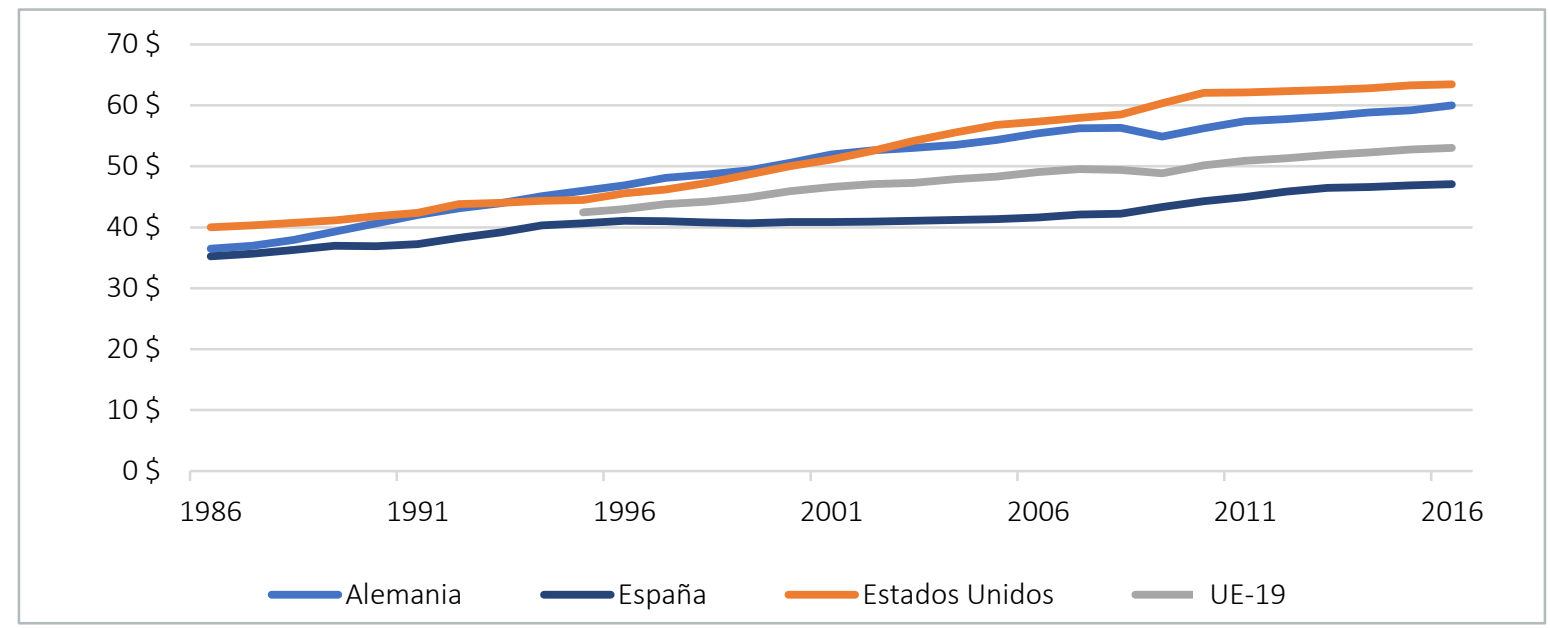

Fuente: OCDE (2018e), OECD Productivity Statistics: GDP per capita and productivity growth.

Además, si hacemos referencia a la productividad total de los factores, la evolución de España desde 1995 es muy negativa frente a otros países. Por otro lado, los avances en productividad de los últimos años en nuestro país se han producido más por reducción de salarios u horas trabajadas que por mejoras en eficiencia (véase la Figura 19). 


\section{Figura 19}

\section{Productividad total de los factores. Tasas de variación, 1986-2015}

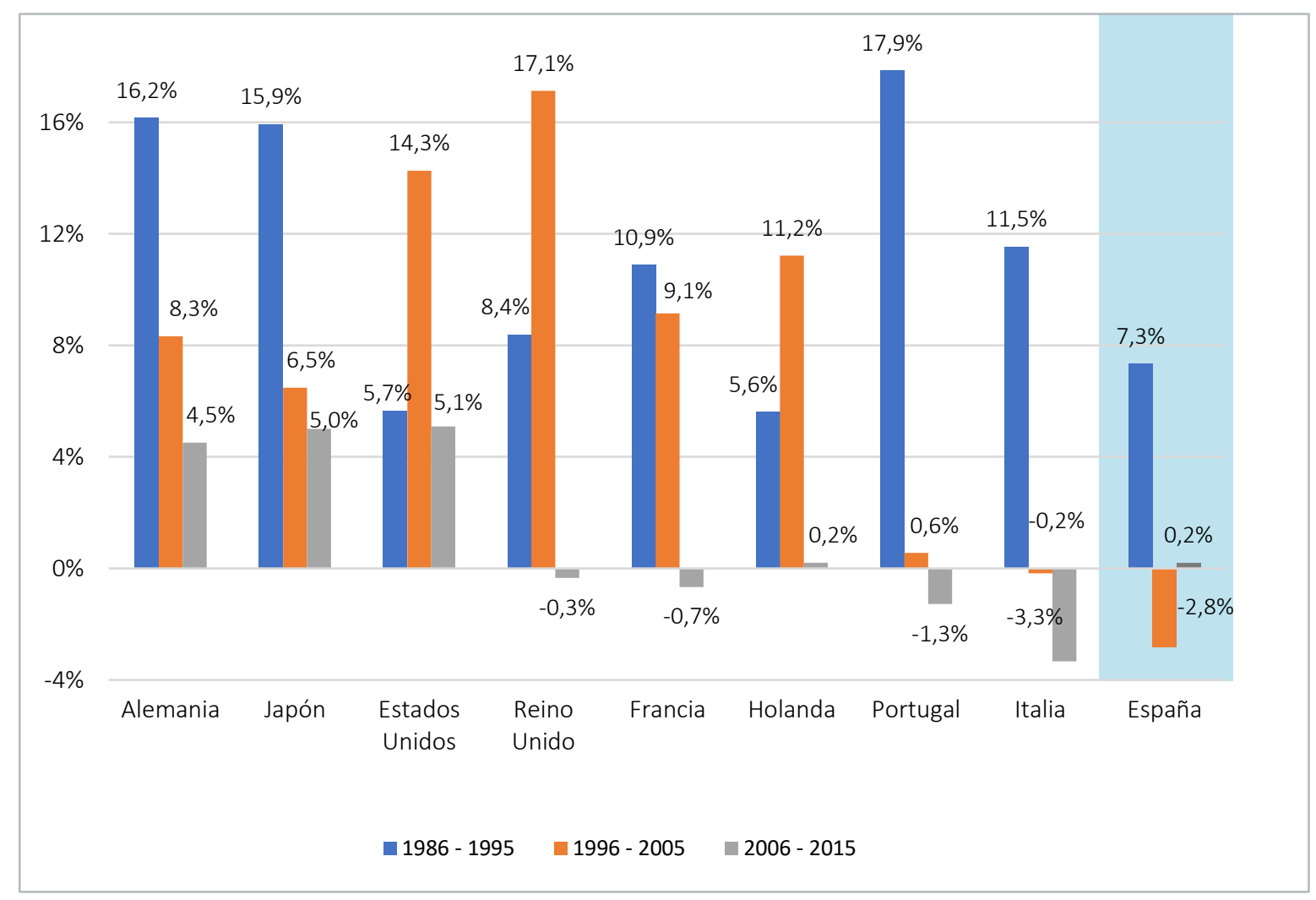

Fuente: OCDE (2018e), OECD Productivity Statistics: GDP per capita and productivity growth.

Parte del efecto del estancamiento general de la productividad puede deberse, según argumentan Harris, Kimson y Schwedel (2018) en su informe publicado por Bain \& Company "Labor 2030: The Collision of Demographics, Automation and Inequality", al crecimiento del empleo en sectores con menor productividad, con trabajadores procedentes de industrias con mayor productividad (de automoción a servicios, por ejemplo). Según el estudio de Harris, Kimson y Schwedel (2018), de 1993 a 2014 la productividad en el sector de la automoción de Estados Unidos aumentó un 128\%, y en el sector hospitalario, un $16 \%$. Sin embargo, en ese periodo hubo un descenso del $28 \%$ de personas empleadas en el sector de la automoción y un incremento del mismo porcentaje en empleados en hospitales. En España, también tenemos un peso superior de sectores de servicios menos intensivos en capital, como el del turismo.

Es previsible que la creciente automatización a la que hemos hecho referencia anteriormente en este informe lleve aparejada una mejora de la productividad, que, en función de los sectores, será más o menos elevada. Harris, Kimson y Schwedel (2018) prevén que, en 2030, las mejoras de productividad derivadas de la automatización alcancen hasta el 55\%, por ejemplo, en las tareas de fabricación, aunque el impacto sería solo del 10\% en el sector de servicios educativos (véase la Figura 20). 
Figura 20

Crecimiento de la productividad como resultado de la automatización, 2015 vs. 2030

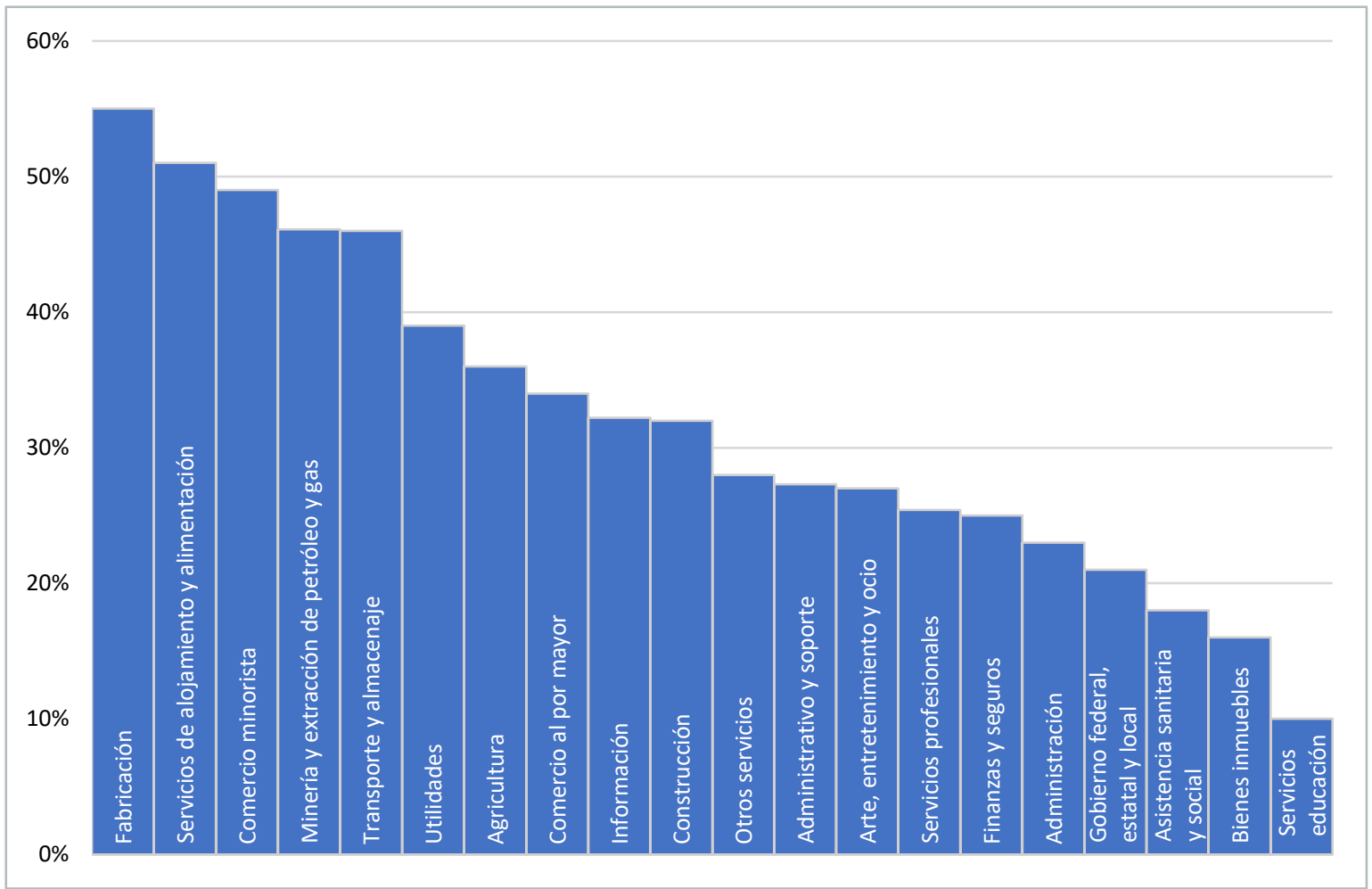

Fuente: Harris, K., A. Kimson y A. Schwedel (2018), "Labor 2030: The Collision of Demographics, Automation and Inequality", Bain \& Company, p. 21.

Al margen de los avances que la tecnología y la automatización generen sobre la productividad, resulta clara la desventaja de España respecto a otros países. Además de la estructura productiva, muchos otros factores se han señalado como razones que han lastrado la productividad y hay que actuar sobre ellos: el reducido tamaño de las empresas, que hace más difícil que se adapten a las nuevas tecnologías; el acceso a la financiación; la alta temporalidad del empleo; y, sobre todo, la calidad de la formación y el fracaso del sistema educativo. Una formación adecuada a las necesidades de las empresas incide directamente sobre la eficiencia con la que los trabajadores desempeñan su labor.

\subsubsection{Crecimiento de los trabajadores autónomos y la expansión de la gig economy. Subcontratación por parte de las empresas de actividades que antes realizaban internamente}

En los últimos años ha cobrado importancia la llamada gig economy. El término 'gig' se refiere a una actuación puntual y, en el ámbito laboral, define trabajos de corta duración para tareas muy concretas, que implican una breve relación entre el que desempeña el trabajo y el que lo recibe. Este trabajo se retribuye por tarea realizada y, en numerosos casos, se entiende que no existe una relación laboral estable entre la persona que lo realiza y la empresa que contrata aquellos servicios. La economía gig empezó a crecer con la subcontratación de ciertos servicios generales (mantenimiento, limpieza de edificios, etc.) hace varias décadas. La digitalización y la posibilidad de definir una tarea y contratar a personas mediante una app ha acelerado su 
explosión durante los últimos años. En una primera aproximación, este modelo proporciona flexibilidad y eficiencia a las empresas, que pueden concentrarse en las tareas en las que aportan más valor y subcontratar otras; ofrece más autonomía y flexibilidad de horarios a los trabajadores; ofrece comodidad y mejores precios y calidad a los usuarios; genera empleo, si bien lo hace a través de trabajos de corta duración; y mejora el encaje entre las labores a desarrollar y las capacidades del trabajador, impactando positivamente en la productividad. Sin embargo, las implicaciones de este modelo sobre la formación de las personas y la propia productividad de las empresas, las condiciones laborales de los trabajadores y la propia contribución al sostenimiento del gasto sanitario y al sistema de pensiones son enormes y plantean incertidumbres aún no resueltas.

La transformación digital y el surgimiento de plataformas que conectan a usuarios con proveedores de servicios de corta duración, como TaskRabbit, Uber o Cabify, han impulsado el crecimiento de la llamada "gig economy". Pese a que no hay todavía estadísticas consensuadas sobre el tamaño de este empleo, McKinsey Global Institute (2016) estimó que entre el $20 \%$ y el 30\% de la población en edad de trabajar en Estados Unidos y la UE-15 (lo que supone 162 millones de personas, y hasta 12 millones en España) realizaba trabajos independientes de alguna u otra forma, ya fuera como complemento a un trabajo habitual o no. En el Reino Unido, por ejemplo, estadísticas más recientes del Office for National Statistics estimaron que cinco millones de personas trabajaban en el país para la gig economy. Aunque los efectos de esta no sean inequívocos y sus interrogantes son enormes, su crecimiento es un hecho objetivo que está transformando el mundo del empleo.

\subsection{Algunos efectos de estas tendencias sobre el empleo}

\subsubsection{Destrucción de empleos tradicionales por la automatización y la globalización}

La automatización, la inteligencia artificial y otras tecnologías implicarán ciertamente la reducción de muchos puestos de trabajo, pero también supondrán la creación de otros nuevos, aunque no hay acuerdo en cuanto a ese número. McKinsey Global Institute (2016) llegó a cifrar la posible pérdida de puestos de trabajo en 800 millones en 2030, si bien esas cifras se han suavizado sensiblemente en recientes informes. Así, Harris, Kimson y Schwedel (2018) estiman que, a finales de la década de 2020, la automatización pueda llegar a eliminar entre el $20 \%$ y el $25 \%$ de los puestos de trabajo actuales, afectando de forma especial a los trabajadores de rentas medias y medias-bajas. Esto supondría entre 30 y 40 millones de empleos en Estados Unidos; además, teniendo en cuenta también que la automatización reducirá costes, abaratará los productos y aumentará la demanda, este proceso ayudará a crear puestos de trabajo. De no contar con este efecto, el impacto podría llegar al 30\% del empleo (50 millones de puestos de trabajo en Estados Unidos).

Por otro lado, la digitalización y las nuevas tecnologías también suponen la creación de nuevos puestos de trabajo ligados, directa o indirectamente, con las nuevas tecnologías. En el caso de España, por ejemplo, Randstad Research (2016), en su informe "La digitalización: ¿crea o destruye empleo?", ha estimado las consecuencias de la tecnología en el mercado laboral, y considera que se crearán alrededor de 1.250 .000 empleos ligados, directa e indirectamente, a las áreas STEM (Science, Technology, Engineering and Mathematics) entre 2017 y 2022 en nuestro país.

Este efecto tendrá un impacto desigual sobre el empleo, en función del tipo de cualificación, y se espera que afecte más a los trabajos de cualificación media, tal como ha venido ocurriendo desde 1995. La Figura 21 muestra cómo el porcentaje de empleo según el nivel de capacidades (alto, medio o bajo) ha variado de forma similar en la mayoría de los países de la OCDE entre 1995 
y 2010, en el sentido de que ha disminuido sensiblemente la cuota de empleos que requieren capacidades medias y ha aumentado la que requiere capacidades altas o bajas (Autor y Dorn, 2013).

Figura 21

\section{Polarización del mercado laboral, 1995-2015}

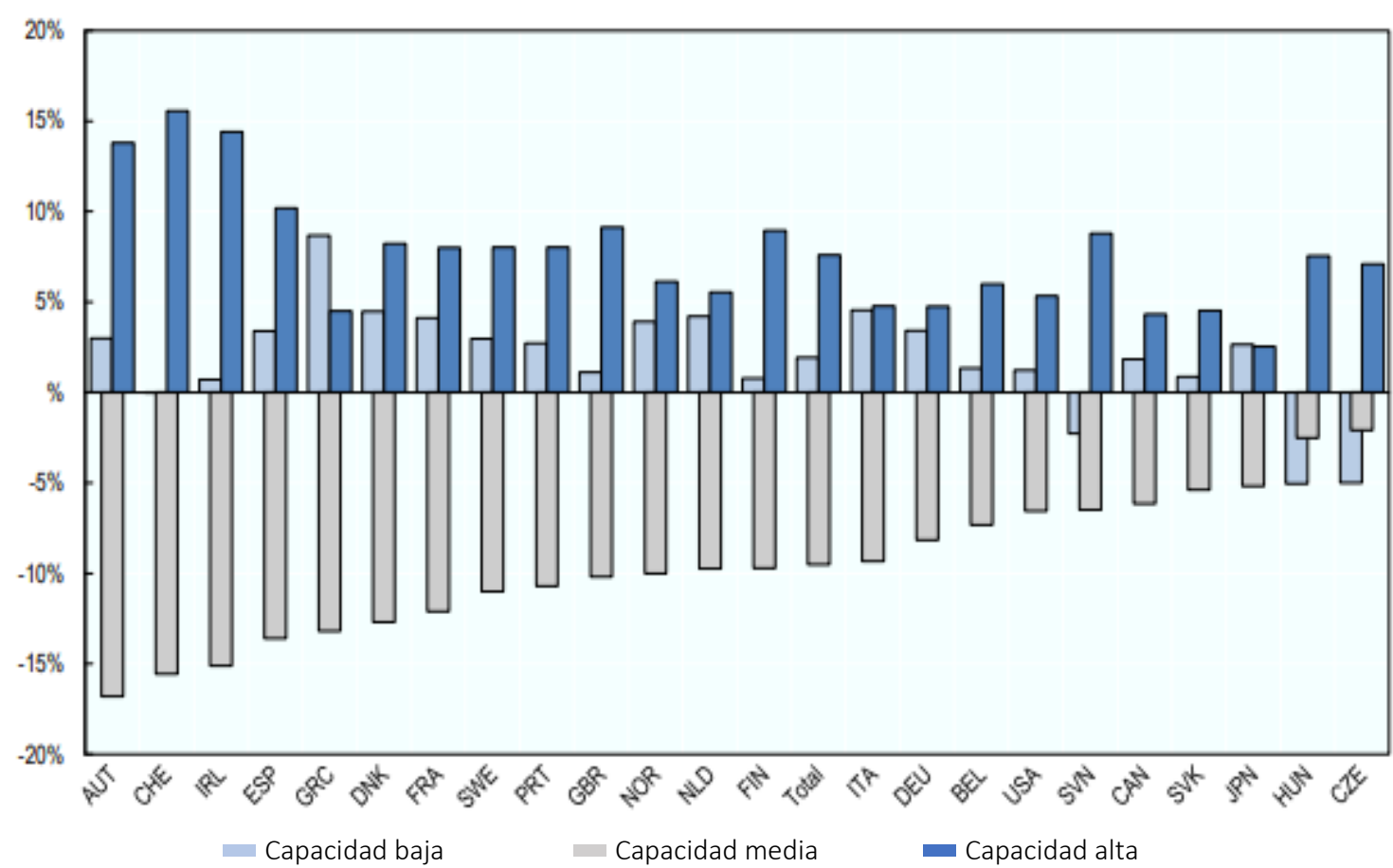

Fuente: OCDE (2017b), OECD Employment Outlook 2017, OECD Publishing, París, p. 121.

Nota: La figura muestra los cambios en el porcentaje de empleos en cada país según el nivel de capacidades requeridas.

Con anterioridad hemos mencionado el efecto que la globalización ha tenido sobre la deslocalización y la desaparición de ciertos trabajos en países desarrollados, al aprovechar las multinacionales las ventajas de abaratar costes laborales en otros países. Un efecto interesante de la automatización es la reducción del diferencial de coste de gastos laborales entre países desarrollados y menos desarrollados, lo que hace variar el rumbo y la magnitud de las deslocalizaciones, afectando directamente al empleo de los países. Por ejemplo, Harris, Kimson y Schwedel (2018) han estimado que, en 1997, el valor añadido en fabricación por dólar de trabajo en México era el doble que en Estados Unidos, y que, en 2013, esta brecha era ya solo del $15 \%$.

El efecto de la sustitución de empleo por la automatización también se verá influido por la flexibilidad y el dinamismo de los mercados laborales en cada país y la rapidez con la que se puedan adaptar a la nueva situación. En lo que sí hay acuerdo es en que la automatización y las nuevas tecnologías cambiarán una gran parte de los trabajos, y las empresas, los trabajadores y los sistemas educativos necesitan adaptarse al cambio. 


\subsubsection{Reducción de los puestos de trabajo estables y las contrataciones estables}

La gig economy antes comentada ha supuesto importantes oportunidades en el mercado de trabajo, pero también cambios en cuanto a seguridad laboral y condiciones de empleo. Según un informe publicado por Gallup en 2018, tan solo un 51\% de los trabajadores de Estados Unidos tienen un trabajo tradicional a tiempo completo, y un 36\% están en el modelo de la gig economy (véase la Figura 22).

\section{Figura 22}

\section{Impacto de la gig economy}

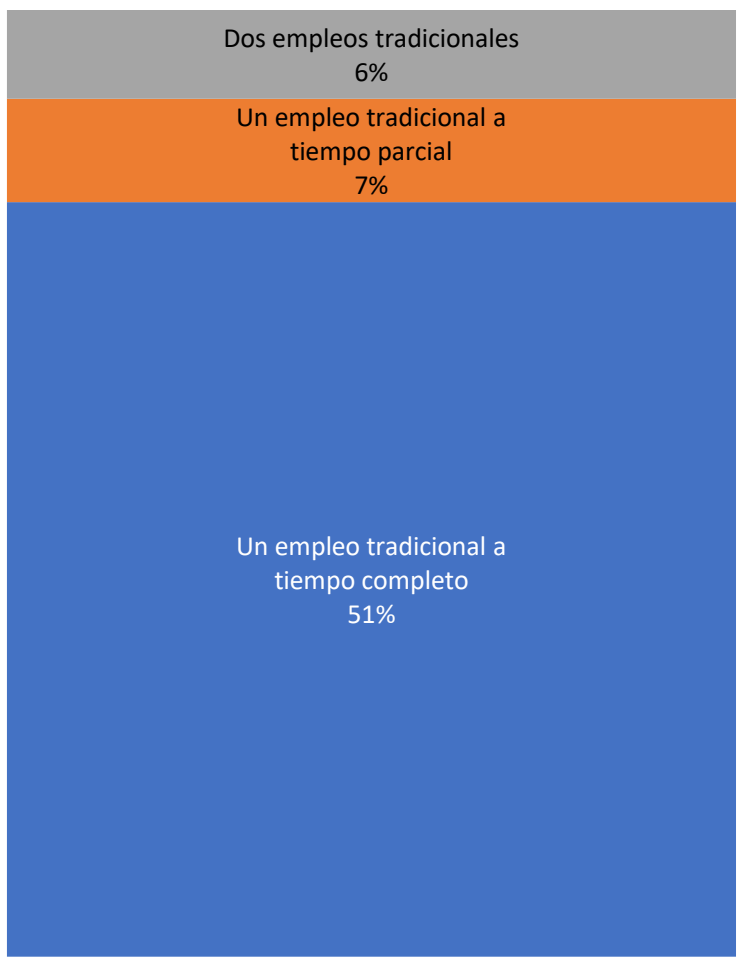

Empleos tradicionales $-64 \%$

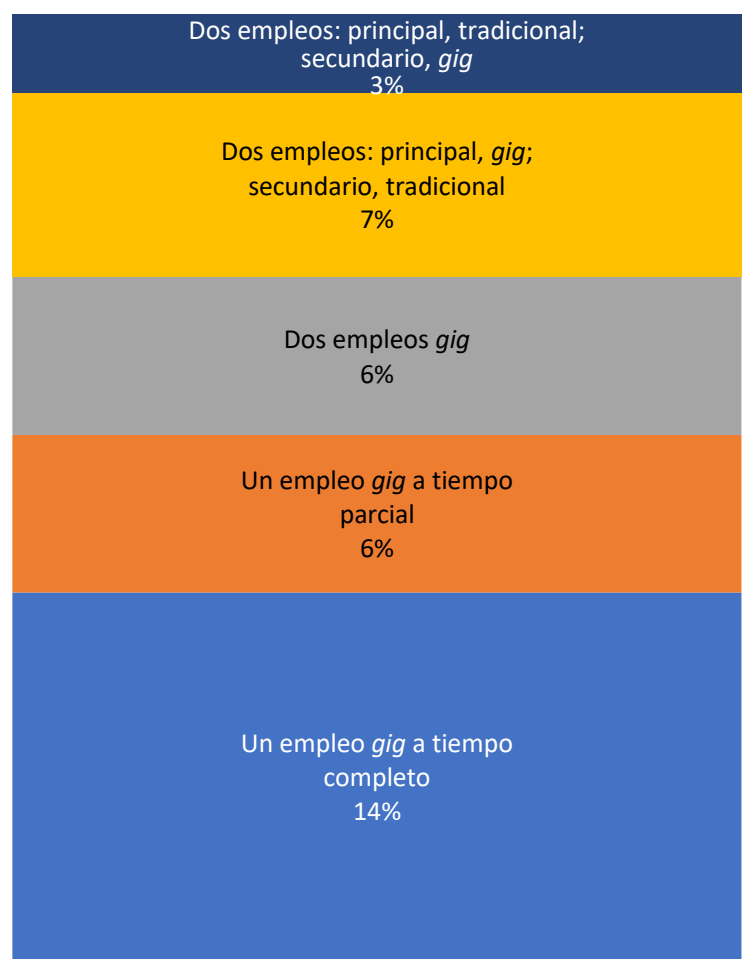

Empleos en economías gig-36\%

Fuente: Gallup (2018), “The Gig Economy and Alternative Work Arrangements”, p. 8. 
La OCDE estima la tendencia del empleo no estándar (incluyendo empleo temporal y empleo a tiempo parcial), y la conclusión es que, entre 2010 y 2016, ha aumentado en términos generales. No ha ocurrido así en el caso del trabajo temporal en España, que disminuyó en 2017 respecto a 2000, pero, como puede observarse en la Figura 23, nuestro país es de los que presentan un mayor porcentaje de todos los considerados.

\section{Figura 23}

\section{Porcentajes de empleo temporal y de empleo a tiempo parcial (200o vs. 2017)}

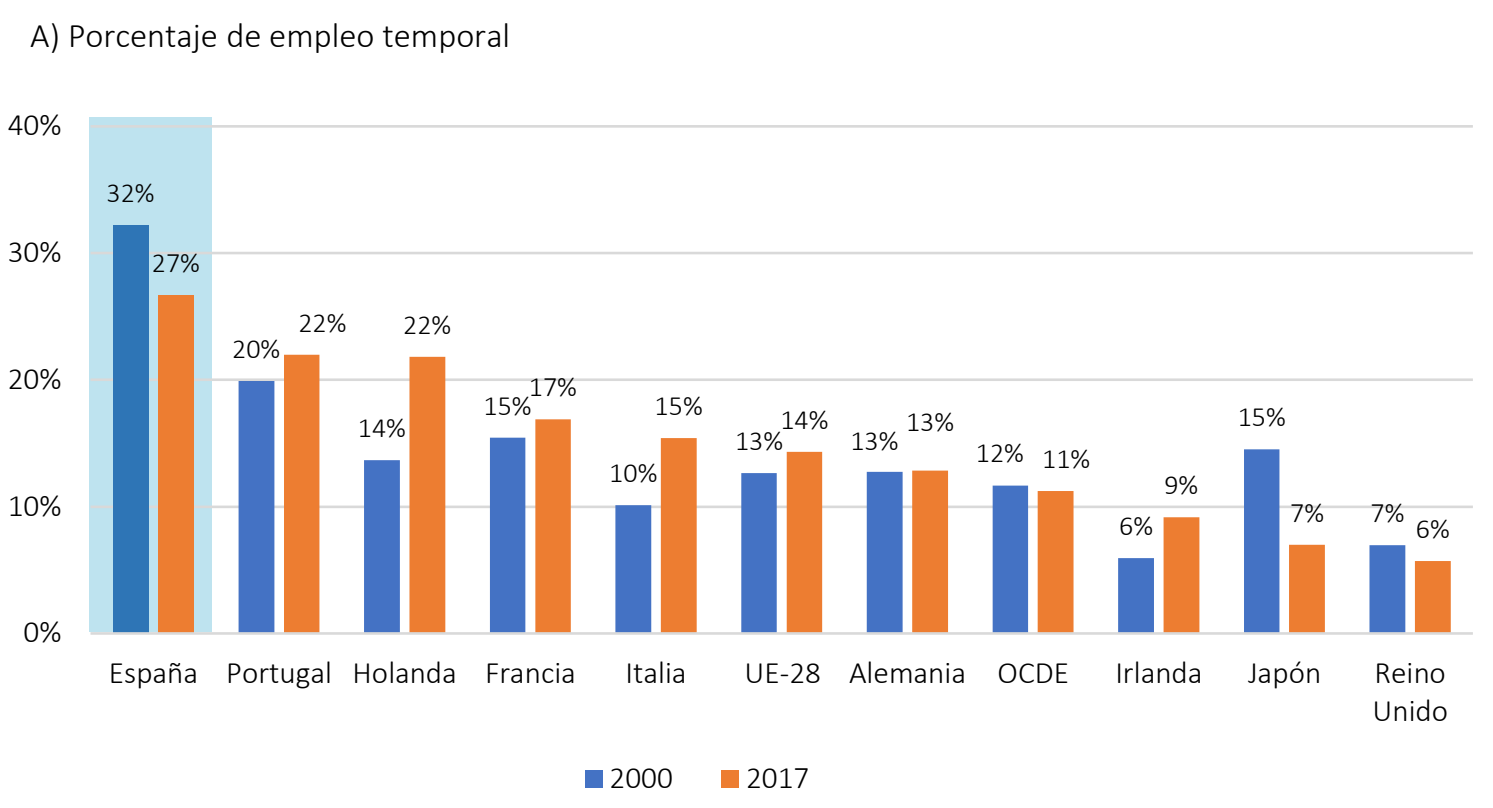

B) Porcentaje de empleo a tiempo parcial

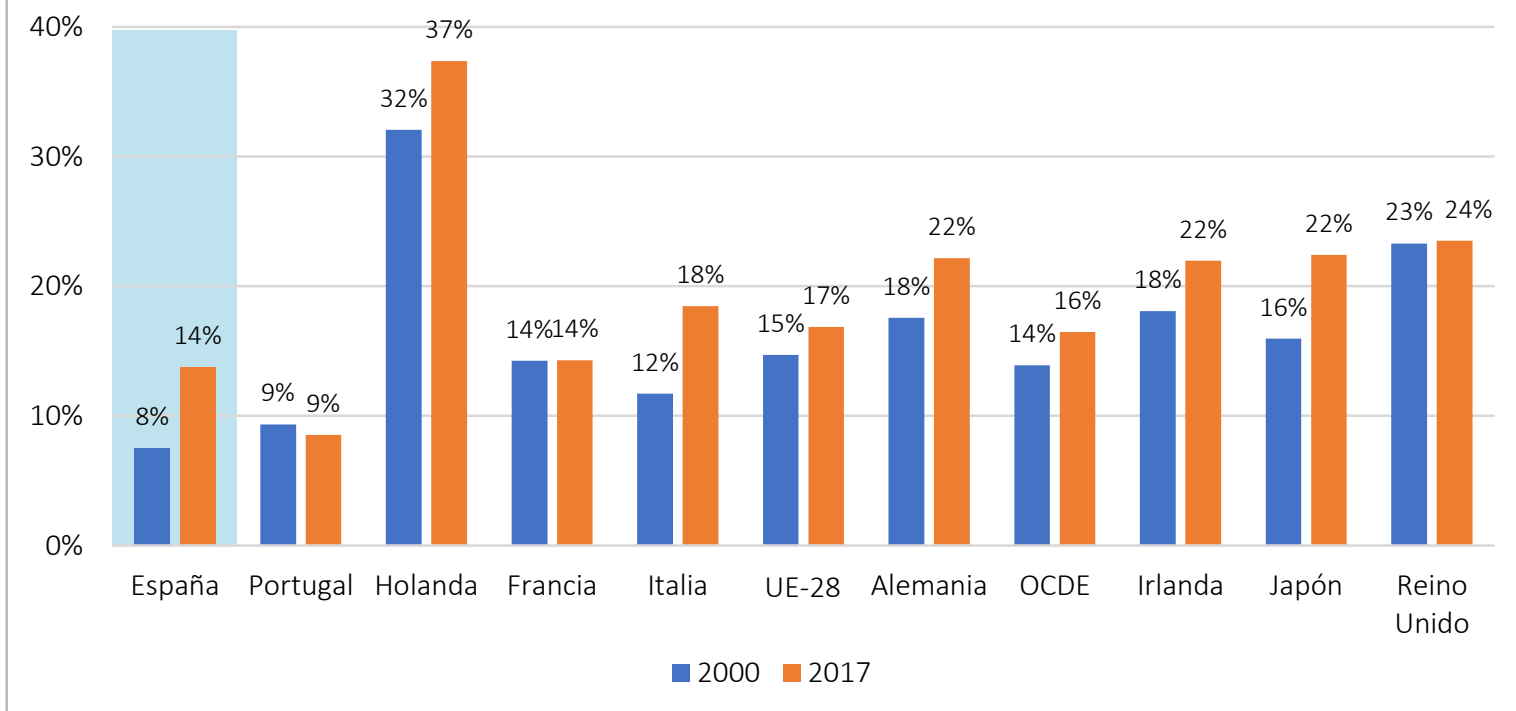

Fuente: OCDE (2018c), "Job Creation and Local Economic Development: Preparing for the Future of Work", OECD Publishing, París. 
El problema añadido es el carácter involuntario de gran parte de esa temporalidad o trabajo a tiempo parcial en algunos países, que se debe no solo a las oportunidades de la gig economy, sino también a la incapacidad de los trabajadores de encontrar puestos de trabajo tradicionales. Holanda, por ejemplo, además de tener un porcentaje considerable de trabajo temporal, es el país con mayor porcentaje de trabajadores a tiempo parcial. Sin embargo, en su inmensa mayoría el trabajo temporal y a tiempo parcial es voluntario. España, por el contrario, es el tercer país con mayor porcentaje de involuntariedad en el trabajo temporal $-73,4 \%$ - y el quinto más alto en cuanto a involuntariedad del trabajo a tiempo parcial $-53,4 \%-$. En el caso de la población joven, el problema de la involuntariedad del trabajo temporal y a tiempo parcial es parecido, tal como se mostró en el apartado anterior de este informe.

Si bien los trabajos a tiempo parcial pueden ser una solución para determinadas situaciones y pueden, también, aportar flexibilidad al sistema, no es menos cierto que la desaparición de trabajos a tiempo completo también tiene implicaciones sobre prestaciones, contribuciones públicas y seguridad laboral, así como sobre la formación que los trabajadores dejan de recibir de las empresas y la integración de las personas en una sociedad, que implican retos que hay que considerar.

\subsubsection{La desigualdad como efecto de la revolución tecnológica y de la diferente evolución de la productividad en diversos puestos de trabajo}

La globalización ha supuesto numerosas oportunidades en muchos ámbitos, en particular, en los países emergentes.

Ello ha ayudado a un proceso de convergencia de crecimiento y nivel de vida entre países. Sin embargo, dentro de cada uno de ellos, a pesar del aumento de los salarios y las rentas en la mayoría, hasta 2008 - antes del comienzo de la gran crisis-, la brecha de la desigualdad, medida por el índice Gini, ha aumentado.

Diversos autores han analizado el impacto de la automatización y la transformación digital sobre la desigualdad en el empleo (Gortázar, 2018), identificando una presión de los salarios a la baja debido a que las máquinas sustituyen trabajo (Autor y Handel, 2013). En términos generales, parece que la automatización ha afectado más directamente a aquellos puestos de trabajo de salarios medios con tareas más mecánicas. Autor y Dorn (2013), Goos et al. (2014) y Autor (2015), describen una polarización del empleo en Europa desde 1993 hasta 2010, viéndose disminuida la proporción de empleos de salarios medios, frente al aumento de la de salarios bajos y altos (véase la Figura 24). 
Figura 24

Cambios en puestos de trabajo, según salarios altos, medios y bajos; 1993-2010

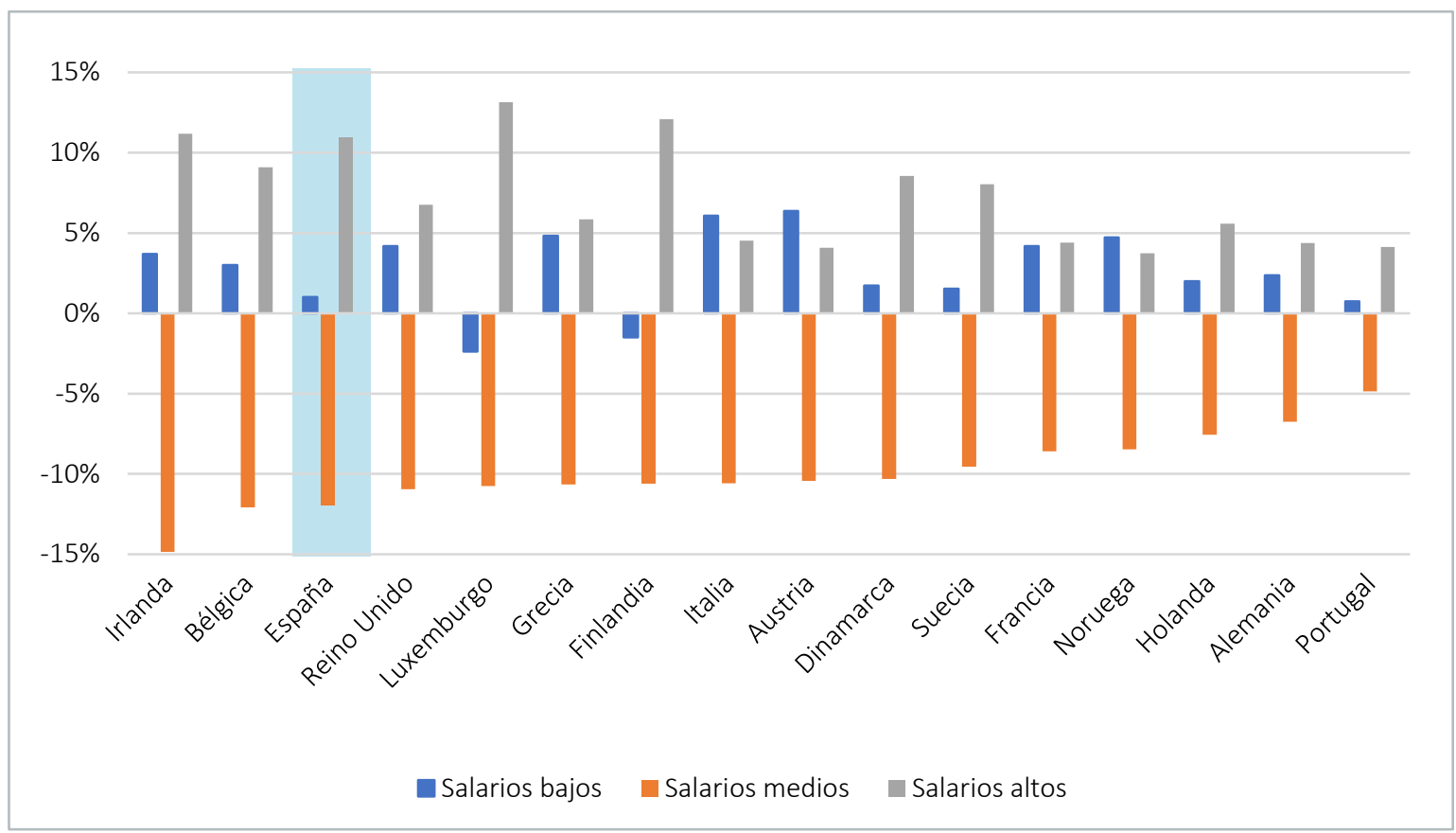

Fuente: Autor, D. (2015), "Why Are There Still So Many Jobs? The History and Future of Workplace Automation" Journal of Economic Perspectives, vol. 29(3), p. 15. 


\section{Nuevas competencias profesionales requeridas para los empleos del futuro}

\subsection{Un cambio de paradigma}

La automatización y las nuevas tecnologías supondrán no solo la sustitución de tareas y puestos de trabajo por máquinas, sino que implicarán un cambio en las competencias profesionales requeridas. Hay capacidades que podrán ser desempeñadas de forma automatizada, como las relacionadas con gestionar o procesar. Sin embargo, otras actividades requieren competencias que las máquinas no pueden adquirir, como la multifuncionalidad, el compromiso, el servicio, el trabajo en equipo, la inteligencia emocional o la resiliencia. Serán estas y otras capacidades las que deban ser contempladas de forma especial por parte del sistema educativo.

Diversas instituciones a nivel internacional se han hecho eco de este desafío y han publicado estudios con previsiones sobre las capacidades del futuro. Así, el World Economic Forum (2016), en su informe "The Future of Jobs Report 2016", señala la importancia de entender que los desajustes de las capacidades deben ser medidos no solo entre la oferta y demanda actual de capacidades, sino entre la base de capacidades actual y las necesidades de capacidades futuras:

"Los esfuerzos destinados a cerrar la brecha de capacidades deberán estar basados en un sólido entendimiento de la base de capacidades actual y las necesidades cambiantes de capacidades para el futuro debido al cambio disruptivo" (p. 26).

En este sentido, el informe "The Future of Jobs Report 2018" presenta una aproximación de la demanda de capacidades para los próximos años (véase la Figura 25). Entre las capacidades que tendrán menos demanda están las de carácter manual, las relacionadas con la memoria o las de gestión de recursos financieros o materiales, todas ellas tareas más fácilmente automatizables. Sin embargo, crecerá la necesidad de capacidades tecnológicas como el diseño o la programación, y otras difícilmente realizables por máquinas, como las de liderazgo, iniciativa, creatividad o inteligencia emocional. 


\section{Figura 25}

\section{Demanda de capacidades, 2018 vs. 2022}

\begin{tabular}{|c|c|c|}
\hline $\begin{array}{l}\text { Capacidades demandadas } \\
\text { (2018) }\end{array}$ & $\begin{array}{c}\text { Capacidades cuya demanda } \\
\text { crece (2022) }\end{array}$ & $\begin{array}{l}\text { Capacidades cuya demanda } \\
\text { decrece (2022) }\end{array}$ \\
\hline Pensamiento analítico e innovación & Pensamiento analítico e innovación & Destreza manual, resistencia y precisión \\
\hline Resolución de problemas complejos & $\begin{array}{l}\text { Aprendizaje activo y estrategias de } \\
\text { aprendizaje }\end{array}$ & $\begin{array}{l}\text { Memoria, habilidades verbales, auditivas } \\
\text { y espaciales }\end{array}$ \\
\hline Pensamiento crítico y análisis & Creatividad, originalidad e iniciativa & Gestión de recursos financieros, materiales \\
\hline $\begin{array}{l}\text { Aprendizaje activo y estrategias de } \\
\text { aprendizaje }\end{array}$ & Diseño y programación de tecnología & Instalación y mantenimiento de tecnología \\
\hline Creatividad, originalidad e iniciativa & Pensamiento crítico y análisis & $\begin{array}{l}\text { Lectura, escritura, matemáticas y } \\
\text { escucha activa }\end{array}$ \\
\hline Atención al detalle, confiabilidad & Resolución de problemas complejos & Gestión de personal \\
\hline Inteligencia emocional & Liderazgo e influencia social & Control de calidad y seguridad \\
\hline $\begin{array}{l}\text { Razonamiento, resolución de problemas } \\
\text { e ideas }\end{array}$ & Inteligencia emocional & Coordinación y gestión del tiempo \\
\hline Liderazgo e influencia social & $\begin{array}{l}\text { Razonamiento, resolución de problemas } \\
\text { e ideas }\end{array}$ & Habilidades visuales, auditivas y del habla \\
\hline Coordinacióny gestión del tiempo & Análisis y evaluación de sistemas & Uso de la tecnología, monitoring y control \\
\hline
\end{tabular}

Fuente: World Economic Forum (2018a), "The Future of Jobs Report 2018”, p. 12.

También el McKinsey Global Institute (2018) aporta evidencia en la misma línea y estima que, hasta 2030, tanto en Estados Unidos como en Europa Occidental se producirá un retroceso de la demanda de trabajo relacionada con capacidades manuales (como operación y reparación de equipos, tareas técnicas o de inspección y control) y cognitivas básicas (como procesamiento de datos e información, comunicación o cómputo básico). Sin embargo, se espera un aumento de la demanda en capacidades cognitivas avanzadas (como estadística, pensamiento crítico o creatividad), socioemocionales (como capacidades interpersonales, liderazgo, iniciativa, emprendimiento y adaptabilidad) y tecnológicas (como programación, análisis de datos, diseño tecnológico, ingeniería o investigación científica) (véase la Figura 26). 


\section{Figura 26}

\section{Cambios en las capacidades requeridas}

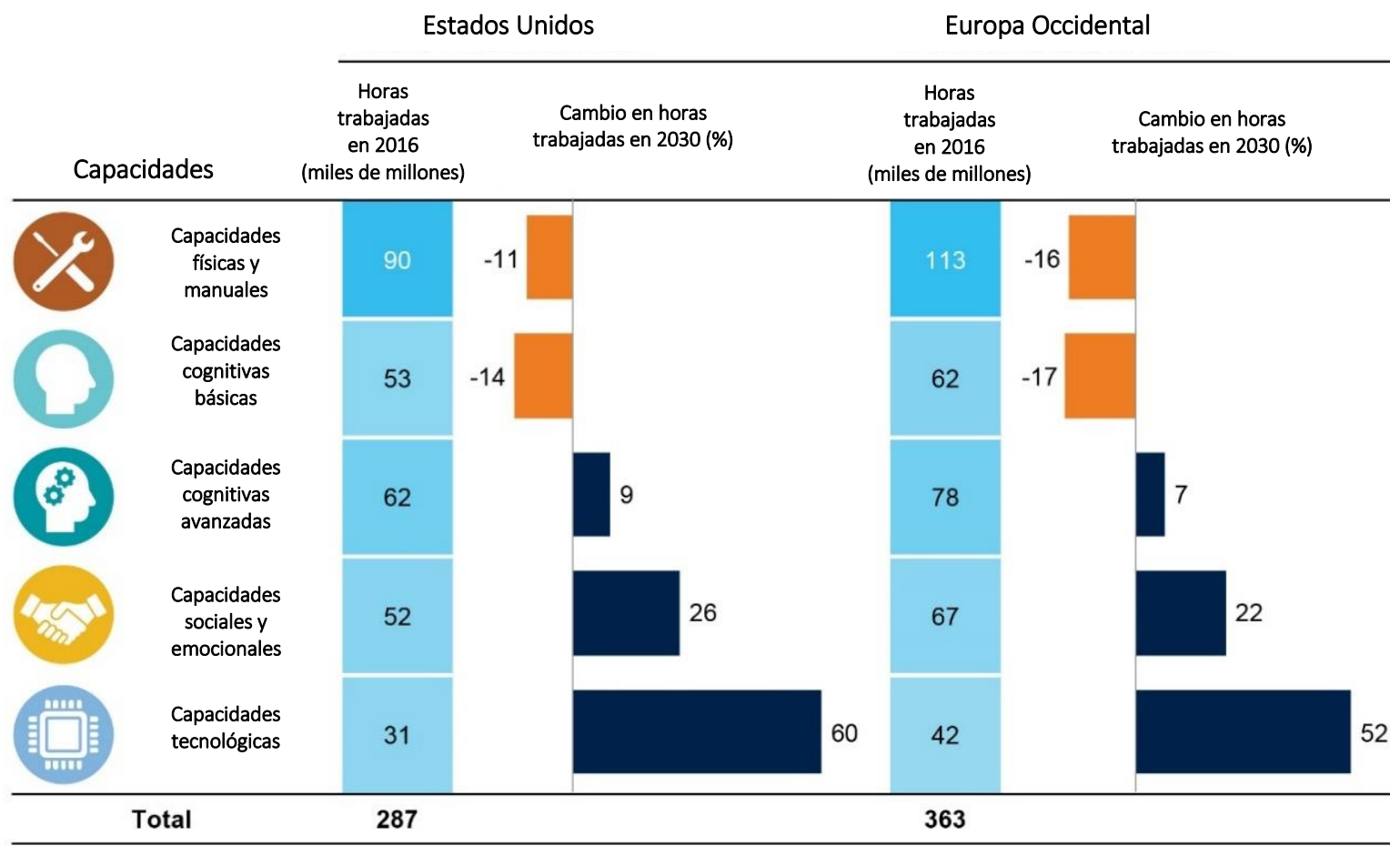

Fuente: McKinsey Global Institute (2018), "Skill shift:Automation and the Future of the Workforce”, McKinsey\&Company, p. 8.

En este esfuerzo de comprensión y desarrollo de las capacidades que se requerirán en el futuro, las empresas, según el informe "The Future of Jobs Report 2018" (World Economic Forum, 2018), señalan la importancia de colaborar con el sistema educativo, tanto a nivel local como internacional, y por parte de expertos. Así, un 52\% de las empresas encuestadas mostraron su preferencia por contar con instituciones académicas internacionales en el esfuerzo de transición de la fuerza de trabajo a las nuevas capacidades requeridas, y un 50\% destacó la conveniencia de contar con instituciones académicas locales.

La rápida evolución de las competencias requeridas demanda un sistema educativo ágil y capaz de responder al mercado. La evolución de las competencias demandadas en el mercado no se ha desarrollado a la misma velocidad que la adaptación del sistema educativo a los nuevos tiempos, y esto ha generado un desajuste de las capacidades requeridas para el puesto de trabajo en la mayoría de países de la OCDE. Este problema es especialmente grave en España, donde este desajuste llega a afectar a más del 33\% de los trabajadores (véase la Figura 27), mayor que en el resto de países debido a una sobrecapacitación para ciertos trabajos, y no a una infracapacitación. 
Figura 27

Desajuste de capacidades para el puesto de trabajo (\% de empleados), 2016

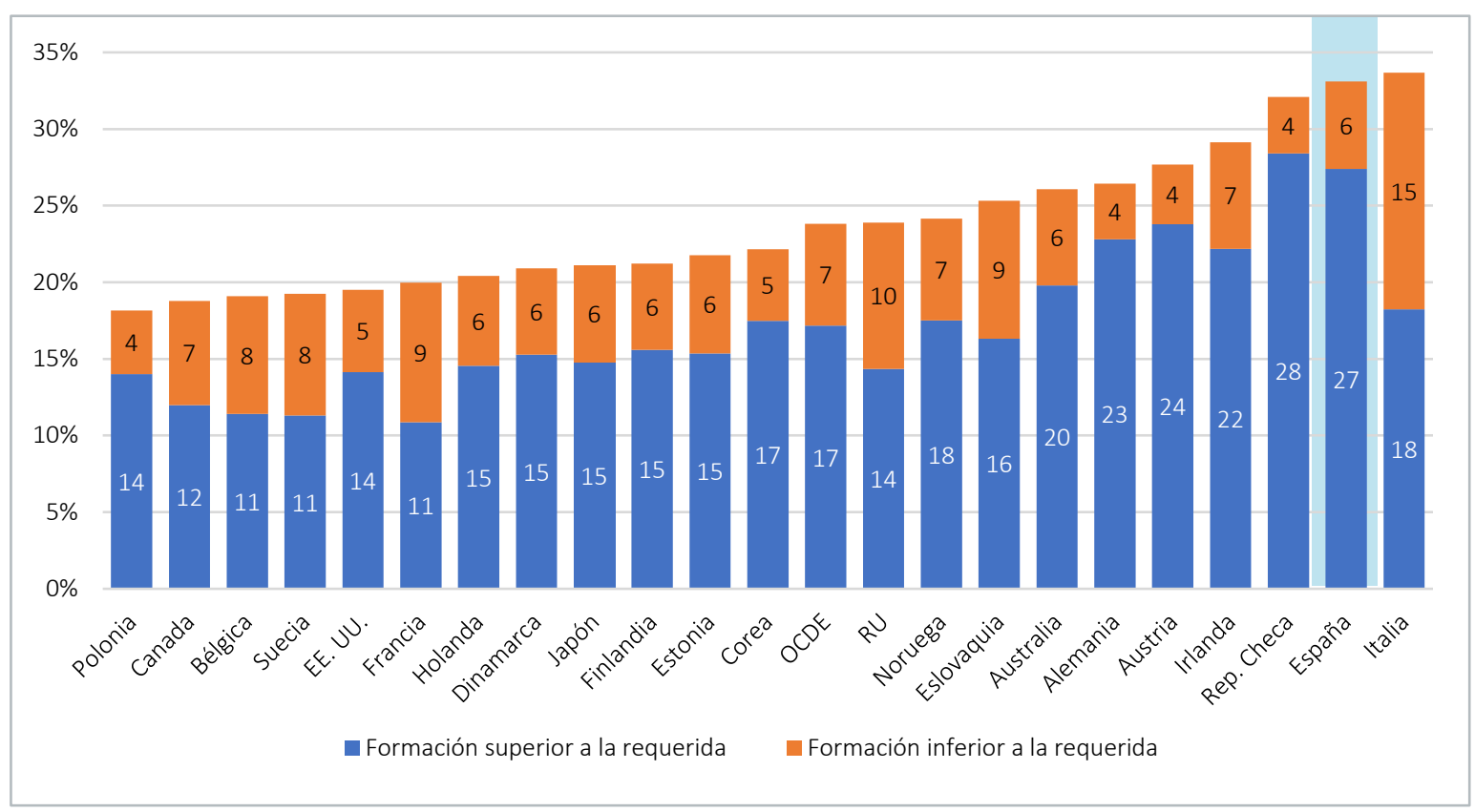

Fuente: OCDE (2017a), “Economic Policy Reforms 2017: Going for Growth”, OECD Publishing, París, p. 77.

El desajuste en España refleja problemas en el sistema educativo que se producen a diferentes niveles. El Círculo de Empresarios (2018), en "El Barómetro de los Círculos", muestra la valoración que índices internacionales dan a nuestro país y la media de la OCDE en calidad del sistema educativo, a distintos niveles. Como puede observarse, España está por debajo de la media de la OCDE en educación primaria, secundaria, formación profesional y conocimientos en ciencias y matemáticas. También se observa la distancia de nuestro país en cada una de estas categorías con los países mejor valorados, que son Finlandia y Suiza (véase la Figura 28).

Figura 28

Valoración de la educación a distintos niveles en España según índices internacionales, 2017

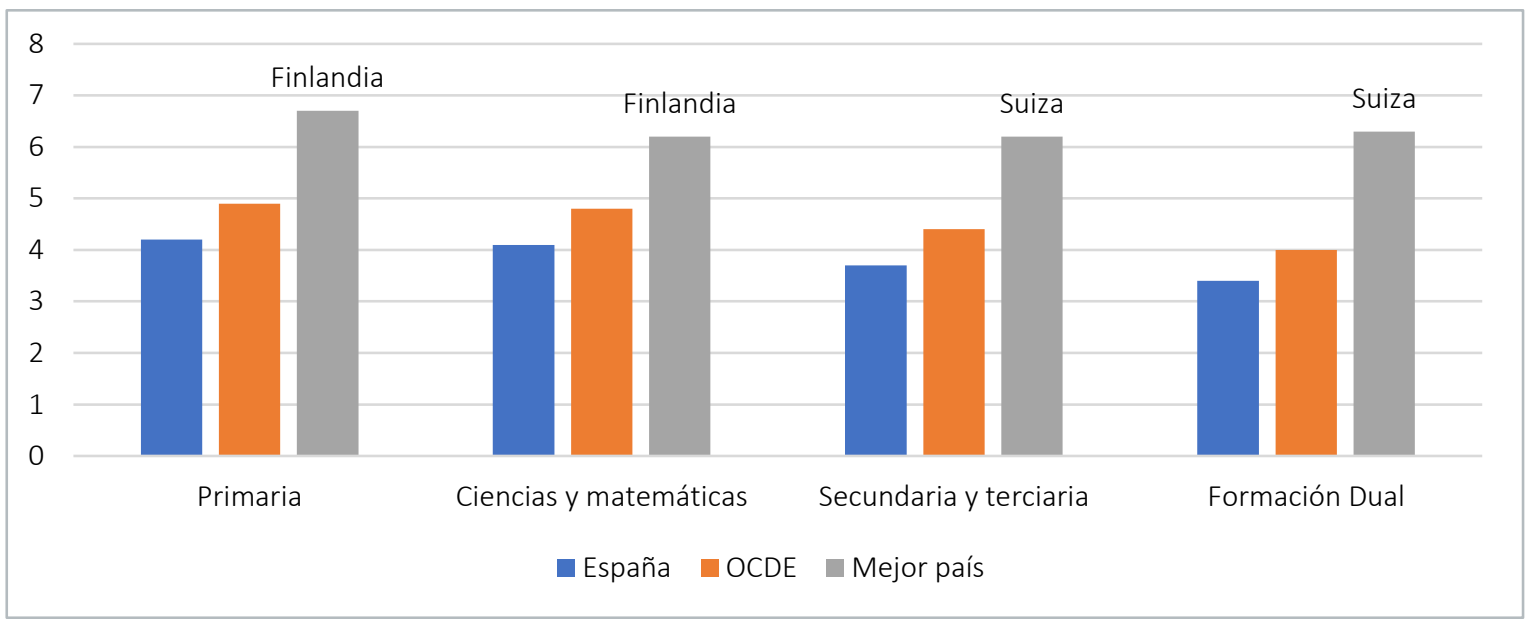

Fuente: Círculo de Empresarios (2018), “El Barómetro de los Círculos”, p. 36. 
Es conocido el bajo índice de penetración que la formación profesional tiene en España en comparación con otros países (ver Figura 9), si bien está aumentando los últimos años. Esta es una de las causas de la sobrecapacitación a la que aludíamos antes, y conlleva que trabajadores con titulación superior estén en paro y otros, en cambio, estén realizando tareas para las que no es necesario un nivel tan alto de capacitación (véase la Figura 29).

\section{Figura 29}

\section{Contratos realizados a graduados universitarios para desempeñar tareas de alta cualificación (\% sobre el total de contratos a universitarios)}

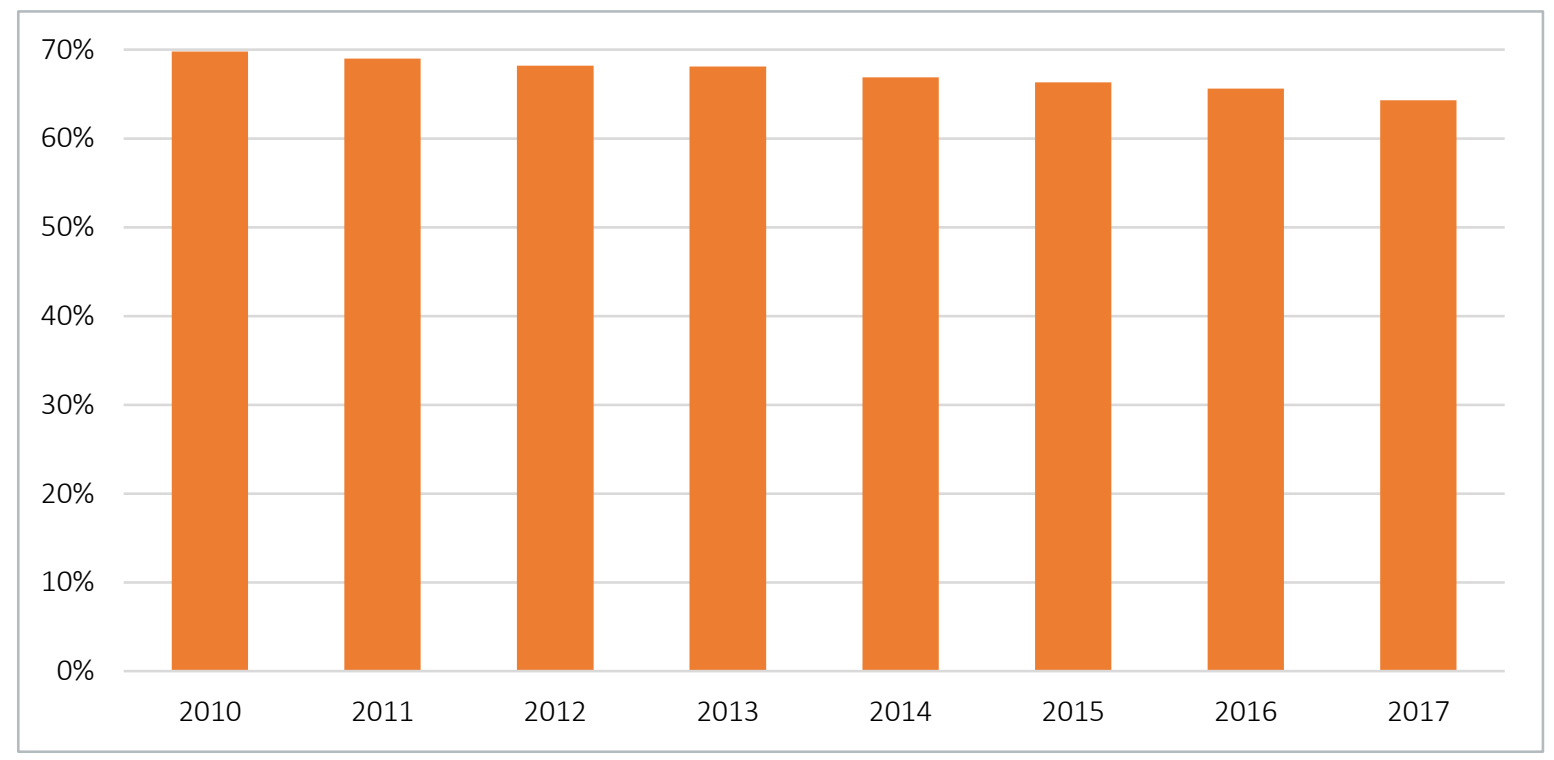

Fuente: Fundación Conocimiento y Desarrollo (2017), “Informe CYD 2017”, p. 108.

En el ámbito universitario, también se percibe claramente el desajuste de capacidades y conocimientos en el tipo de estudios seguidos en España. La distribución de ofertas de empleo y alumnos matriculados es desigual. Hay un exceso de alumnos matriculados respecto a las ofertas de empleo en Ciencias Sociales y Jurídicas, Salud y Servicios sociales, y, sobre todo, en Educación, Arte y Humanidades. Al mismo tiempo, hay más oferta de empleo que alumnos matriculados en Ingeniería, Industria y Construcción (véase la Figura 30). 
Figura 30

Distribución de las ofertas de empleo y del alumnado, por familias profesionales

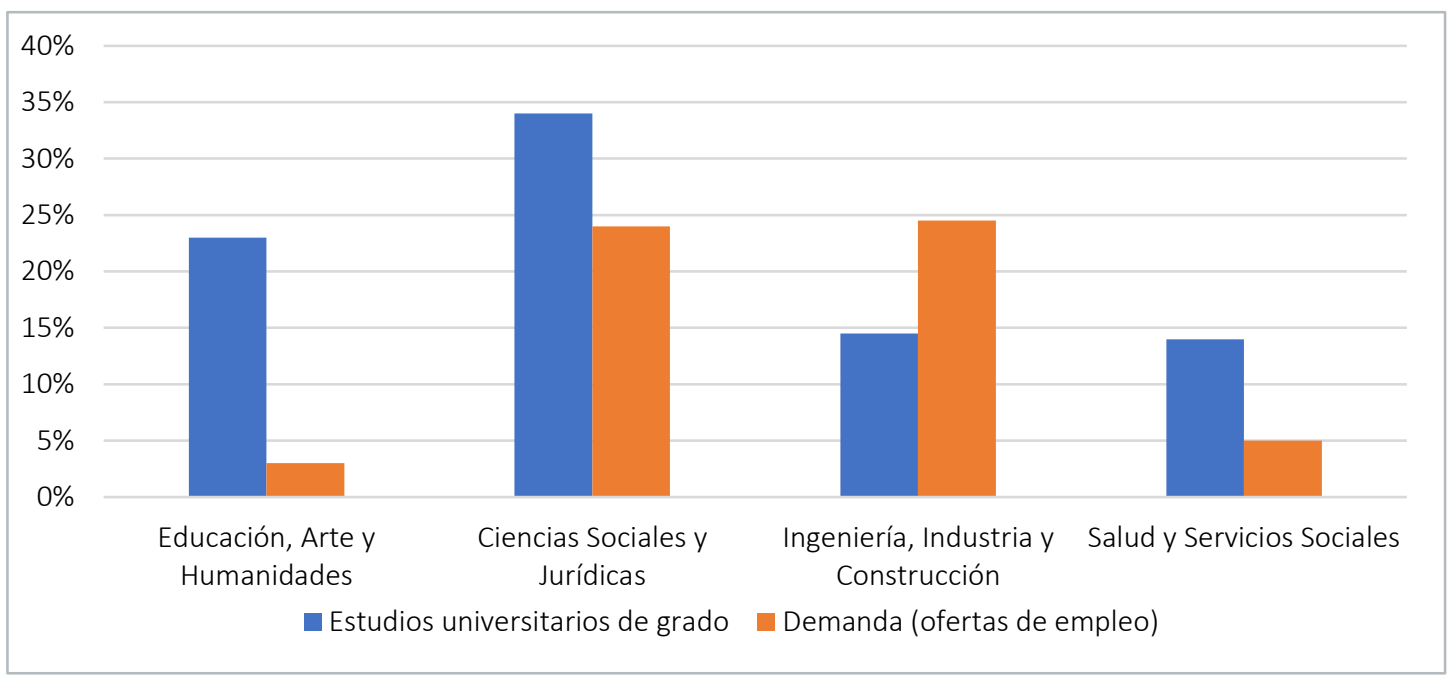

Fuente: Consejo Económico y Social (2015), “Informe 03/2015. Competencias profesionales y empleabilidad”, p. 166.

En esta línea, si bien las empresas cada vez demandan más conocimientos y capacidades tecnológicas, en España la ratio de graduados universitarios en campos STEM sobre el total $(22,4 \%)$ es inferior a la media de la UE (26\%), y mucho menor que en países como Alemania $(36,1 \%)$ o Finlandia (29,5\%). Si se aplica a la población joven, de entre 20 y 34 años, el resultado es asimismo desfavorable en nuestro país, tal y como muestra la Figura 31, lo que no jugará a favor del ajuste de capacidades y conocimientos necesarios para el futuro del empleo. Por otro lado, se estima que esta cifra seguirá hasta 2021 en la senda descendente que ha mostrado desde 2008 (véase la Figura 32). 


\section{Figura 31}

Ratio entre los graduados universitarios en campos STEM y la población de 20 a 34 años, 2016

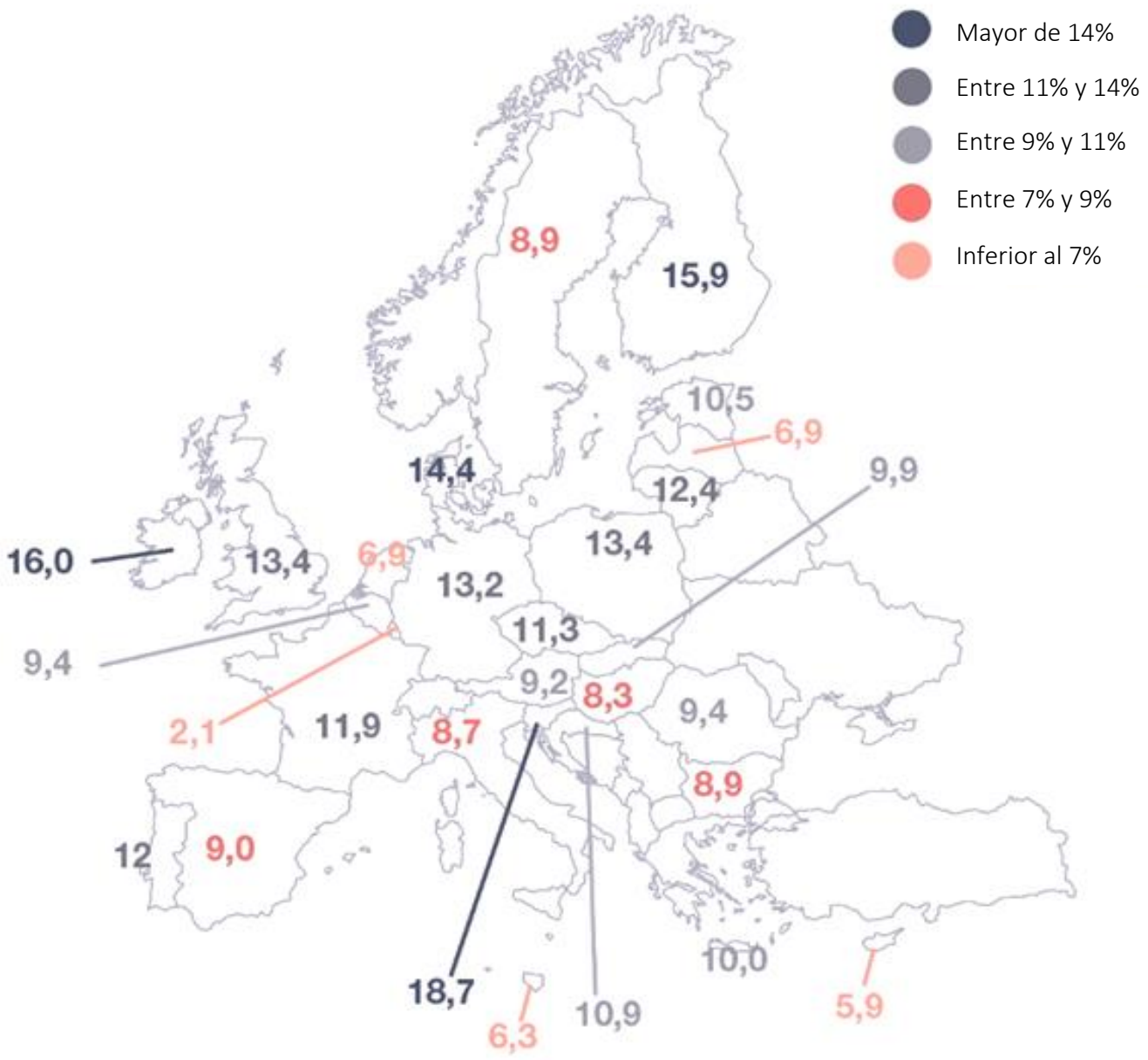

Fuente: Fundación Conocimiento y Desarrollo (2017), "Informe CYD 2017", p. 100. 
Figura 32

Alumnos STEM matriculados en las universidades españolas

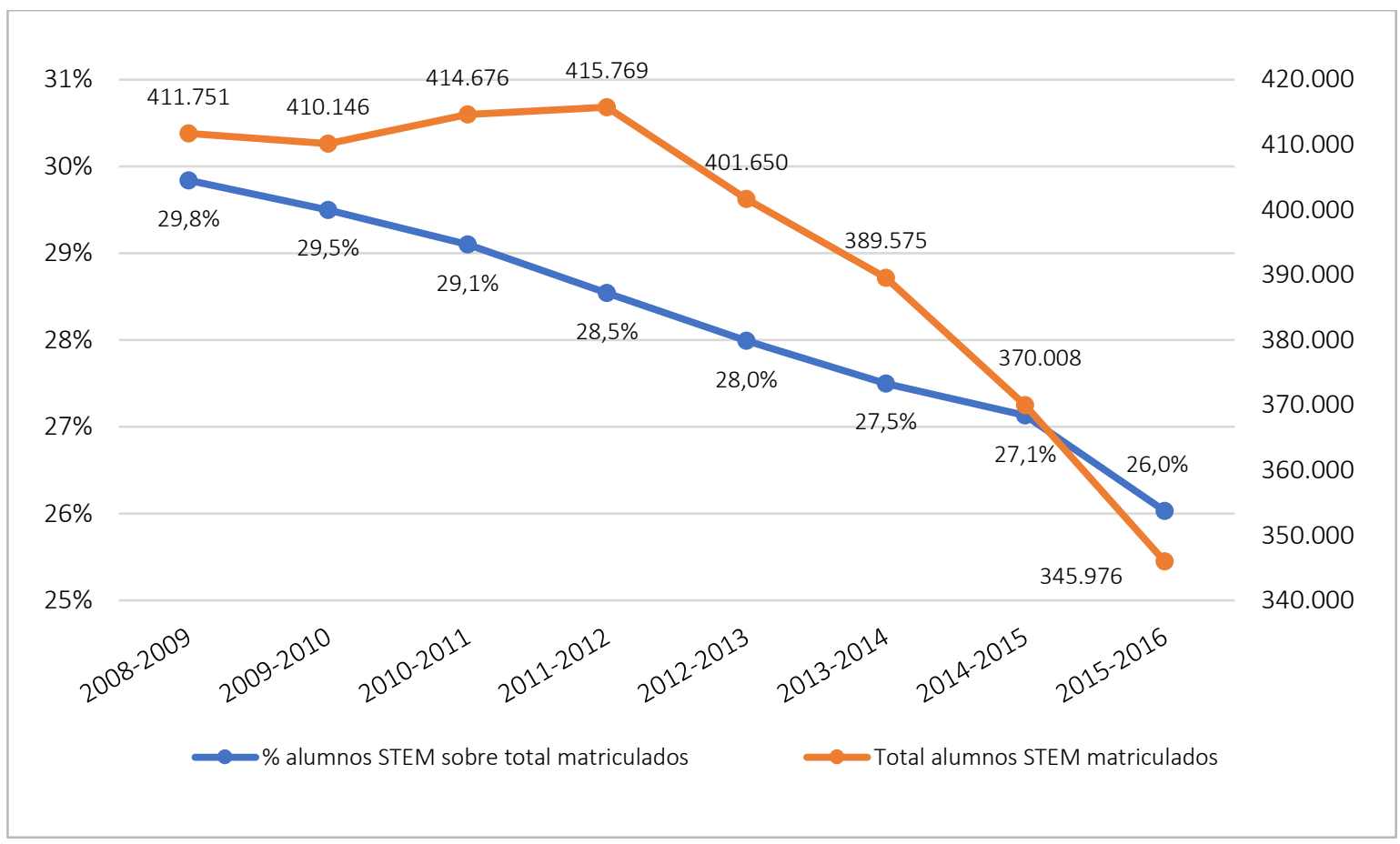

Fuente: Randstad Research (2016), “La digitalización: ¿crea o destruye empleo?”.

En definitiva, las capacidades y los conocimientos requeridos en el mercado de trabajo están cambiando de forma acelerada, y el sistema educativo español no está siendo capaz de dar una respuesta adecuada. Son necesarios cambios en varios niveles, pero con un enfoque claro en las necesidades reales de las empresas, que son protagonistas centrales en la creación de empleo.

\subsection{Necesidad de educación en las competencias profesionales del futuro: las empresas como motor de la demanda de empleo}

Las tendencias económicas y sociales que hemos descrito en las páginas anteriores muestran con claridad un cambio en el tipo de puestos de trabajo del futuro, así como en los perfiles y competencias profesionales necesarios para el empleo en los años venideros. Este cambio se está acelerando y es necesario que toda la sociedad sea consciente de la magnitud del reto que debemos afrontar para garantizar el empleo y minimizar el riesgo de exclusión social en los próximos años.

El enfoque específico de este informe se centra en aportar un punto de vista más orientado a la definición de las competencias y capacidades que las empresas necesitarán en los próximos años -como resultado de los profundos cambios del entorno en que operan- y que el sistema educativo debería ayudar a cubrir para asegurar el empleo del futuro. Las políticas en el ámbito laboral, por ejemplo, las modalidades de contratos, son importantes, pero en este informe queremos profundizar en las necesidades de competencias profesionales que tienen las empresas, que son las que acaban contratando. Este enfoque es coherente con los estudios recientes de la OCDE (2018b) o del World Economic Forum (2016, 2018a). No obstante, en este 
estudio seguimos un enfoque metodológico algo diferente, y que se apoya en encuestas y entrevistas detalladas a grandes empresas.

En este esfuerzo, las empresas deben desempeñar un papel fundamental, puesto que crean empleo, tienen el conocimiento de los perfiles y formación que se requerirán en el futuro, y el uso de dicha información debería ser una pieza fundamental para guiar los cambios que deben hacerse en el sistema educativo para asegurar un encaje adecuado con las necesidades reales de las empresas y de la sociedad. La educación no se puede limitar a transmitir un conjunto de capacidades para trabajar, sino que debe incluir también una formación intelectual y en hábitos, virtudes y actitudes; pero si las capacidades para trabajar no se ofrecieran, el modelo educativo estaría condenado al fracaso. Las empresas pueden aportar unos ingredientes indispensables para asegurar el éxito del modelo educativo del futuro y la creación de ocupación.

\subsection{Estructura del proyecto: educación para el desarrollo de competencias}

En este estudio, hemos realizado un primer diagnóstico sobre las necesidades de competencias profesionales de las empresas y la brecha de capacidades a partir de la información que hemos extraído de las compañías entrevistadas ${ }^{7}$.

Existen iniciativas de gran interés sobre cómo combatir el desempleo juvenil. Nosotros abordamos este problema situando a las empresas en un lugar principal, ya que son las que están experimentando los cambios mencionados en los perfiles profesionales requeridos y pueden descubrir y definir las necesidades profesionales de los próximos años. Por tanto, su contribución en la definición de las competencias profesionales que deben desarrollarse para el empleo del futuro resulta fundamental.

Hemos contado con la participación de 53 compañías relevantes de la economía española, pertenecientes a doce sectores, que se han seleccionado de acuerdo con varios criterios: empresas que cotizan en bolsa; empresas privadas de tamaño grande o mediano; liderazgo en el sector expresado por la cuota de mercado; y oferta de empleo especialmente cualificado ${ }^{8}$. Las personas entrevistadas que han colaborado en este proyecto son los directores de la División de Personas, de Recursos Humanos o Desarrollo de Talento de dichas empresas. El Anexo 1 incluye un listado de las empresas participantes, así como de las personas que han intervenido en las encuestas.

Las empresas que han participado en este informe tuvieron aproximadamente una facturación total de 447.413 millones de euros en 2017, y daban empleo aproximadamente a 447.763 personas en España y a 2.970.233 personas a nivel mundial en diciembre de 2017 (véase el Anexo 1, Tabla 1). Estas cifras indican la clara relevancia de esta muestra de empresas, de doce sectores diferentes, sobre el PIB y el empleo.

La metodología que hemos seguido para realizar el diagnóstico consta de dos elementos básicos: una encuesta exhaustiva (véase el Anexo 3) y una entrevista personal.

En la gran mayoría de los casos, tanto la encuesta como la entrevista se han realizado con las mismas personas de las empresas. Estas han recibido la encuesta con anterioridad y se ha dedicado la entrevista a matizar las respuestas obtenidas y a comentar otros aspectos de las competencias profesionales del futuro, de la contratación y del empleo juvenil.

\footnotetext{
7 Para la clasificación de las competencias, hemos seguido algunos estudios sobre el desarrollo de competencias profesionales esenciales, como los de Cardona y García-Lombardía (2005) o Canals (2012).

8 No hemos incluido empresas de sectores como Construcción -a excepción de Ferrovial, que es una empresa de servicios e ingeniería, principalmente- que contratan, mayoritariamente, personas con baja cualificación profesional.
} 
Las empresas elegidas no representan el conjunto del tejido empresarial español, pero son especialmente relevantes y muchas de ellas son líderes de su sector. La información que presentamos nos permite avanzar en un primer diagnóstico de la situación.

\subsubsection{Encuesta}

Hemos realizado una encuesta que consta de 17 preguntas con diversos apartados, clasificadas en 4 epígrafes:

1. Perfiles profesionales contratados por la empresa y su evolución.

2. Ajuste/desajuste de conocimientos, capacidades y actitudes.

3. Propuesta de soluciones al reto del empleo juvenil.

4. Posible implicación de la empresa para abordar el reto del empleo.

La encuesta incluye preguntas de valoración numérica, algunas de elección múltiple y otras abiertas.

Las encuestas se han realizado a los directores de la División de Personas, de Recursos Humanos o de Desarrollo de Talento de las empresas participantes durante el periodo comprendido entre mayo y diciembre de 2018.

\subsubsection{Entrevistas}

Se han realizado entrevistas personales a los directores de la División de Personas, de Recursos Humanos o de Desarrollo de Talento de las empresas participantes con el objetivo de obtener información cualitativa que permitiera ampliar y matizar la información recogida en las encuestas. En las entrevistas, las compañías han compartido con nosotros iniciativas interesantes que han puesto en práctica en las áreas de contratación, formación o retención de personas jóvenes; algunas de estas prácticas se han incluido en este estudio.

Las entrevistas han tenido una duración aproximada de entre 60 y 90 minutos, y se han realizado entre mayo y diciembre de 2018.

El resto del informe se estructura de la siguiente manera: en el apartado 5 expondremos de forma esquemática los resultados del análisis procedente de las encuestas realizadas a las empresas; en el apartado 6 presentaremos un diagnóstico de conjunto a partir del análisis de las encuestas y las entrevistas realizadas a las empresas participantes; finalmente, en el apartado 7, perfilaremos algunas ideas para un plan de acción. 


\section{Educación para el desarrollo de competencias. El punto de vista de las empresas}

En este apartado se presentan los principales resultados de las encuestas realizadas a 50 de las 53 empresas participantes (las encuestas a tres de ellas no presentan resultados completos, pero se utilizan para la valoración cualitativa de las competencias profesionales).

\subsection{Perfiles profesionales en la empresa y evolución}

\subsubsection{Perfiles actuales}

El 76\% de los puestos de trabajo en las empresas encuestadas están cubiertos, en la actualidad, por personas con un nivel educativo de grado universitario superior o medio ${ }^{9}$.

El porcentaje de puestos ocupados por personas procedentes de formación profesional es reducido (un 17\%), y aquellas con nivel educativo de educación secundaria tan solo cubren el $7 \%$ de los puestos (véase la Figura 33).

Figura 33

Perfiles actuales

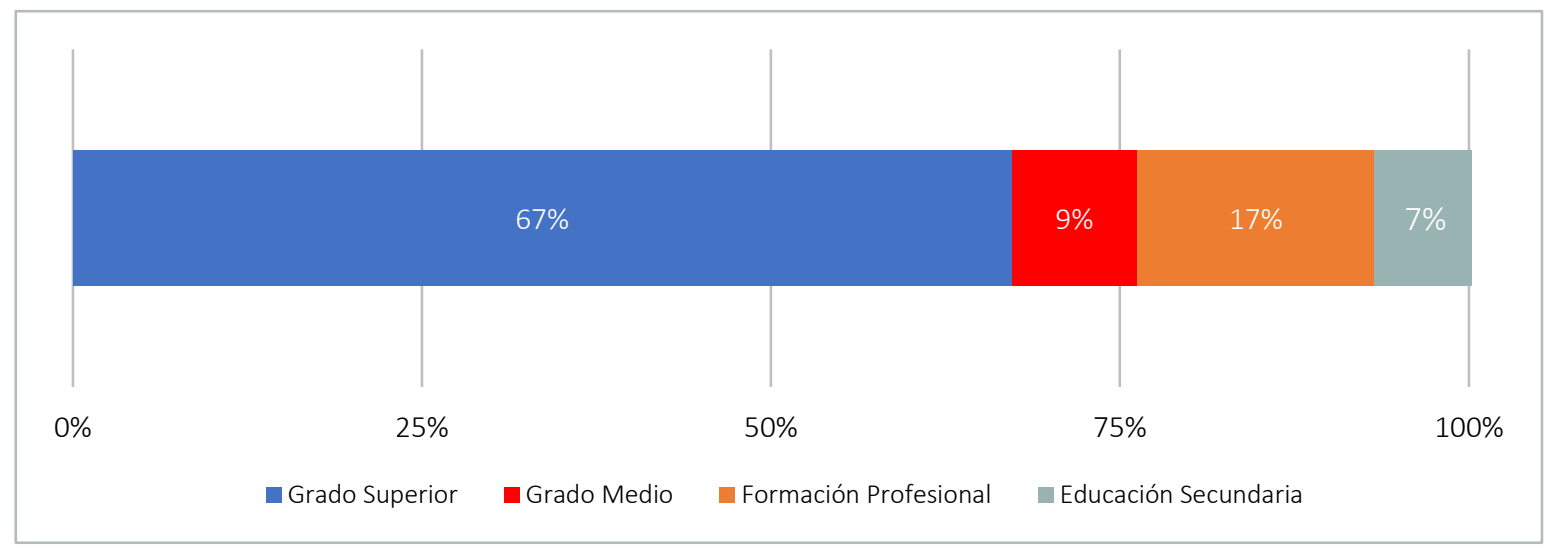

\subsubsection{Nivel educativo por función}

La inmensa mayoría de los puestos en el área Comercial (83\%) están ocupados por profesionales con un nivel educativo de grado superior. Tan solo un $6 \%$ tienen estudios de formación profesional y un $4 \%$, de educación secundaria.

Los niveles educativos en el área de Servicios Corporativos siguen un patrón parecido a los del área Comercial, aunque menos acentuado, con un $72 \%$ de los puestos cubiertos por profesionales con estudios de grado superior.

En el área de Operaciones, hay un porcentaje mucho mayor de profesionales con estudios de formación profesional (34\%), así como con un nivel de educación secundaria (14\%) (véase la Figura 34).

\footnotetext{
${ }^{9}$ Con "nivel de estudios de grado medio" nos referimos a las antiguas diplomaturas universitarias.
} 
Figura 34

Perfiles actuales por función

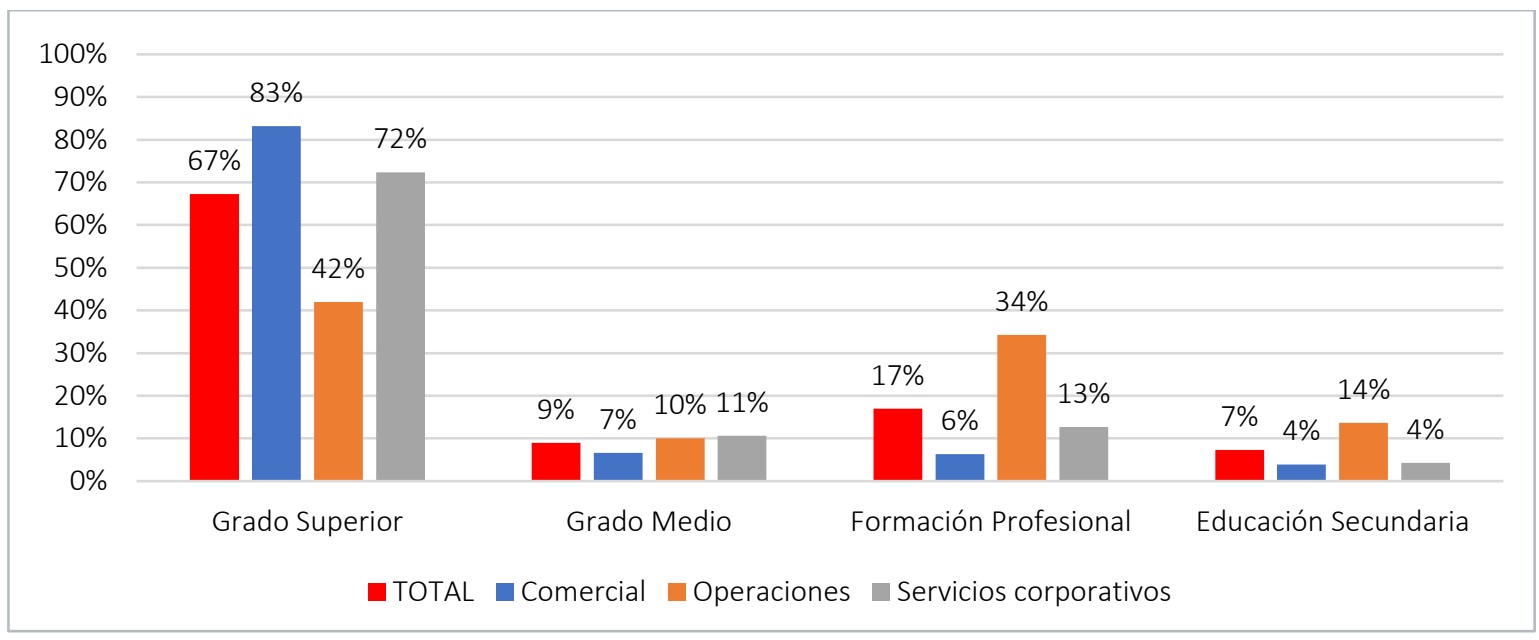

\subsubsection{Evolución de los perfiles contratados}

Los perfiles con estudios universitarios suponen el $76 \%$ de los puestos de trabajo actuales y el $65 \%$ de las contrataciones realizadas entre octubre de 2017 y el mismo mes de 2018. En relación a los perfiles con estudios de formación profesional, estos suponen el 17\% de los puestos de trabajo actuales y el 21\% de los ofrecidos entre octubre de 2017 y octubre de 2018 en las compañías entrevistadas (véase la Figura 35). Como se ha señalado anteriormente, en España existe un porcentaje mayor de desajuste de capacidades para el puesto de trabajo en comparación con otros países, principalmente, debido a la sobrecapacitación de los empleados (véase la Figura 27). Una mayor penetración de la formación profesional podría ayudar a combatir dicho problema, aunque, como también se ha comentado en el apartado 2 (véase la Figura 9), el porcentaje de estudiantes de formación profesional es menor que en la mayoría de países de la UE.

Figura 35

Nivel de educación de empleados (\% sobre el total de empleados) vs. nivel de educación de nuevas contrataciones (\% sobre el total de contrataciones)

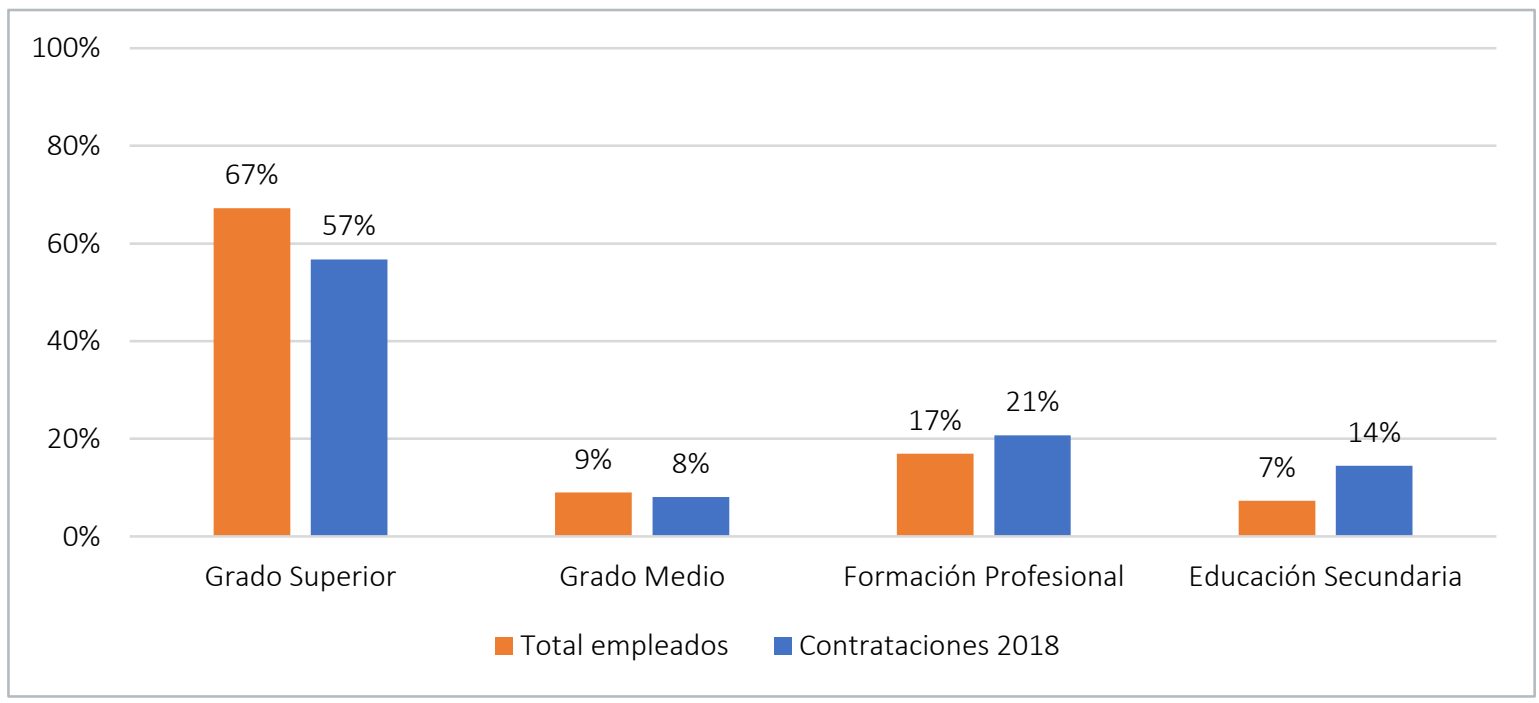




\subsubsection{Cambios en los perfiles profesionales buscados por las empresas}

Se aprecia un cambio muy significativo en los perfiles profesionales que necesitan las empresas, siendo claramente más acusado en las posiciones de Operaciones y Tecnología y en los grados de formación superior. Tanto en el área de Servicios Corporativos como en niveles de educación secundaria, el cambio de perfil experimentado en los últimos años es algo inferior (véanse las Figuras 36 y 37).

\section{Figura 36}

\section{Cambio de perfil según nivel formativo}

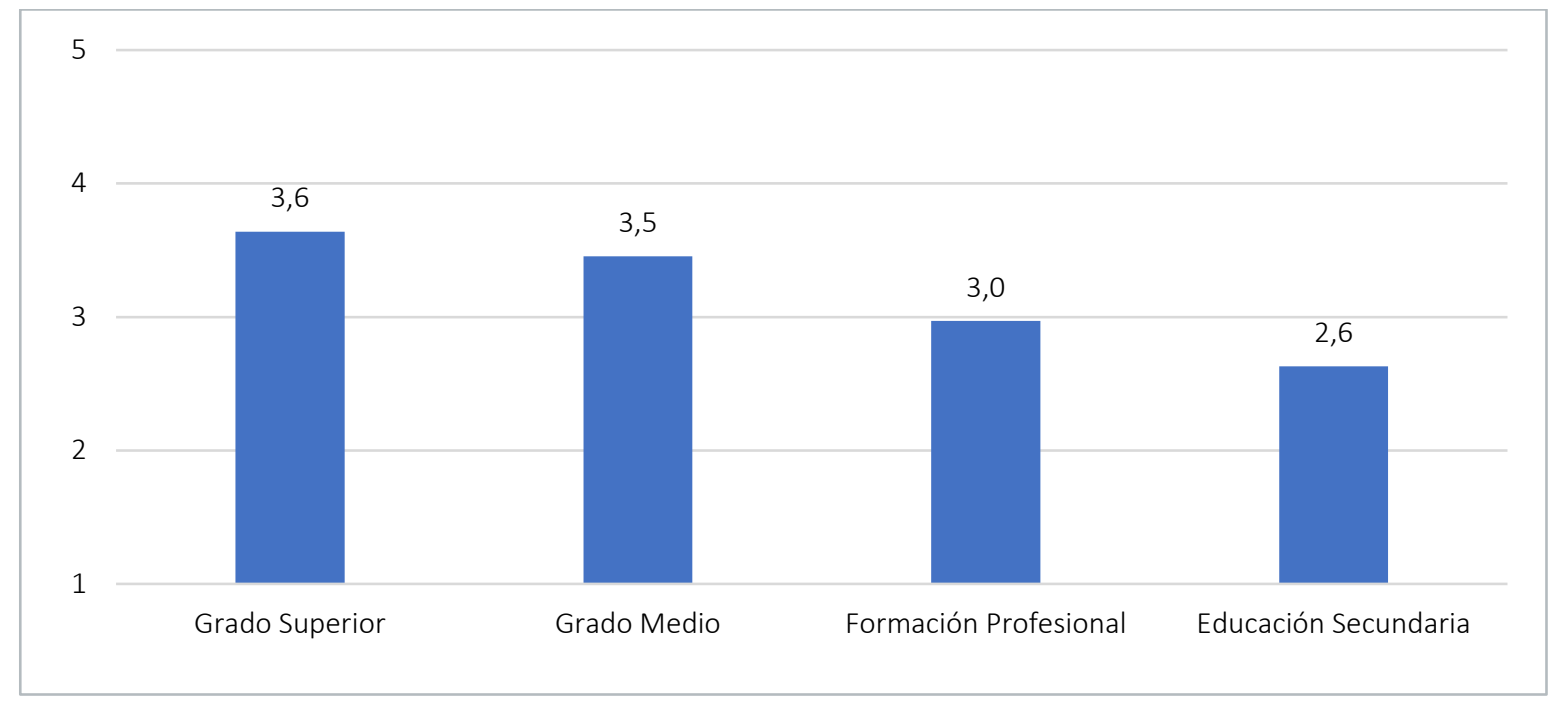

Figura 37

Cambio de perfil según departamento/función

5

3,6

3,2

3

2

1

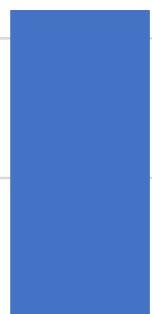

Comercial

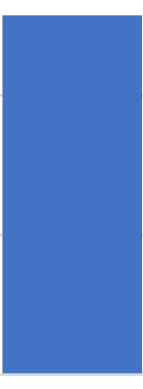

Operaciones
3,0

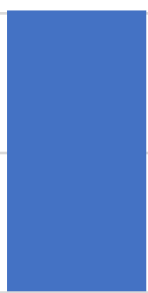

Servicios corporativos 


\subsubsection{Causas de los cambios en los perfiles profesionales buscados por las empresas}

En el apartado 3 se ha analizado el efecto que han tenido sobre el empleo algunas tendencias como la globalización, la revolución tecnológica o la automatización. En la encuesta realizada a las empresas, estas reconocen el impacto que dichos factores han supuesto sobre los perfiles profesionales requeridos.

En términos generales, el principal motivo de cambio en los perfiles es la revolución digital, a la que el $46 \%$ de las empresas encuestadas atribuye el máximo impacto, seguida de las necesidades de los clientes y la internacionalización.

Hay diferencias significativas según el tipo de empresa. Si bien la revolución digital afecta a la gran mayoría, la internacionalización tiene un impacto más variado. En muchas compañías, el impacto no consiste en que esta opere internacionalmente, sino en que la organización de la compañía está cada vez más globalizada - en parte como consecuencia de las nuevas tecnologías - y las formas de trabajo exigen la interacción con equipos de otros países. Así, el $33 \%$ de ellas considera que la internacionalización tiene un impacto muy alto en el cambio de los perfiles (véase la Figura 38).

\section{Figura 38}

\section{Causas del cambio en los perfiles: nivel de impacto}

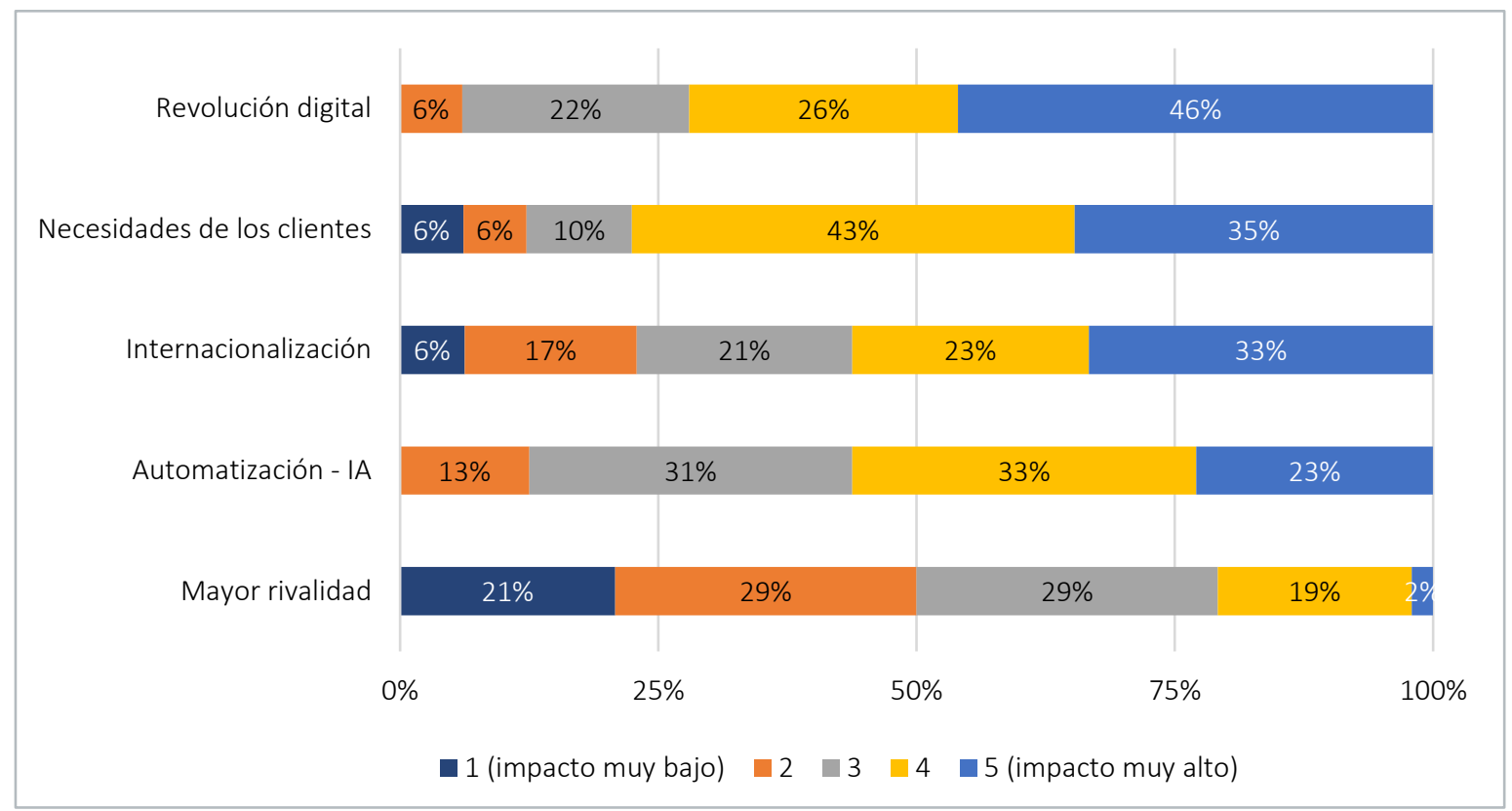




\subsubsection{Impacto de la automatización por funciones}

La automatización es otro de los factores que influyen en el cambio de perfil, y se prevé que siga afectando de forma intensa en los próximos cinco años, aunque de forma desigual según el tipo de actividad y el nivel educativo.

Así, se espera que el impacto de la automatización sea claramente mayor en los puestos de trabajo del área de Operaciones, seguido por los puestos de trabajo del área de Servicios Corporativos (véase la Figura 39).

\section{Figura 39}

Impacto de la automatización en puestos de trabajo por funciones

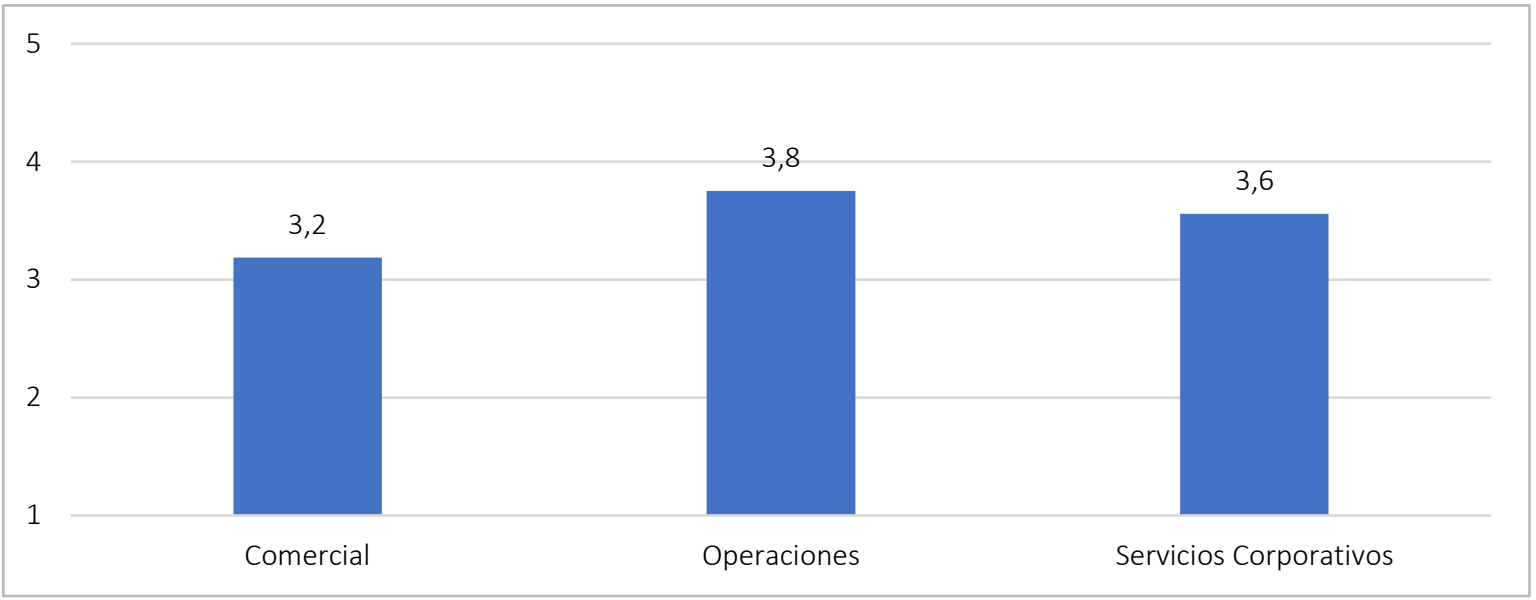

\subsubsection{Impacto de la automatización en los diversos niveles formativos}

Según el nivel educativo, se prevé un impacto mayor de la automatización en puestos de trabajo ocupados por personas con estudios de formación profesional y, sobre todo, de educación secundaria. También influirá en los perfiles de grado medio y superior, pero de forma más moderada (véase la Figura 40).

\section{Figura 40}

Impacto de la automatización en puestos de trabajo por nivel formativo

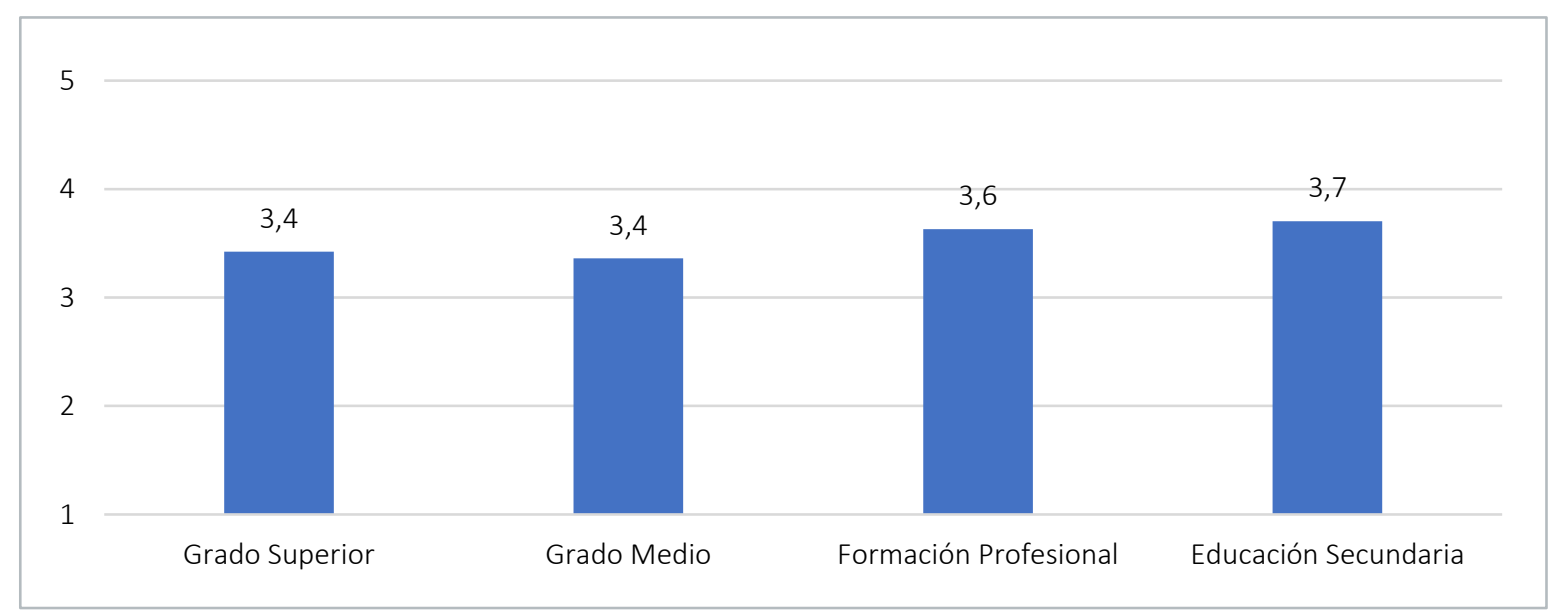




\subsection{Ajuste/desajuste de las empresas en conocimientos, capacidades y actitudes de las personas que contratan}

\subsubsection{Dificultades para cubrir los puestos de trabajo}

El 72\% de las empresas participantes encuentra muchas o bastantes dificultades para cubrir los puestos de trabajo debido a los cambios de perfiles exigidos y de las competencias requeridas (véase la Figura 41).

Figura 41

Dificultades para cubrir los puestos de trabajo

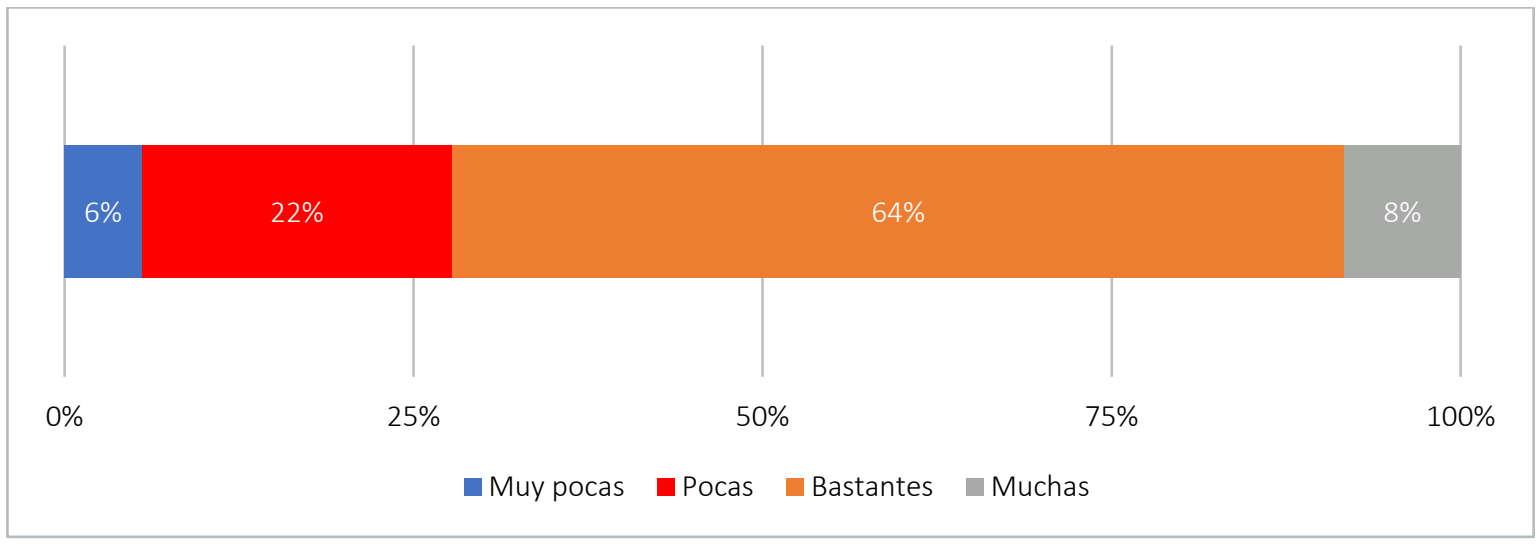

\subsubsection{Grado de satisfacción}

En general, las empresas se muestran satisfechas con la calidad formativa de las personas que acaban contratando con educación superior, de grado medio y con estudios de formación profesional, aunque no ocurre lo mismo con los empleados que cuentan con educación secundaria (véase la Figura 42). Es necesario recordar que el grado de satisfacción no es general, sino relativo a las personas que han contratado. En cambio, a las compañías les cuesta encontrar ciertos perfiles profesionales debido a la falta de adecuación del sistema educativo con respecto a sus necesidades, en particular en el nivel de educación secundaria.

Figura 42

Grado de satisfacción con la calidad de la formación de las personas contratadas

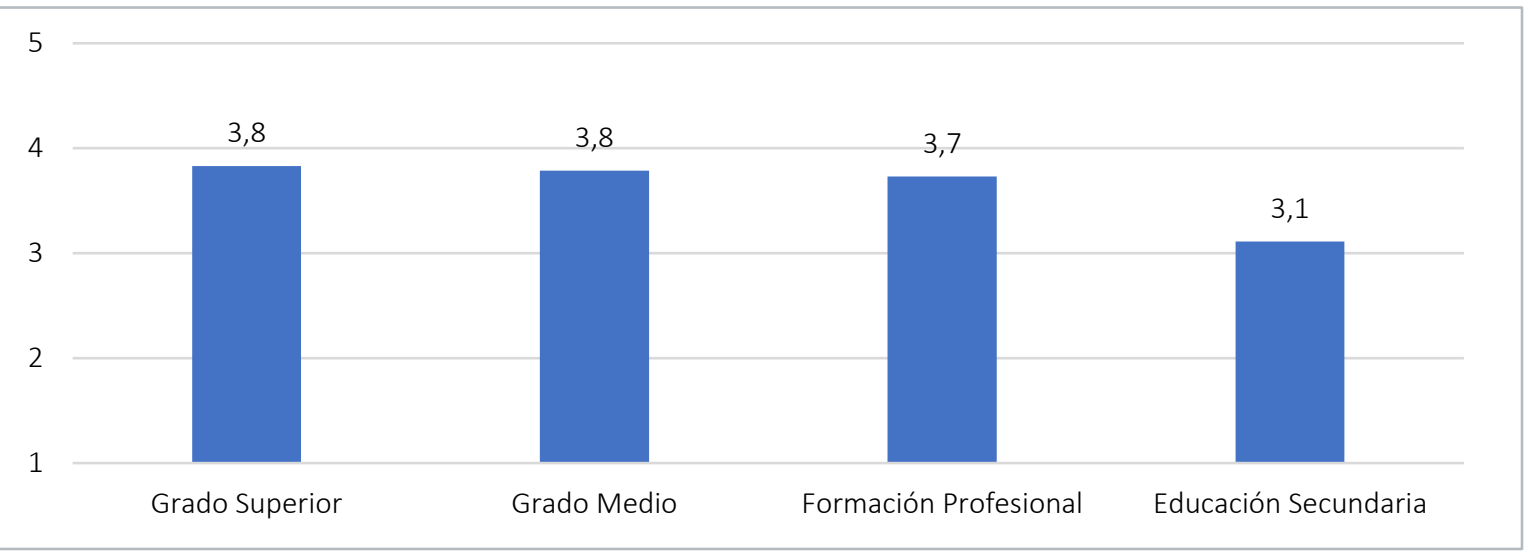




\subsubsection{Desajuste general por niveles educativos}

Las empresas encuestadas consideran que el mayor desajuste entre lo que necesitan y lo que ofrece el sistema educativo se encuentra en los niveles de educación secundaria, aunque también existen problemas considerables en cuanto a la formación profesional. En los perfiles de grado superior o medio, el nivel de desajuste es menor (véase la Figura 43).

\section{Figura 43}

\section{Grado de desajuste entre la empresa y el sistema educativo}

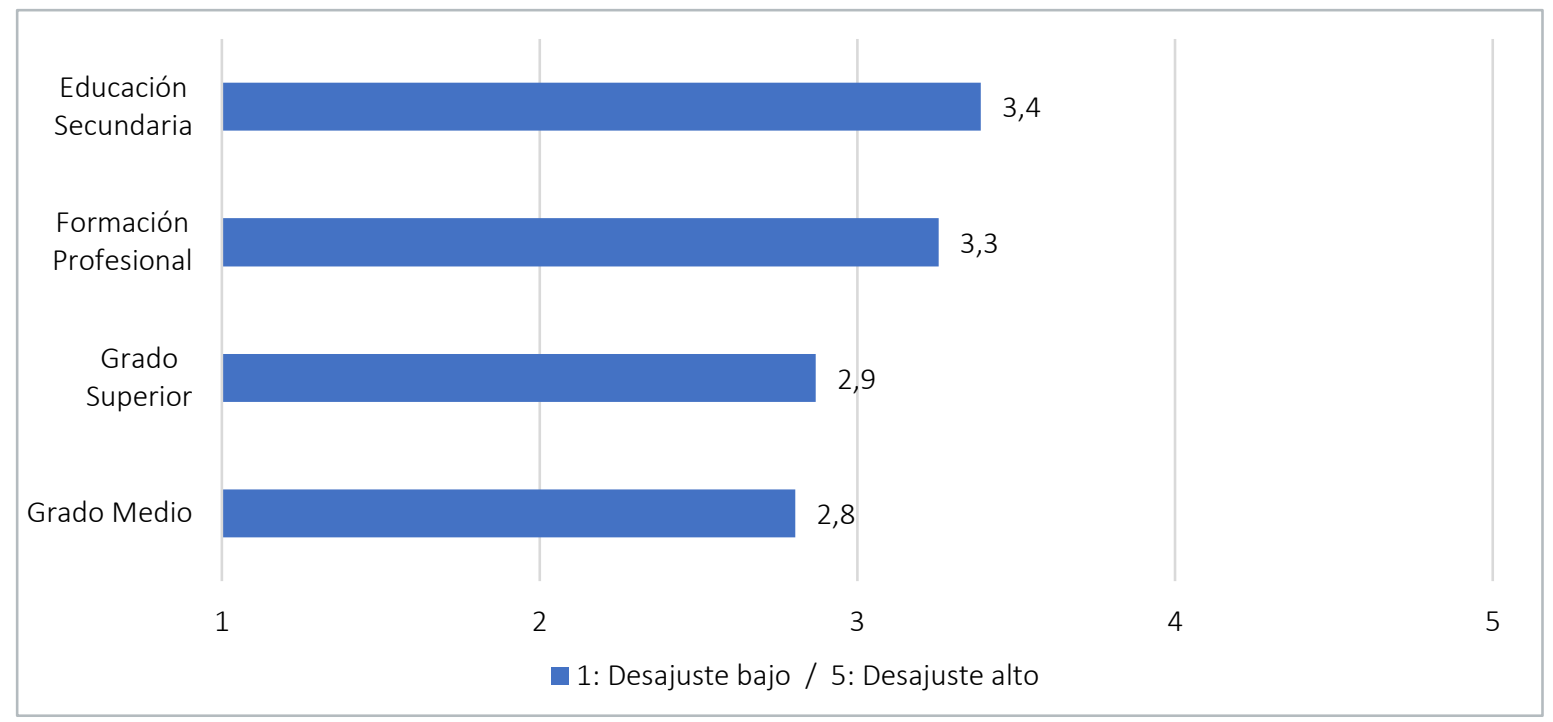

\subsubsection{Conocimientos, capacidades y actitudes requeridos y no encontrados: educación superior}

En cuanto a los conocimientos, las empresas consideran que hay áreas importantes que no están bien cubiertas por el sistema educativo. El principal problema reside en los conocimientos relativos a las nuevas tecnologías: el $68 \%$ de las empresas encuestadas afirma que no encuentra los conocimientos que necesita. Por otro lado, más de la mitad (52\%) considera que el nivel de idiomas no está bien cubierto, a pesar de que es un área muy importante para el 95\% de ellas (véase la Figura 44).

En relación con las capacidades, un 52\% de las empresas considera que el sistema educativo no proporciona lo que necesitan en cuanto a la capacidad de comunicación, siendo esta muy importante para el 91\% de ellas. El trabajo en equipo tampoco se considera cubierto por el sistema educativo en un $56 \%$ de los casos, y esta es una habilidad considerada muy importante por la totalidad de las encuestadas, al igual que la capacidad de ejecución, no encontrada por más de un tercio de las entrevistadas (38\%) (véase la Figura 45).

Con respecto a las actitudes, el $72 \%$ de las empresas considera que el sistema educativo actual no prepara a los jóvenes en términos de adaptabilidad y resiliencia, actitudes muy importantes para el $95 \%$ de las encuestadas. Tampoco se consideran bien preparadas la iniciativa (32\%) o sentido emprendedor (24\%), aunque ambas son actitudes a las que atribuyen una importancia máxima (véase la Figura 46). 
Figura 44

Brecha de conocimientos: educación superior

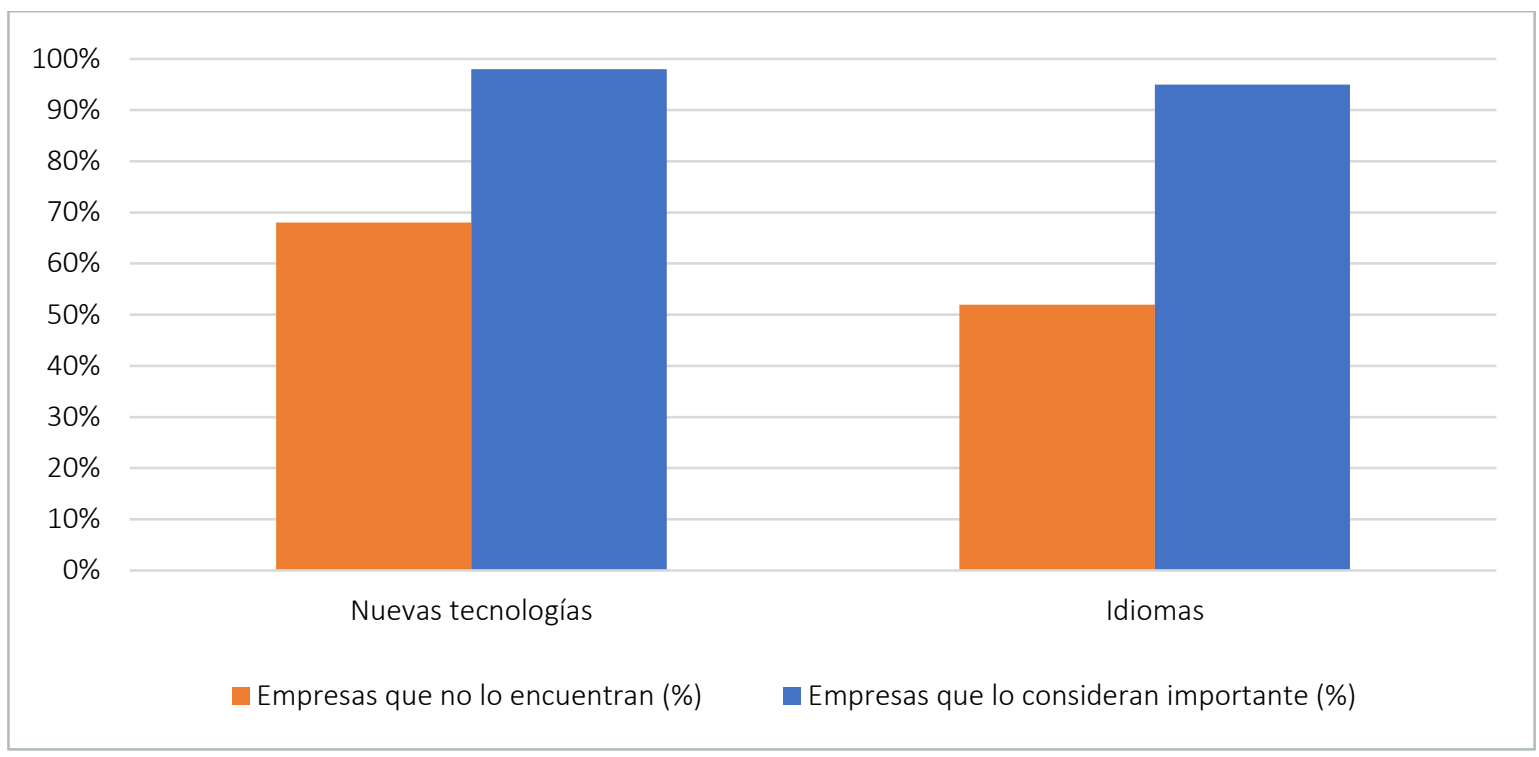

Figura 45

Brecha de capacidades: educación superior

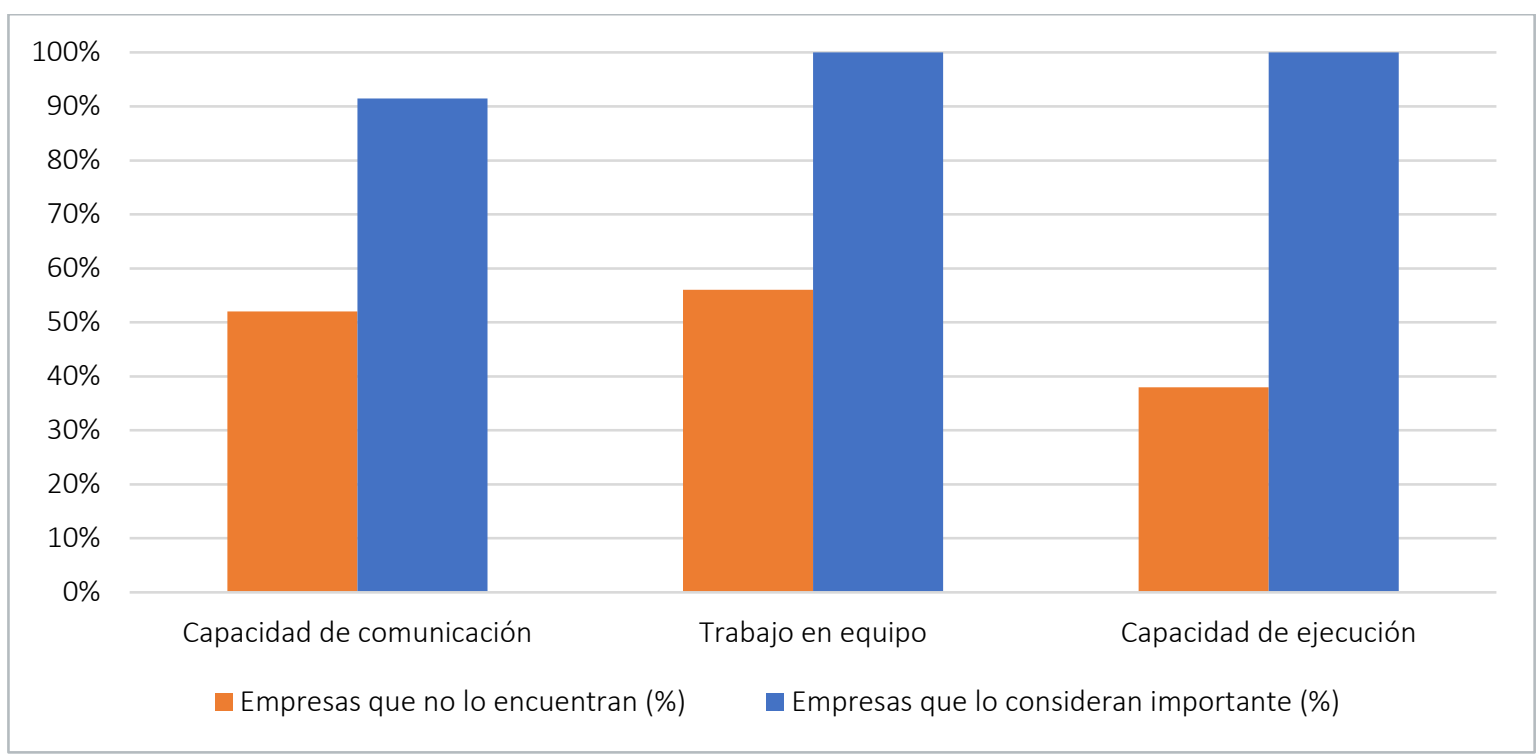




\section{Figura 46}

\section{Brecha de actitudes: educación superior}

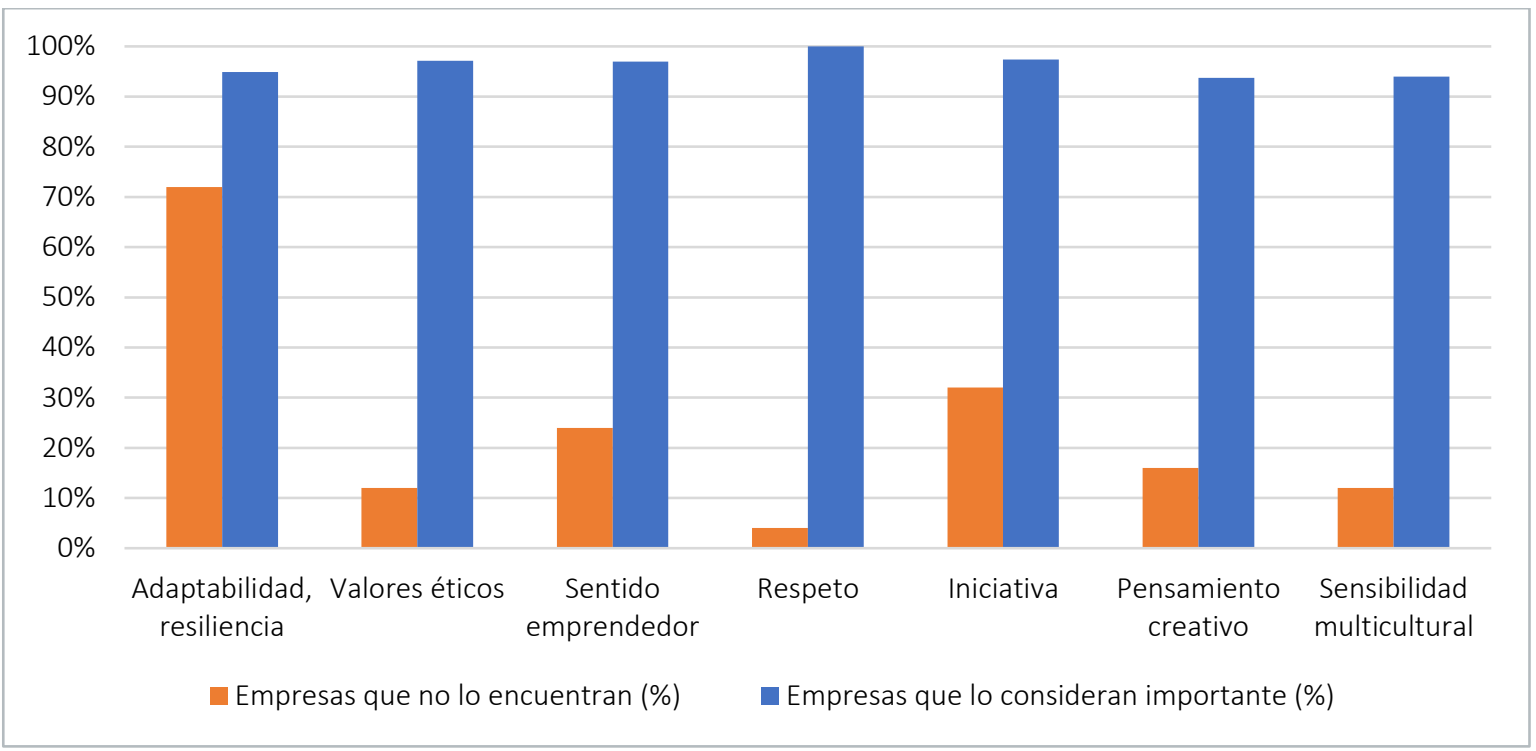

\subsubsection{Conocimientos, capacidades y actitudes requeridos y no encontrados: formación profesional}

Con respecto a los graduados de formación profesional, las empresas encuentran carencias parecidas a las de grado superior o medio. Así, según el $48 \%$ de las compañías encuestadas, los conocimientos en nuevas tecnologías no están bien cubiertos por el sistema educativo, mientras que el 52\% no encuentra el nivel deseado en cuanto a idiomas (véase la Figura 47).

En cuanto a capacidades, la capacidad de trabajo en equipo tampoco se considera bien cubierta por el $48 \%$ de las empresas, a pesar de que es muy importante para todas las encuestadas. Por otra parte, el $52 \%$ no encuentra un nivel satisfactorio en cuanto a la capacidad de comunicación en el caso de los perfiles con estudios de formación profesional (véase la Figura 48).

Finalmente, en cuanto a actitudes, la principal brecha radica en la adaptabilidad o la resiliencia, no encontradas por el $52 \%$ de las compañías encuestadas, y en la iniciativa (40\%). No obstante, ambas actitudes son muy importantes para el 91\% de las empresas (véase la Figura 49). 
Figura 47

Brecha de conocimientos: formación profesional

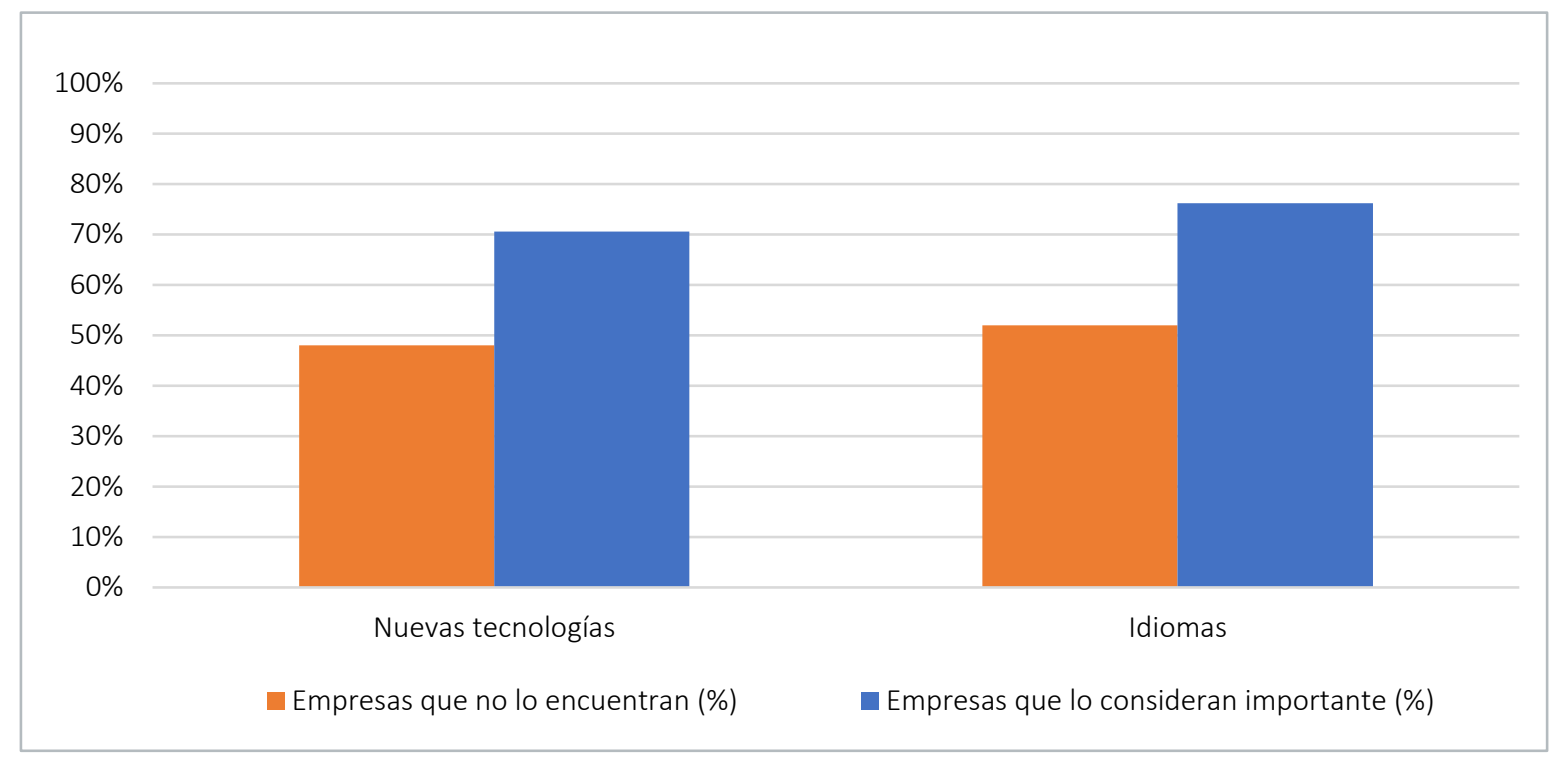

Figura 48

Brecha de capacidades: formación profesional

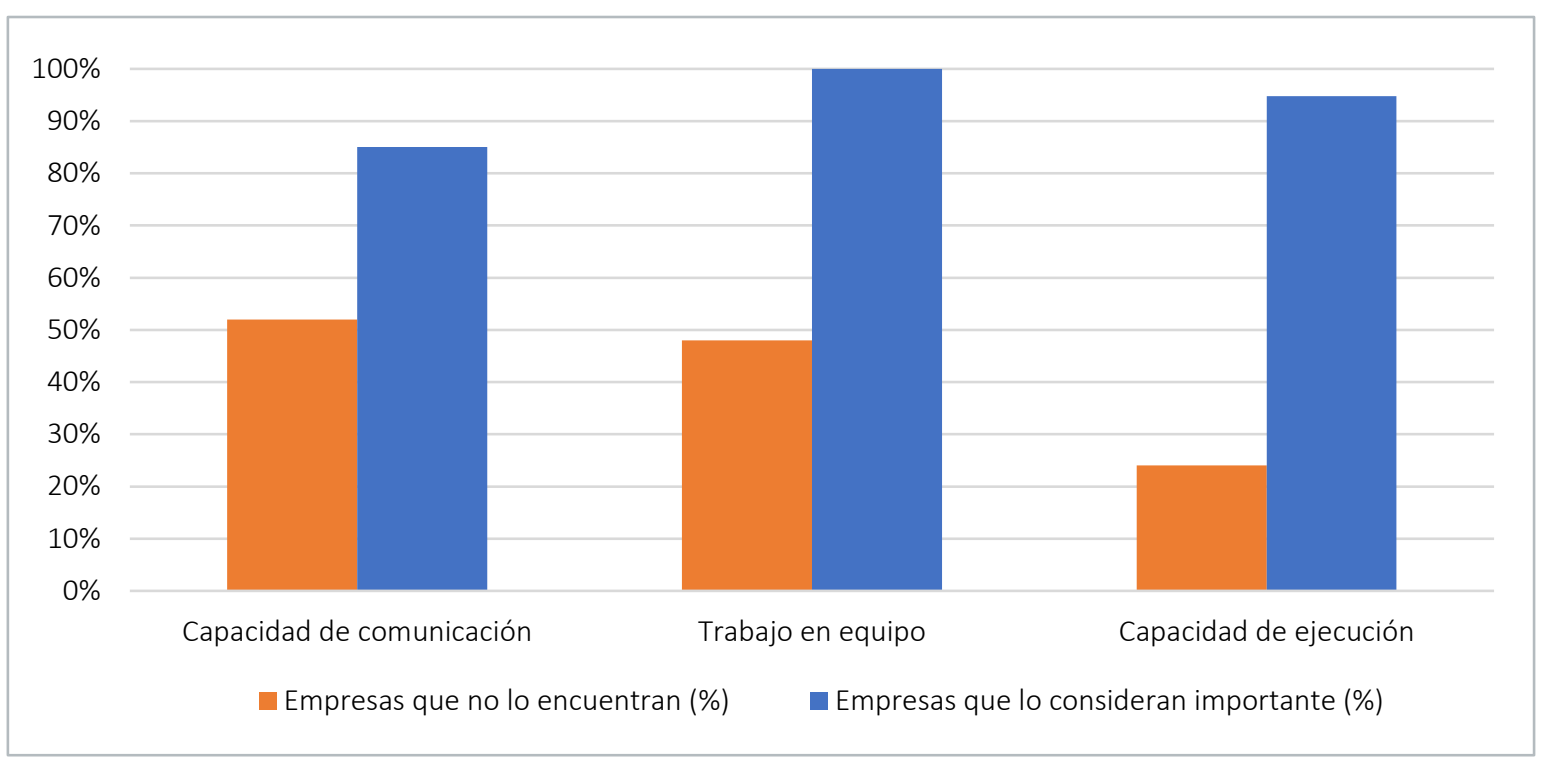




\section{Figura 49}

\section{Brecha de actitudes: formación profesional}

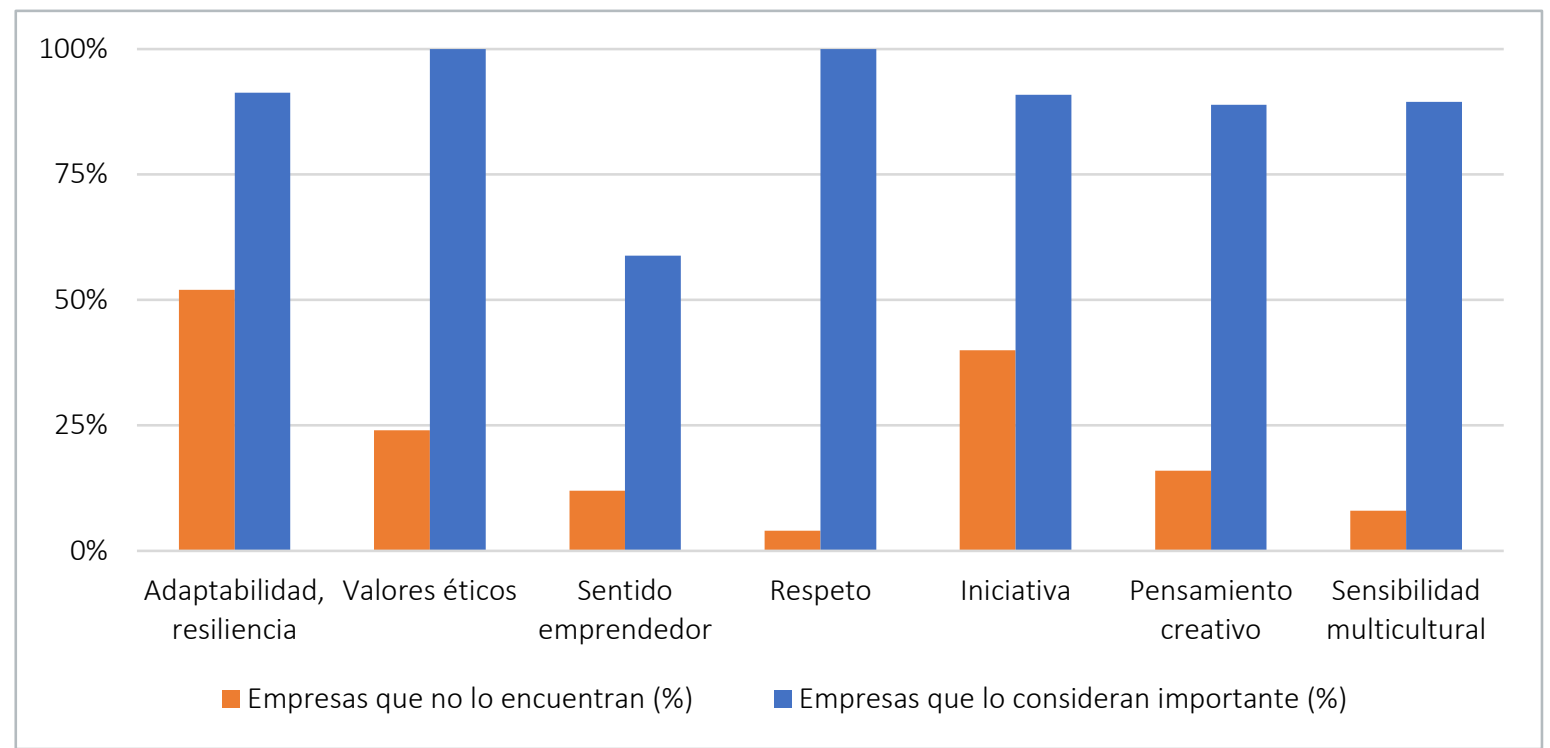

\subsubsection{Conocimientos, capacidades y actitudes requeridos y no encontrados: educación secundaria}

En los perfiles de educación secundaria, las empresas (un 67\%) observan una deficiencia importante de conocimientos en idiomas. El $78 \%$ no encuentra la capacidad de trabajo en equipo, mientras que un $44 \%$ percibe la dificultad de encontrar la capacidad de ejecución.

Con respecto a las actitudes, el $44 \%$ no encuentra el nivel requerido en términos de adaptabilidad y resiliencia. Asimismo, cabe destacar que, con respecto a los perfiles de educación superior y formación profesional, un mayor porcentaje de empresas tiene dificultades para encontrar la actitud necesaria en cuanto a valores éticos (véanse las Figuras 50, 51 y 52). 
Figura 50

Brecha de conocimientos: educación secundaria

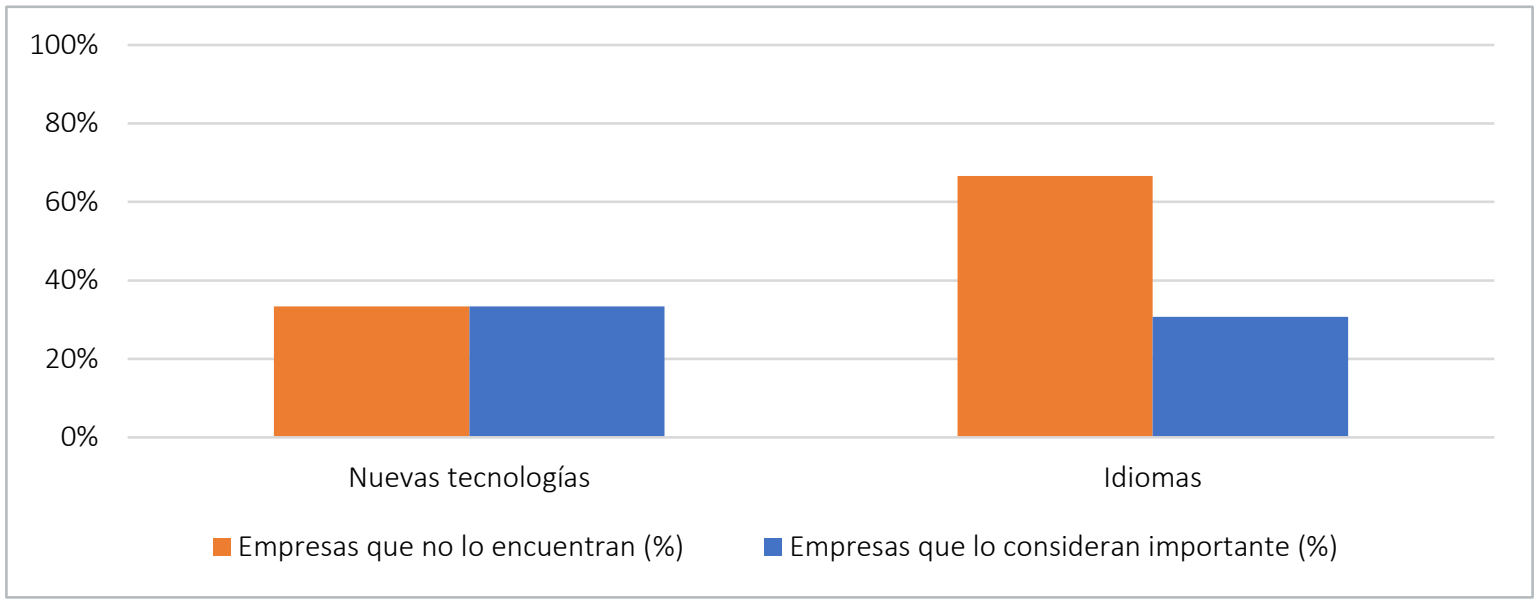

Figura 51

Brecha de capacidades: educación secundaria

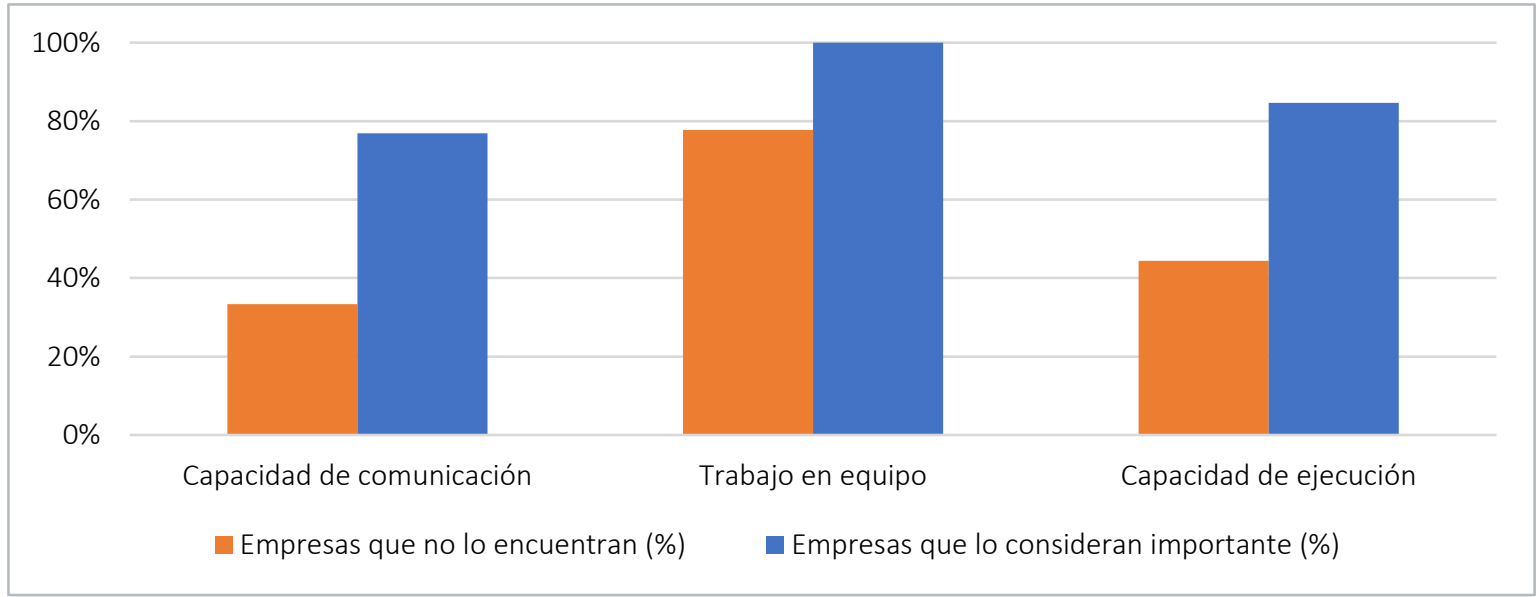

Figura 52

Brecha de actitudes: educación secundaria

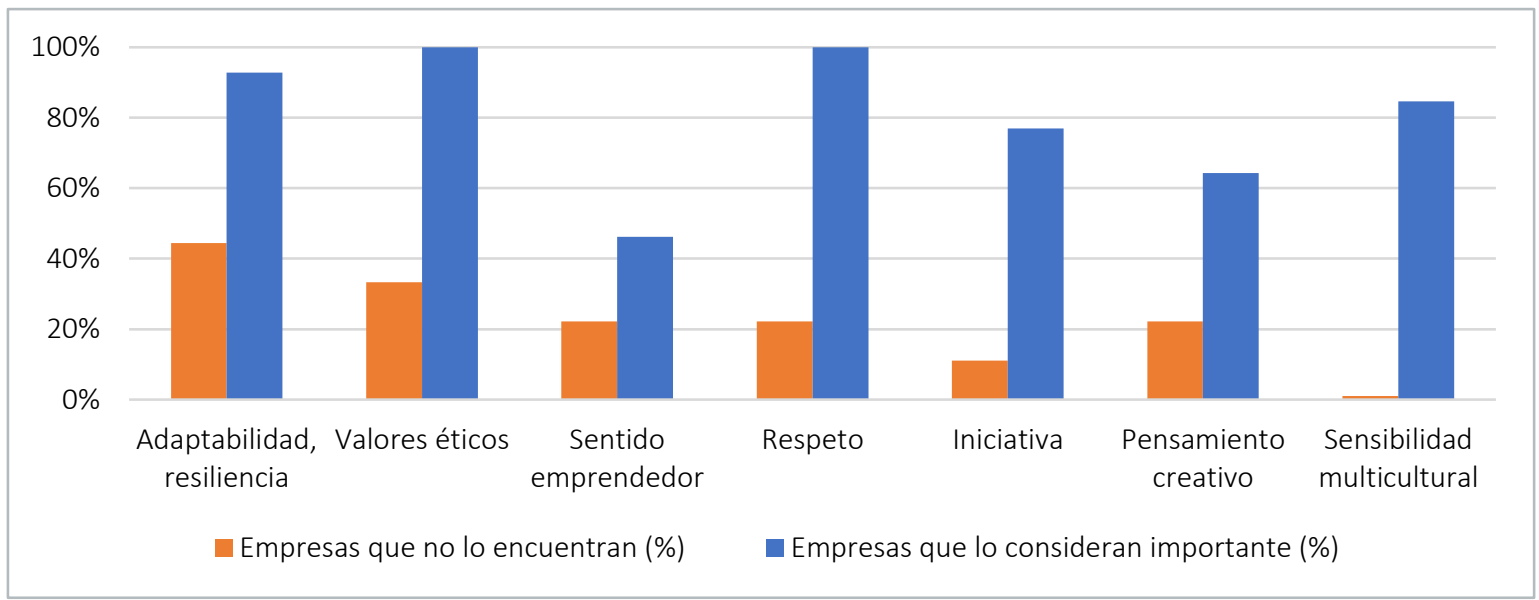




\subsubsection{Otros conocimientos, capacidades y actitudes no encontrados en el sistema educativo}

Finalmente, las empresas también consideran que, en general, en el sistema educativo falta formación específica en determinados conocimientos sectoriales, lenguajes de programación o nuevas tecnologías. También destacan carencias formativas en ciertas capacidades y actitudes como la visión de conjunto, la capacidad analítica y de gestión, la capacidad de aprendizaje y el compromiso (véase la Figura 53).

\section{Figura 53}

Otros conocimientos, capacidades y actitudes no encontrados en el sistema educativo

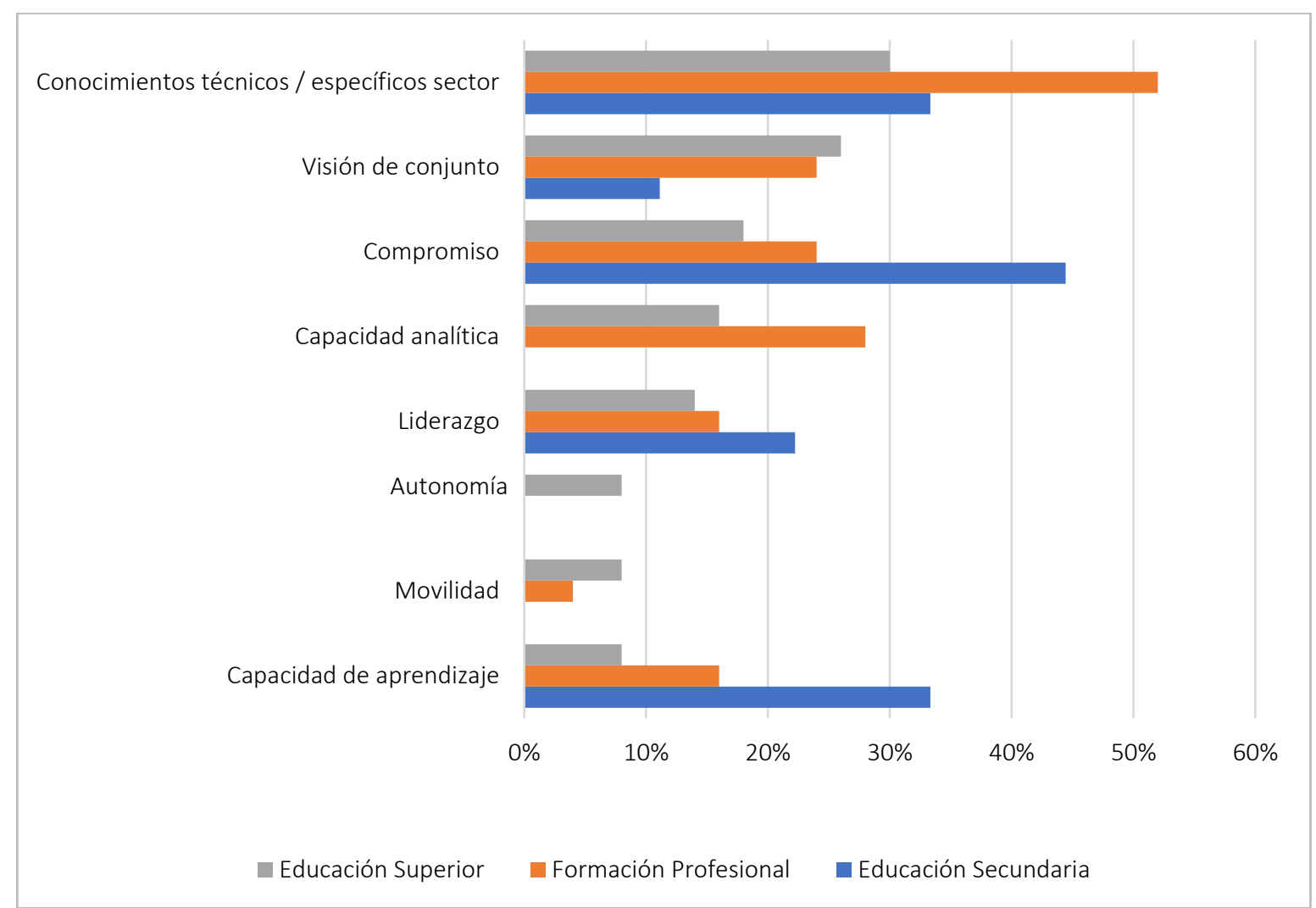

\subsubsection{Conocimientos, capacidades y actitudes requeridos y evolución en los próximos cinco años}

Se ha analizado para cada nivel educativo cuáles son los conocimientos, capacidades y actitudes requeridos en la actualidad y cómo variará en los próximos cinco años para poder apreciar si la brecha existente hoy en día aumentará en dicho periodo.

En términos generales, las empresas han otorgado un nivel de importancia muy alto a las capacidades y actitudes requeridas tanto en los niveles educativos superiores como en formación profesional y educación secundaria.

Sin embargo, el grado de exigencia tanto en conocimientos como en capacidades y actitudes presenta una clara correlación con el nivel de estudios. Así, las empresas piden un nivel más alto (tanto de conocimientos como de capacidades y actitudes) a los empleados de grado superior y 
medio que a los que tienen estudios de formación profesional, y más alto para estos últimos que para los de educación secundaria.

La variación entre las necesidades actuales y las de los próximos cinco años es mayor en el caso de los conocimientos que en el de las capacidades y actitudes, hecho que será más evidente en los profesionales con un nivel de estudios de grado medio o superior.

A continuación se presentan los resultados específicos por nivel de estudios.

\section{Educación superior}

En lo relativo a conocimientos, las áreas en las que se observa una brecha que deberá cubrirse en los próximos cinco años son las relacionadas con conocimientos tecnológicos (como el big data, la inteligencia artificial, el blockchain o el marketing digital). El big data y el marketing digital serán, además, las dos áreas de conocimiento más requeridas en 2023 (véase la Figura 54). El dominio de otros idiomas sigue siendo una necesidad muy relevante en España y no bien atendida.

\section{Figura 54}

\section{Conocimientos: educación superior}

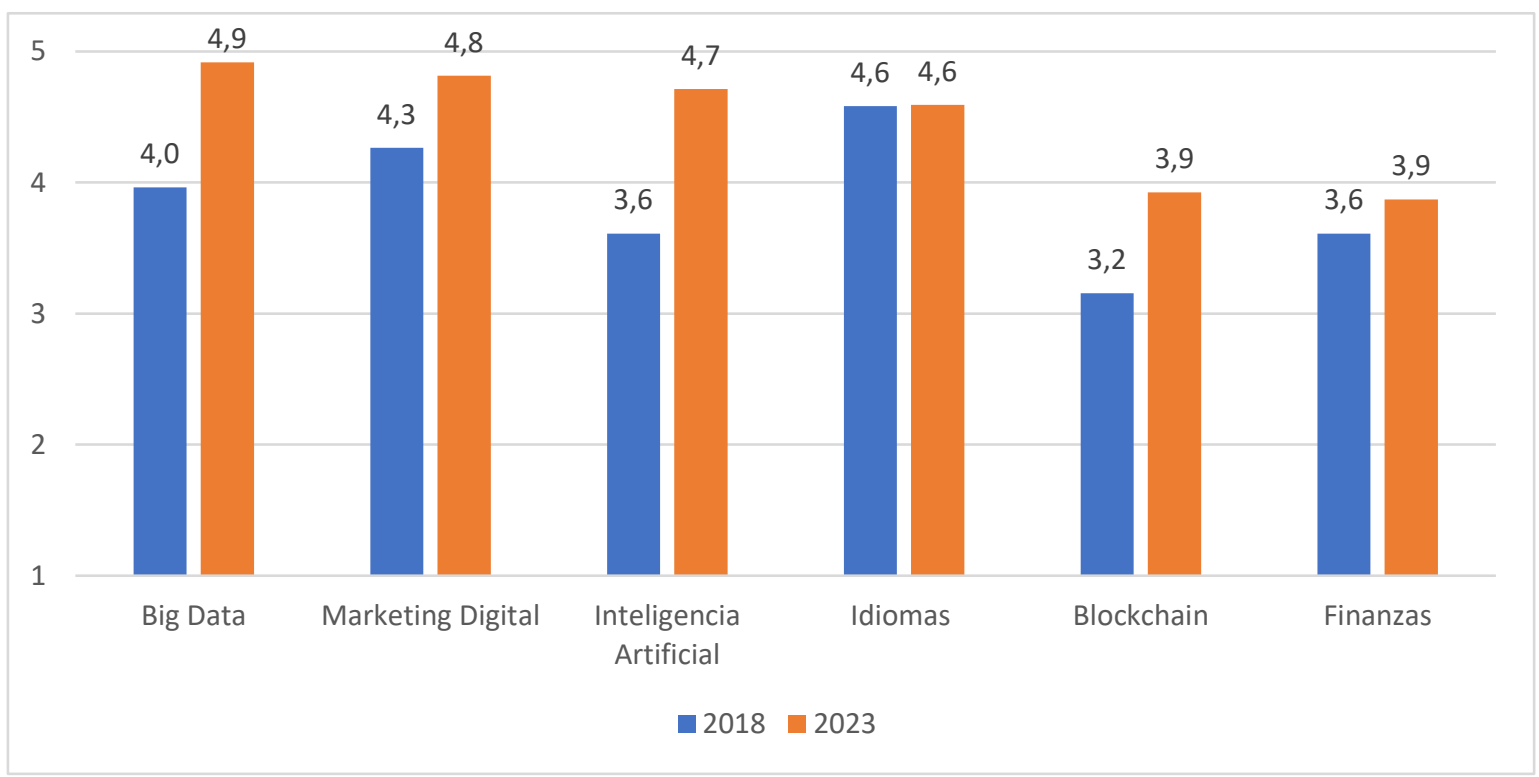

En cuanto a las capacidades, la brecha entre 2018 y 2023 es muy reducida, pero ello se debe a que el nivel de exigencia en el año 2018 es ya muy elevado para estas capacidades, y lo seguirá siendo en los próximos cinco. La capacidad de trabajo en equipo, la orientación al cliente y la capacidad de comunicación son consideradas también muy importantes (véase la Figura 55). 


\section{Figura 55}

\section{Capacidades: educación superior}

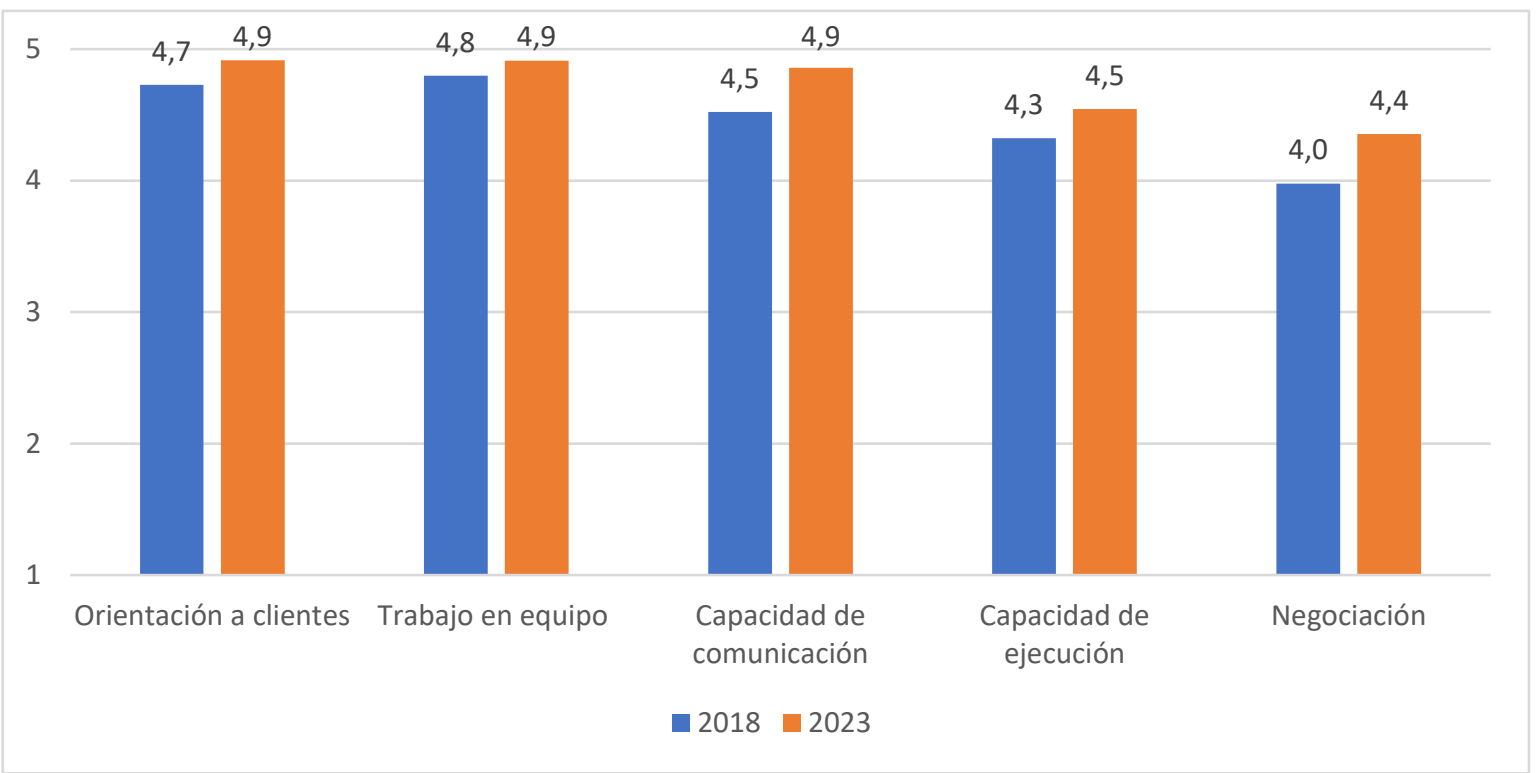

También las actitudes presentan un elevado grado de exigencia en el caso de personas con estudios de grado superior y medio, y en los próximos cinco años aumentará la necesidad de encontrar empleados con sensibilidad multicultural, adaptabilidad y resiliencia, y sentido emprendedor (véase la Figura 56).

Figura 56

Actitudes: educación superior

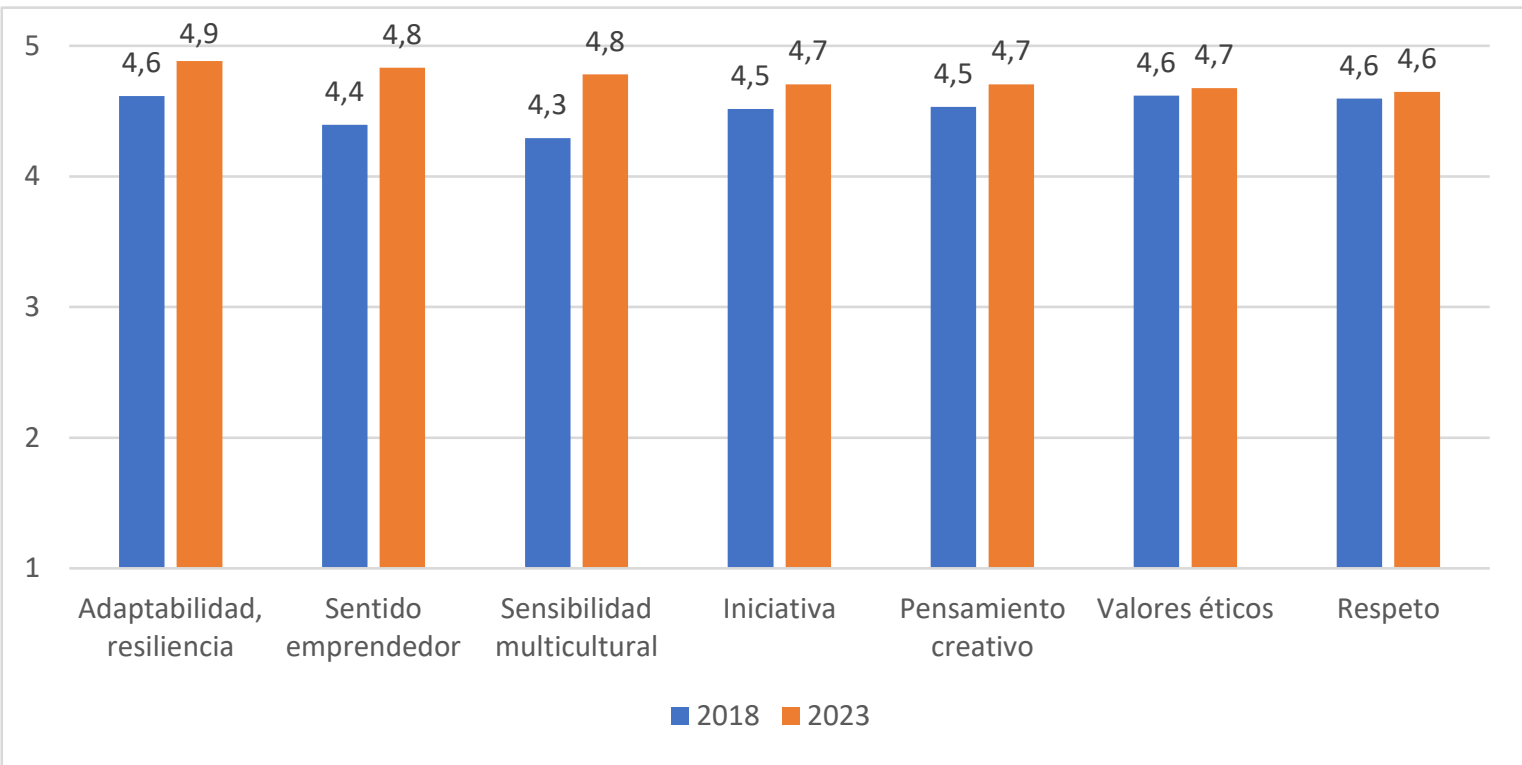




\section{Formación profesional}

En cuanto a la formación profesional, se observa un mayor cambio en los requerimientos para los próximos cinco años, por los que se amplía la brecha existente entre 2018 y 2023.

En el ámbito de conocimientos, las empresas muestran un grado de exigencia medio o bajo en la mayoría de temas tecnológicos, como big data, blockchain, inteligencia artificial o marketing digital. Sí se da una mayor importancia en los perfiles actuales a los idiomas, aunque el grado de exigencia es claramente menor en comparación con los niveles educativos superiores. Sin embargo, el nivel exigido en todas las áreas experimentará un aumento relevante en los próximos cinco años; la brecha más importante se encuentra en las áreas de big data, inteligencia artificial y marketing digital (véase la Figura 57).

\section{Figura 57}

\section{Conocimientos: formación profesional}

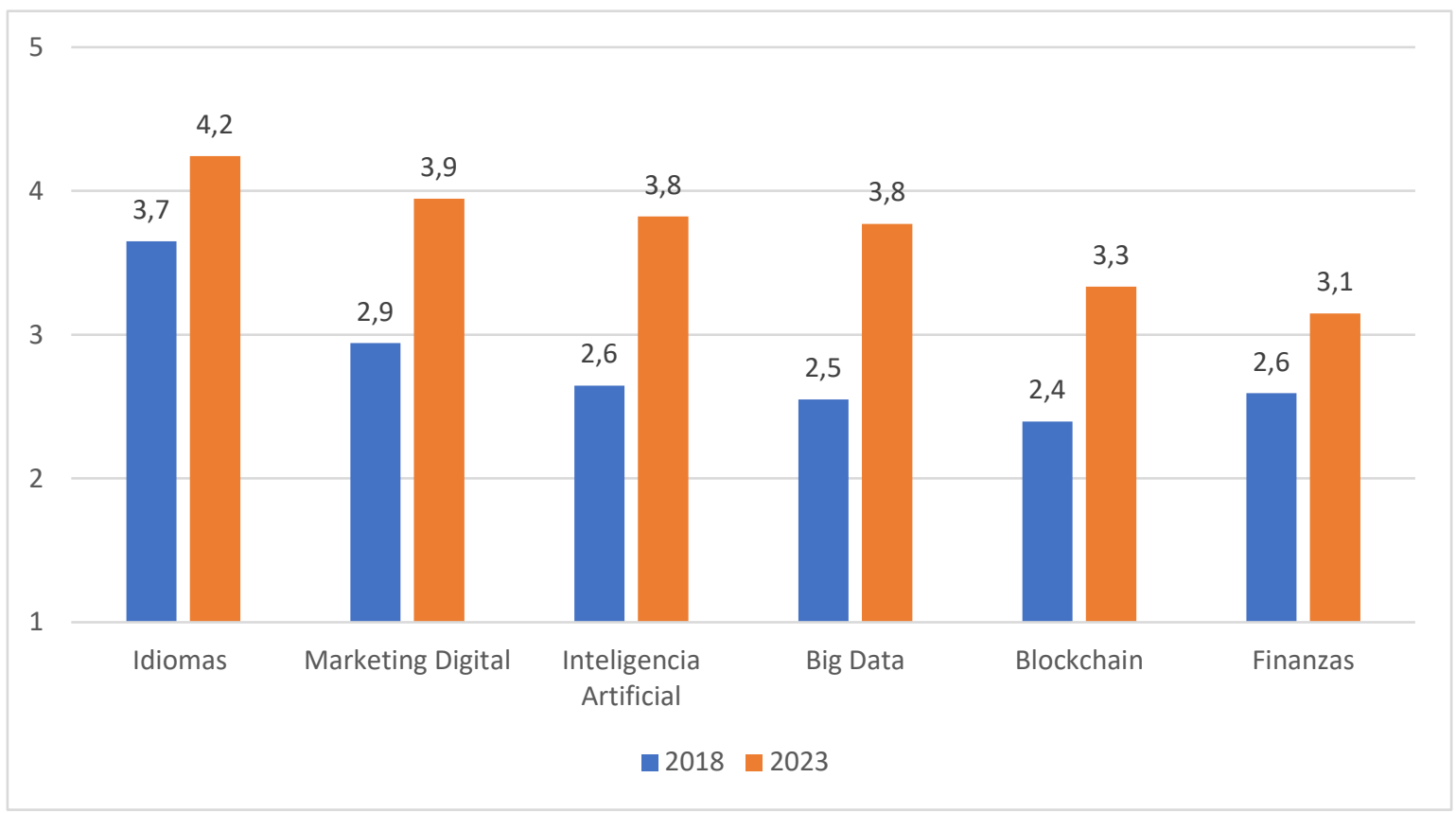

En cuanto a las capacidades, el nivel de exigencia en orientación al cliente, trabajo en equipo, ejecución y comunicación aumentará (véase la Figura 58). 


\section{Figura 58}

\section{Capacidades: formación profesional}

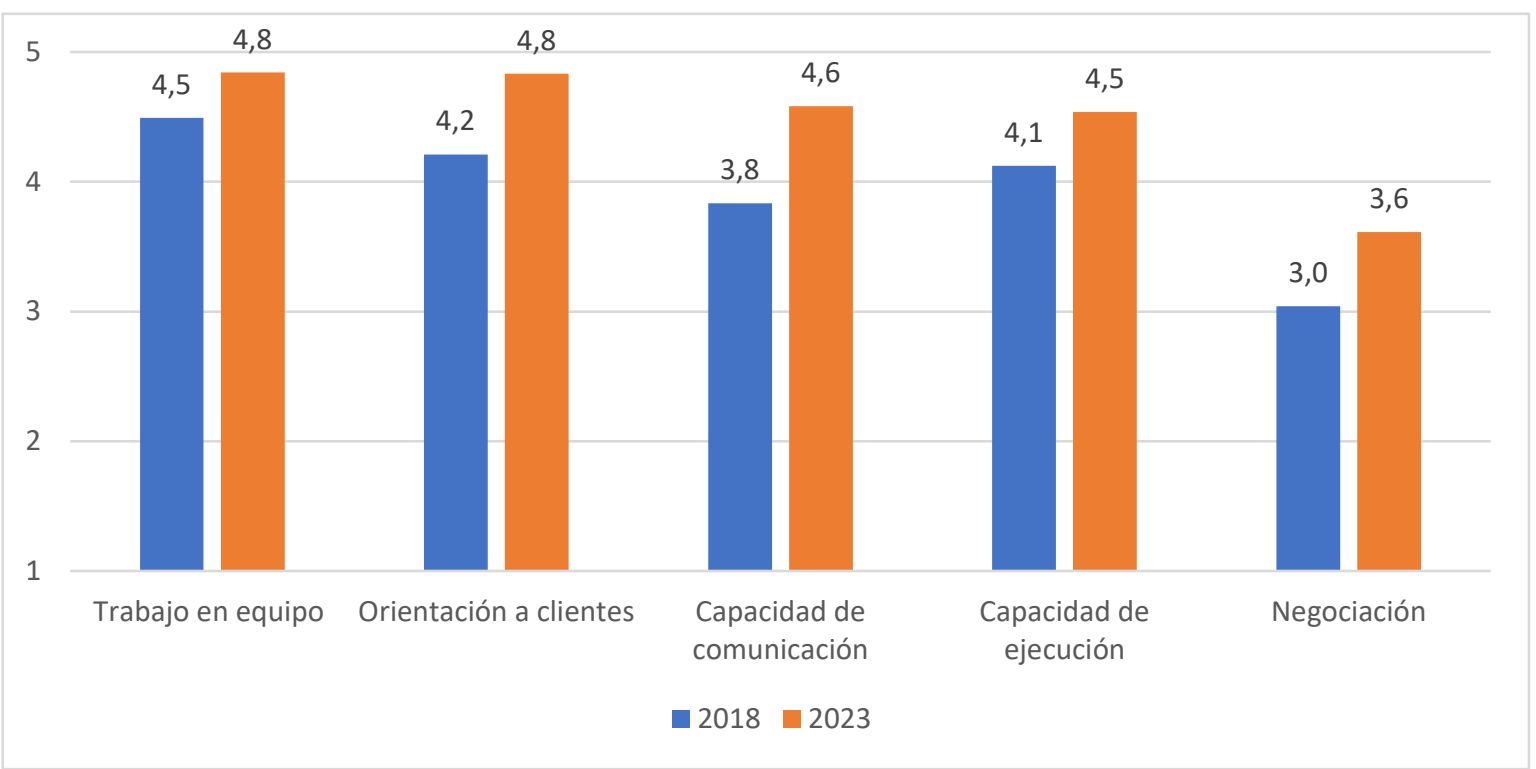

Los valores éticos, la adaptabilidad y el respeto son las actitudes más importantes para los perfiles de formación profesional según las empresas encuestadas, y lo seguirán siendo en los próximos cinco años. En la actualidad, para estos perfiles no tienen tanta importancia el sentido emprendedor, el pensamiento creativo o la sensibilidad multicultural, aunque dicha relevancia aumentará en 2023, por lo que habrá que trabajar estas actitudes. En cualquier caso, el pensamiento creativo y el sentido emprendedor se mantendrán claramente por debajo del nivel de exigencia otorgado a perfiles de grado superior o medio (véase la Figura 59).

\section{Figura 59}

\section{Actitudes: formación profesional}

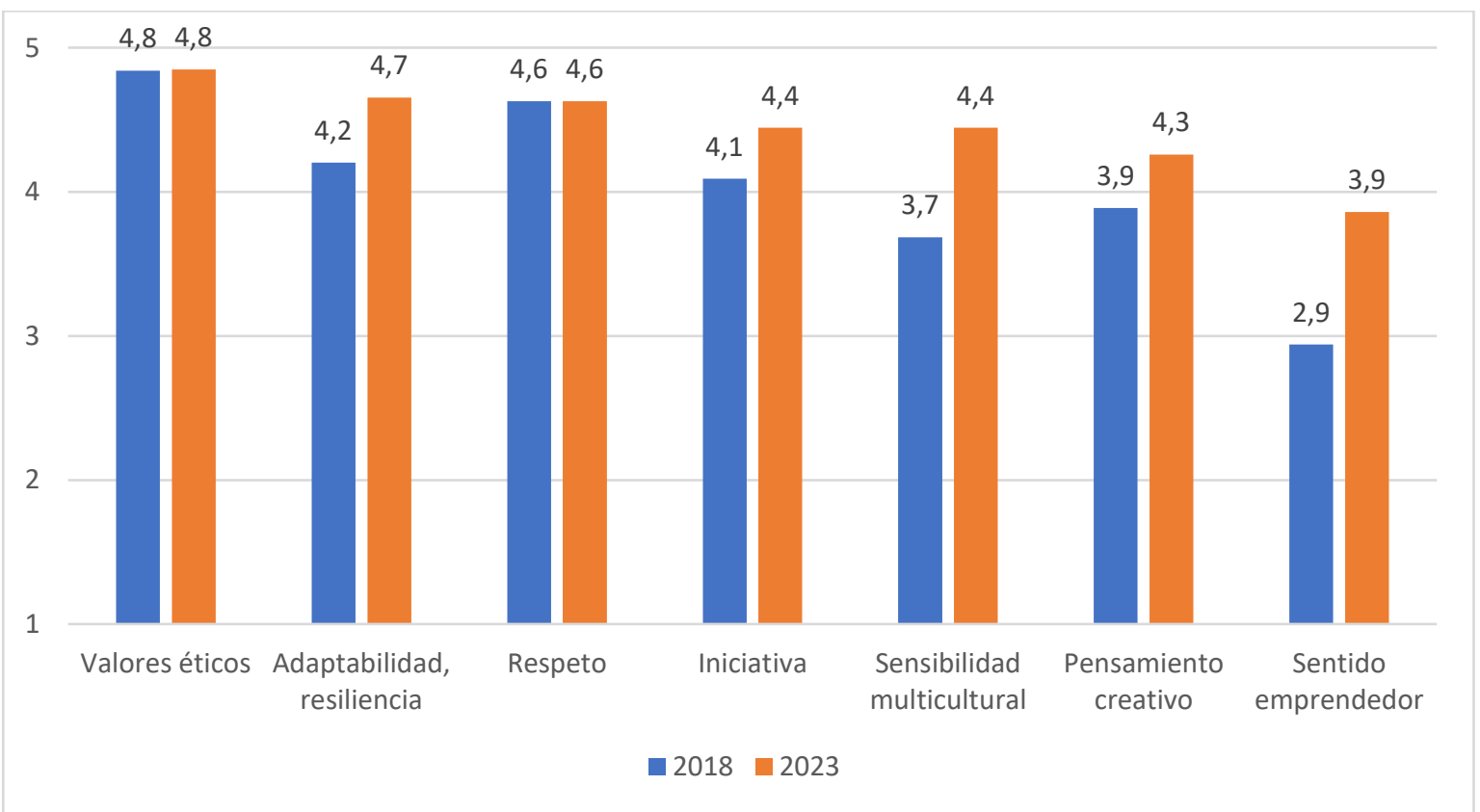




\section{Educación secundaria}

En el caso de la educación secundaria, todas las áreas mantienen niveles inferiores de exigencia en comparación con los de los perfiles con estudios de formación profesional y grado superior o medio, si bien evolucionan de forma relevante en su gran mayoría.

Los conocimientos exigidos a nivel tecnológico o de idiomas en 2018 para estos perfiles son bajos. El principal reto lo encontramos en los idiomas, que en 2023 será el área de conocimiento más importante (véase la Figura 60).

\section{Figura 60}

\section{Conocimientos: educación secundaria}

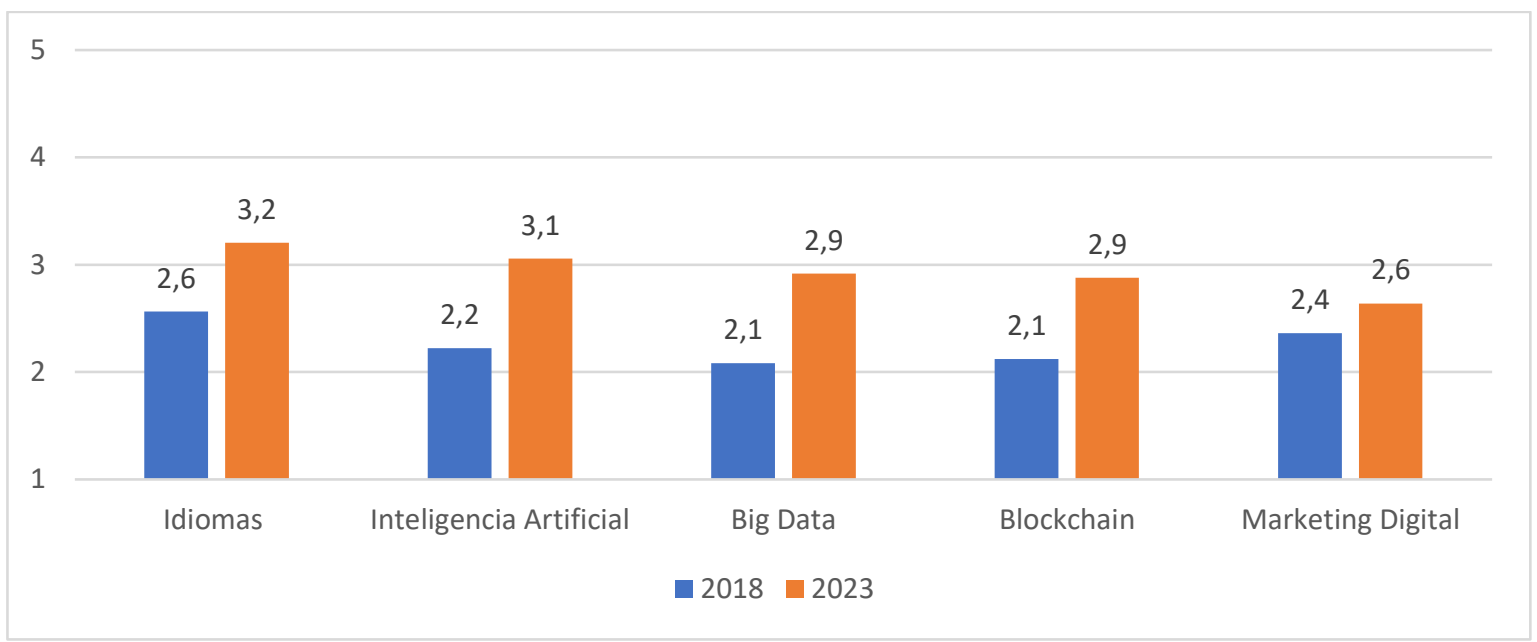

En cuanto a capacidades, el perfil exigido es similar al de formación profesional, destacando en 2018 el trabajo en equipo. En los próximos cinco años, las empresas también exigirán mayores niveles en las capacidades de comunicación, ejecución y orientación al cliente (véase la Figura 61).

\section{Figura 61}

\section{Capacidades: educación secundaria}

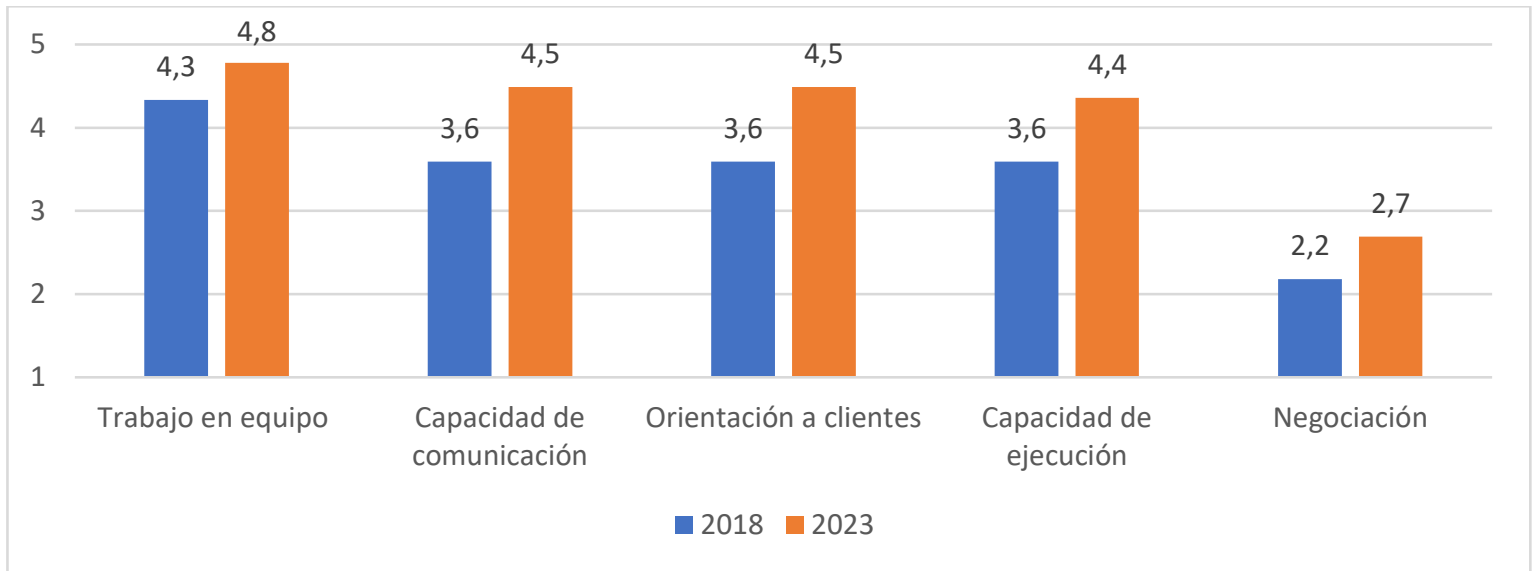


Finalmente, los valores éticos y el respeto tienen el máximo nivel de importancia, al igual que en el resto de perfiles. También se considera fundamentales la adaptabilidad y la resiliencia (véase la Figura 62).

\section{Figura 62}

\section{Actitudes: educación secundaria}

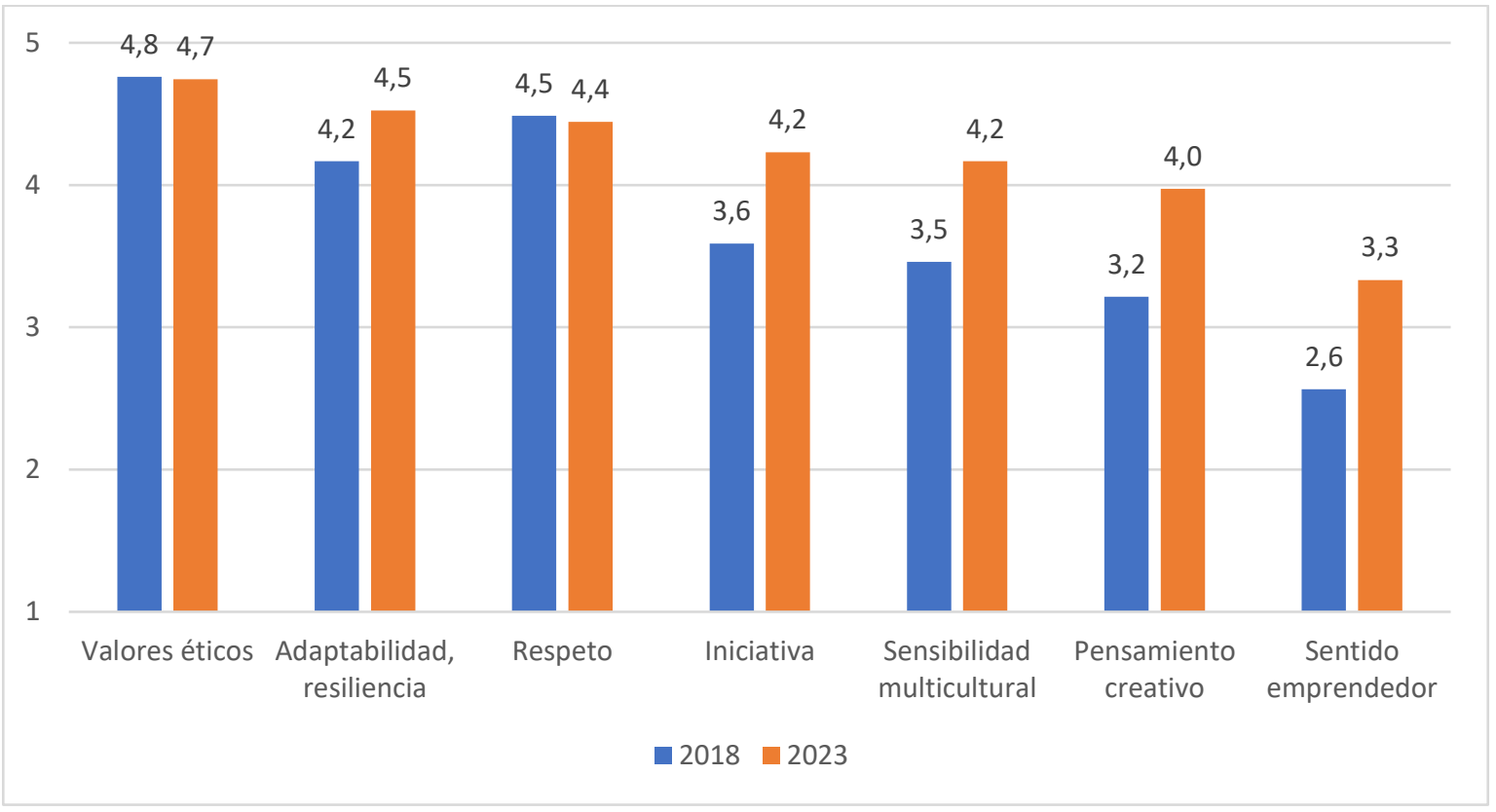

\subsection{Algunas soluciones}

\subsubsection{Posibles vías para mejorar el encaje de los perfiles demandados y encontrados}

Las empresas consideran diferentes iniciativas que podrían seguirse para mejorar la adecuación entre los perfiles demandados y los encontrados. Un $87 \%$ de las empresas consideran importante tener un papel más activo en la definición de los conocimientos y las capacidades necesarios, y su traslación a los planes de formación de los centros educativos. También consideran importante un mayor énfasis en la formación profesional dual y en las prácticas en empresas, la mejora de la orientación que se proporciona a los estudiantes y la asignación a los alumnos de tutores con experiencia (véase la Figura 63). 
Figura 63

\section{Valoración de posibles iniciativas}

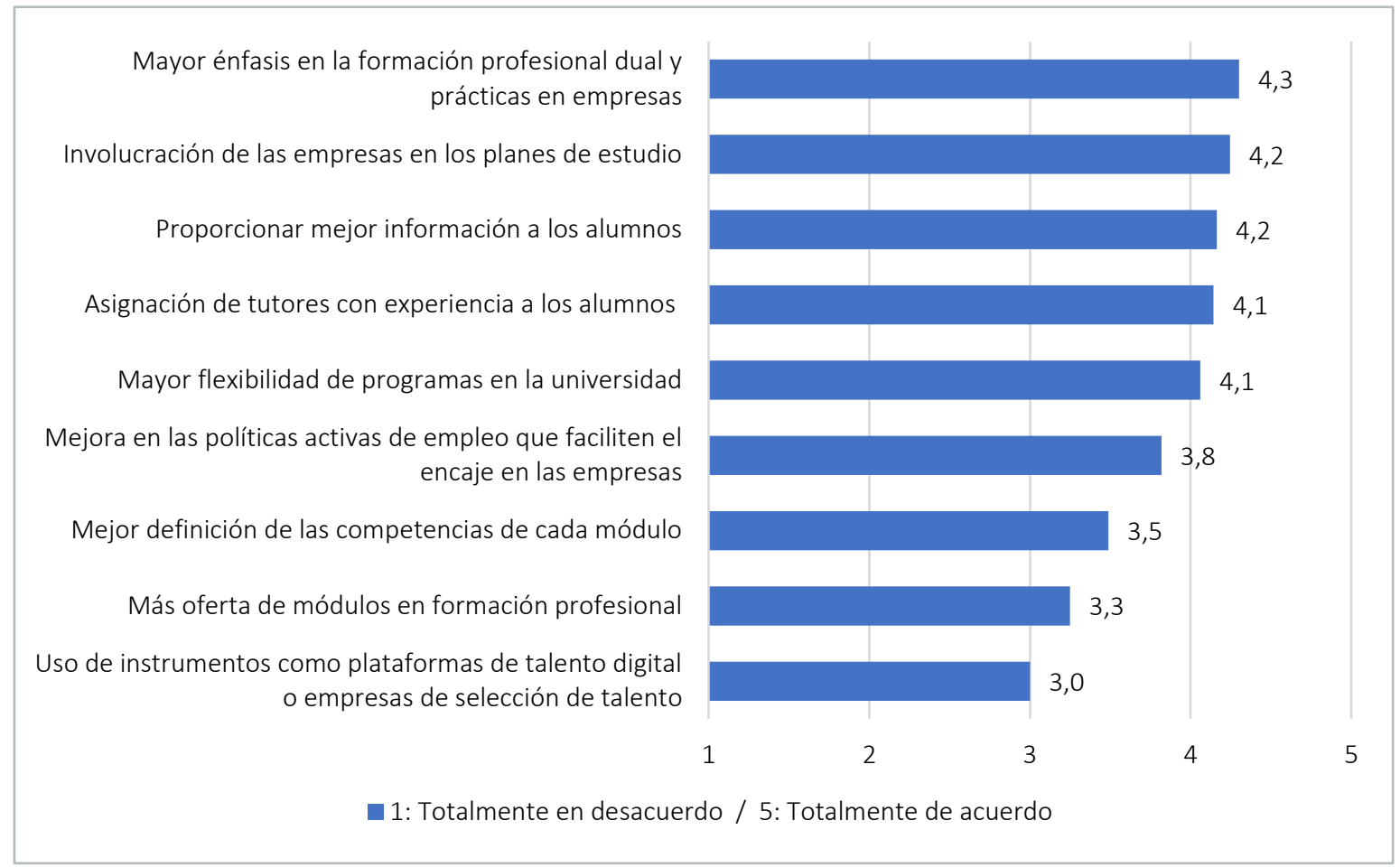

\subsubsection{Actores clave para asegurar el futuro del empleo y papel de cada actor}

Las empresas consideran, mayoritariamente, que la responsabilidad debe ser compartida por los gobiernos, las empresas y los centros educativos.

Por parte de la administración, tanto a nivel del gobierno central como de las comunidades autónomas, se considera fundamental la flexibilización de los planes de estudio (véanse las Figuras 64 y 65).

\section{Figura 64}

\section{Valoración de posibles iniciativas: gobierno central}

Flexibilizar el contenido y adaptación de los módulos

Cambio legislativo

Facilitación de la creación de nuevos grados

Financiación directa o mediante ayudas

Desarrollo de una plataforma de mercado de trabajo

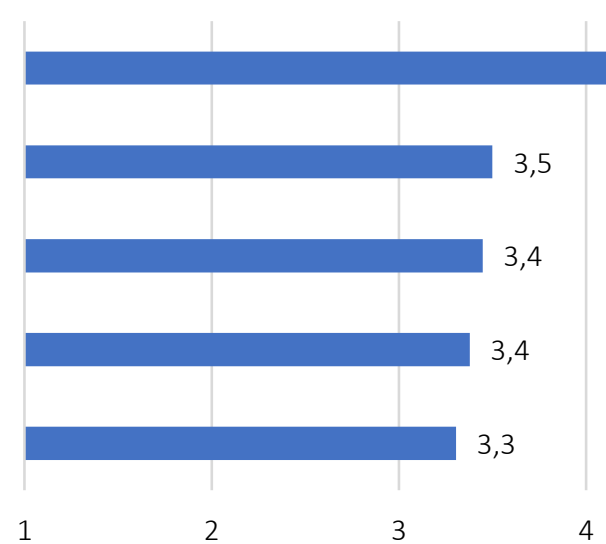

1

1: Totalmente en desacuerdo / 5: Totalmente de acuerdo 
Figura 65

Valoración de posibles iniciativas: gobiernos de las comunidades autónomas

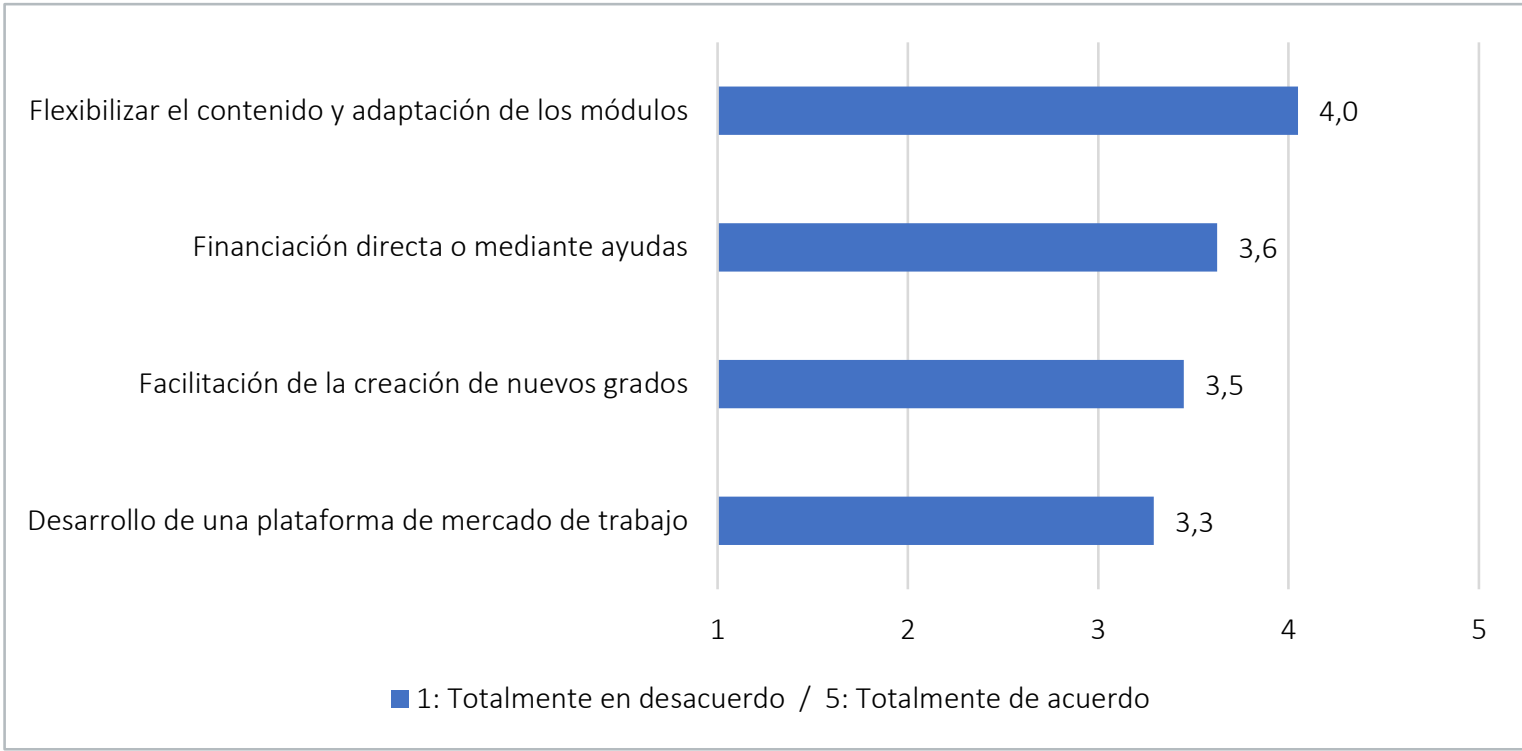

A los centros de formación profesional se les pide, sobre todo, un mayor nivel de colaboración con las empresas y la flexibilización de los módulos existentes (véase la Figura 66).

Figura 66

Valoración de posibles iniciativas: centros de formación profesional

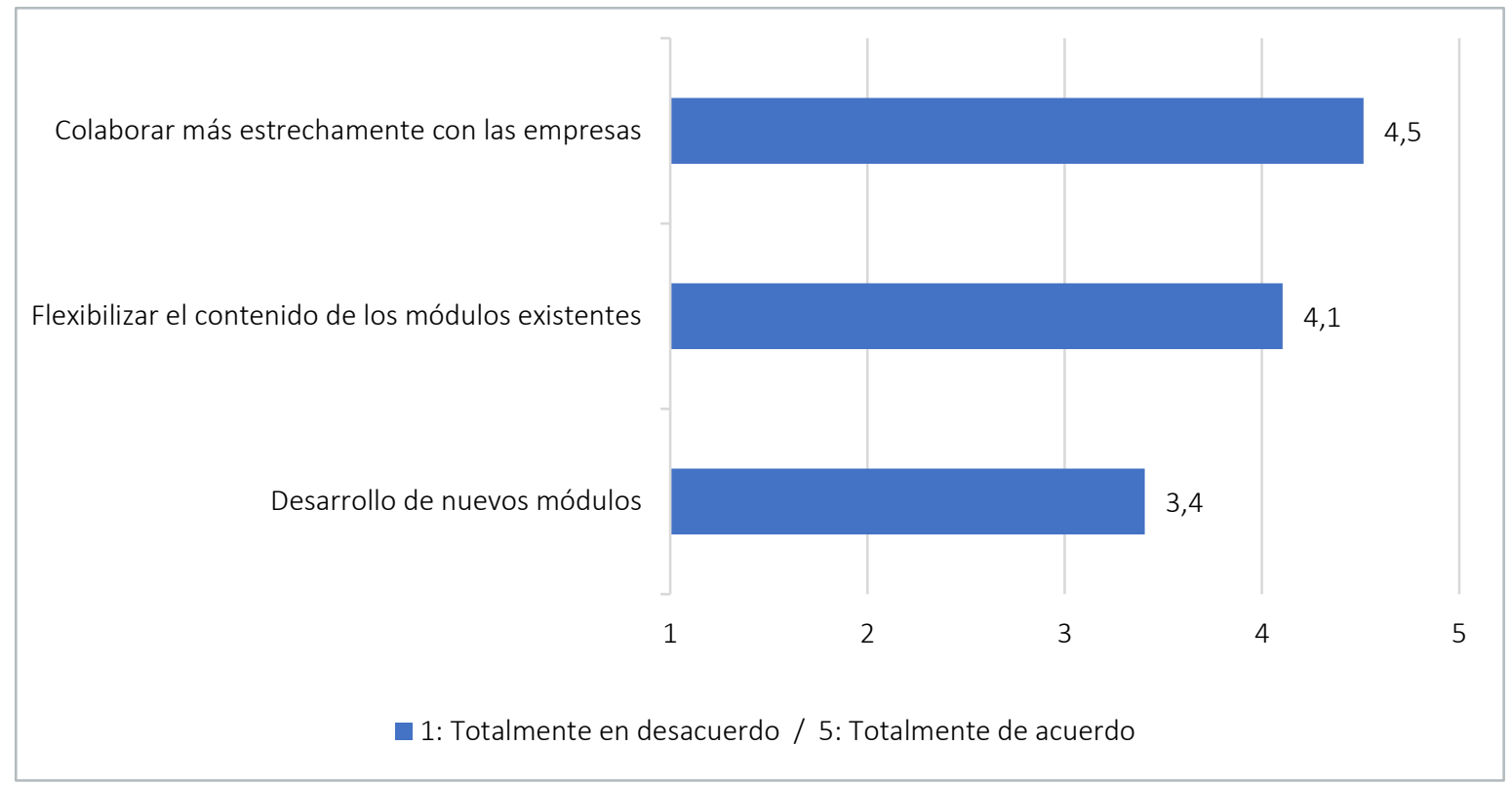


Las compañías consideran que su papel también es muy relevante, y que sus principales áreas de actuación son la colaboración continua con los centros de formación, tanto universidades como centros de formación profesional, y la facilitación de prácticas a los alumnos (véase la Figura 67).

\section{Figura 67}

\section{Valoración de posibles iniciativas: empresas}

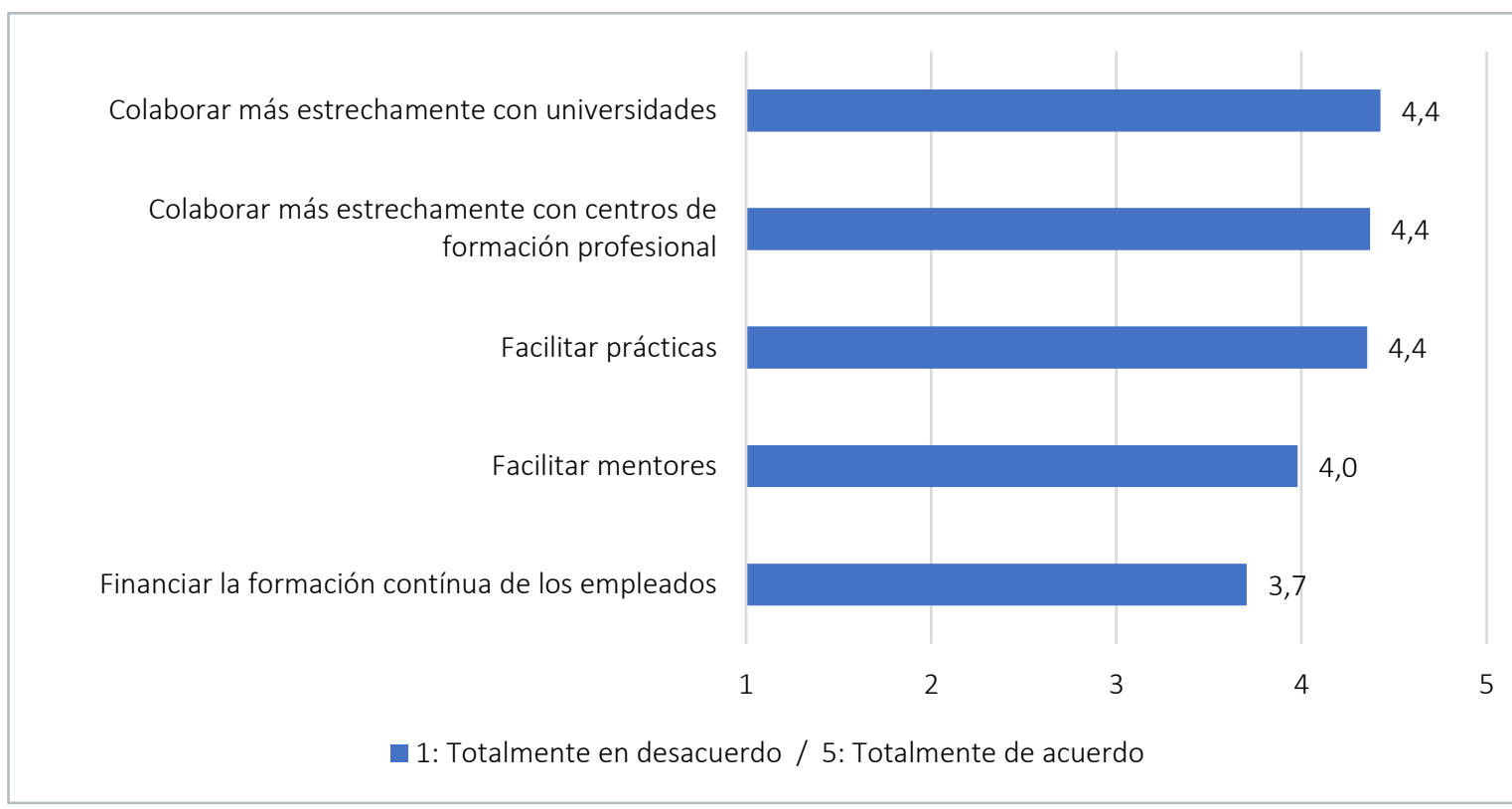

Finalmente, también se atribuye un papel importante para asegurar el futuro del empleo a la UE, que deberá compartir mejores prácticas y facilitar la movilidad de estudiantes y trabajadores (véase la Figura 68).

\section{Figura 68}

\section{Valoración de otras iniciativas}

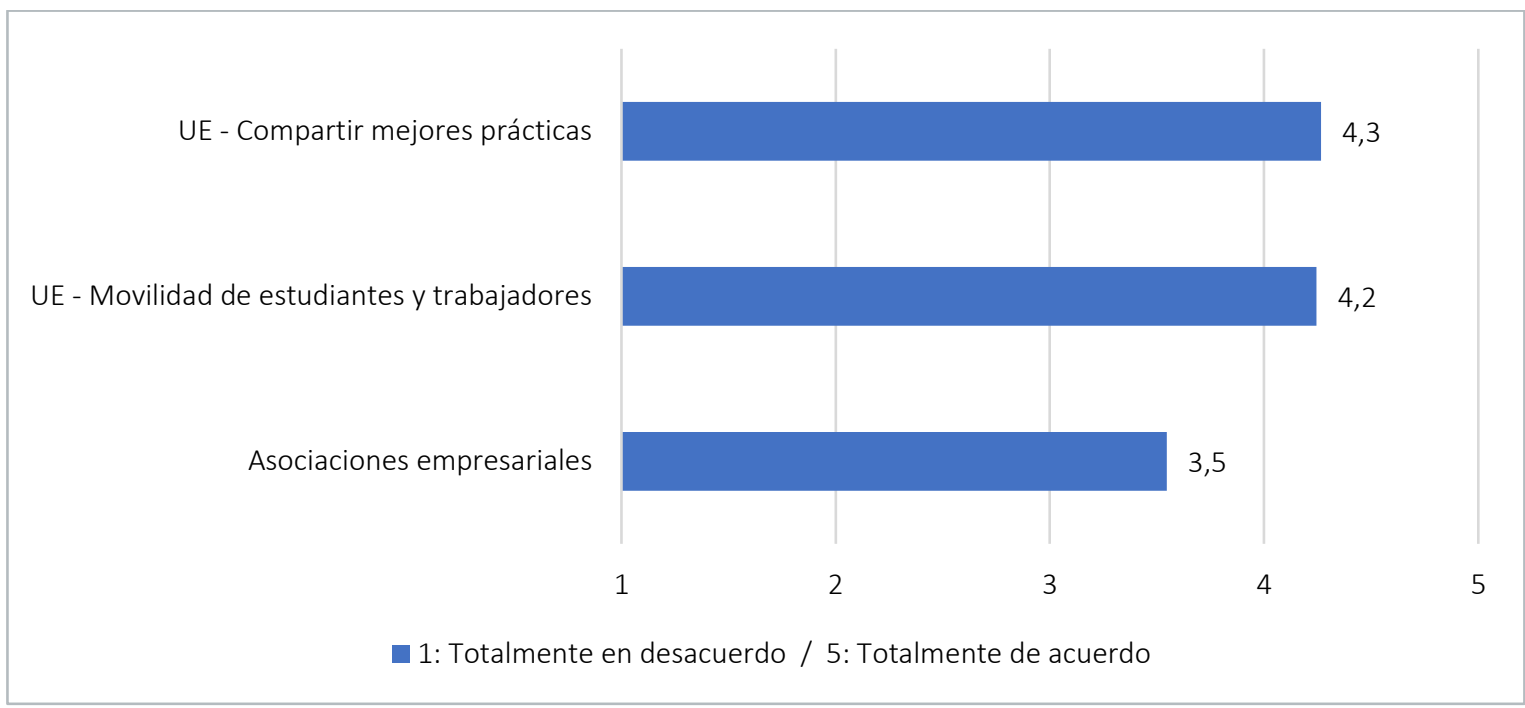




\subsection{Un papel más amplio para las empresas}

\subsubsection{Relación actual de las empresas con los centros educativos}

En la actualidad, las empresas mantienen un nivel de relación más estrecho con universidades que con centros de formación profesional. Esta relación se centra en las actividades encaminadas a la contratación de alumnos y en un vínculo de tipo institucional, y mucho menos en la colaboración con profesores o en la involucración en el diseño de programas y cursos (véase la Figura 69).

\section{Figura 69}

Relación actual de las empresas con centros educativos

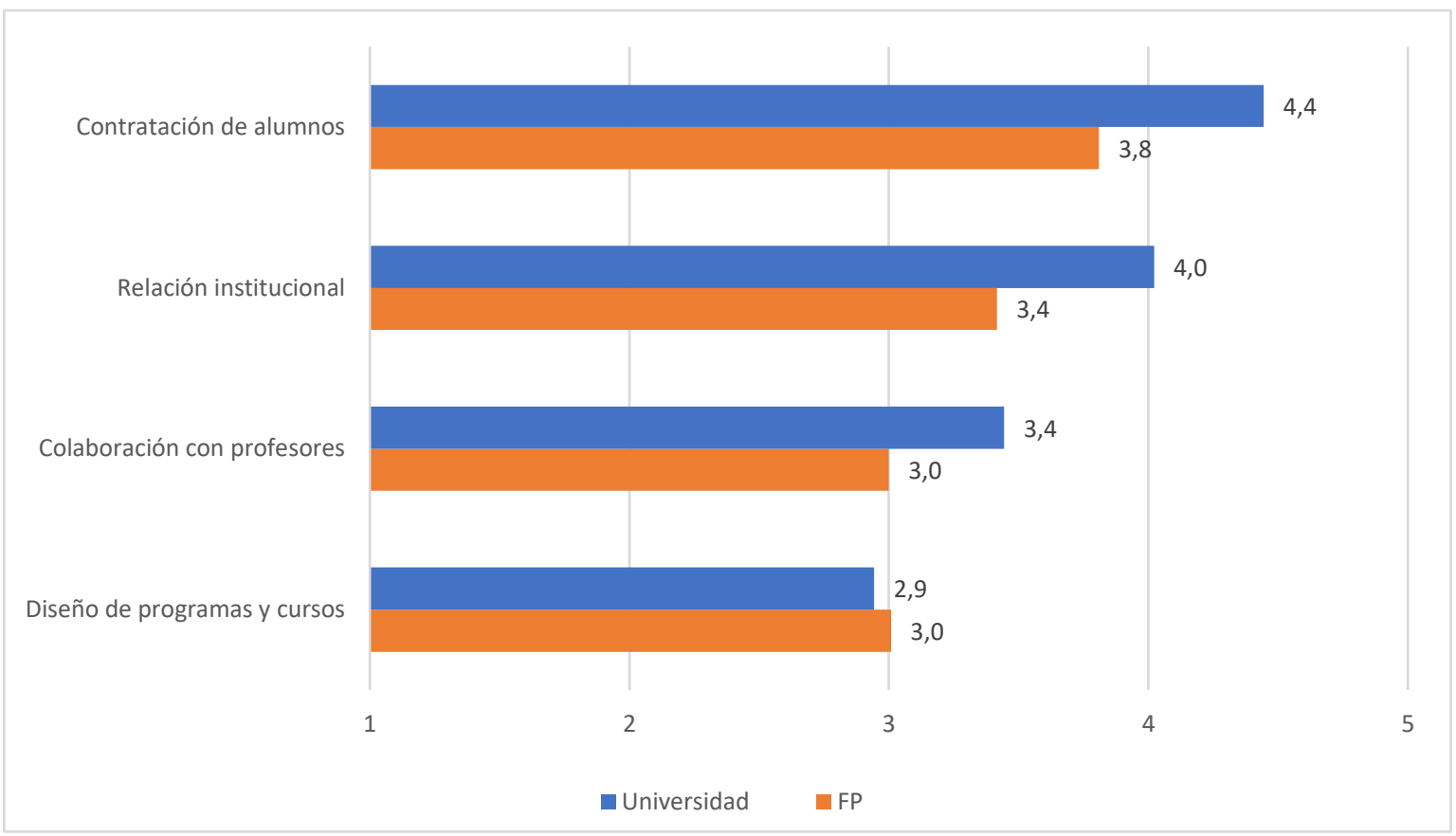

\subsubsection{Posibles áreas de colaboración de las empresas con los centros de formación en el futuro}

De cara al futuro, las empresas se muestran dispuestas a seguir proporcionando trabajo en prácticas a los alumnos y a colaborar en la definición de los perfiles necesarios, así como en la de los módulos y competencias necesarios para cubrirlos (véase la Figura 70). 
Figura 70

Posibles áreas de colaboración

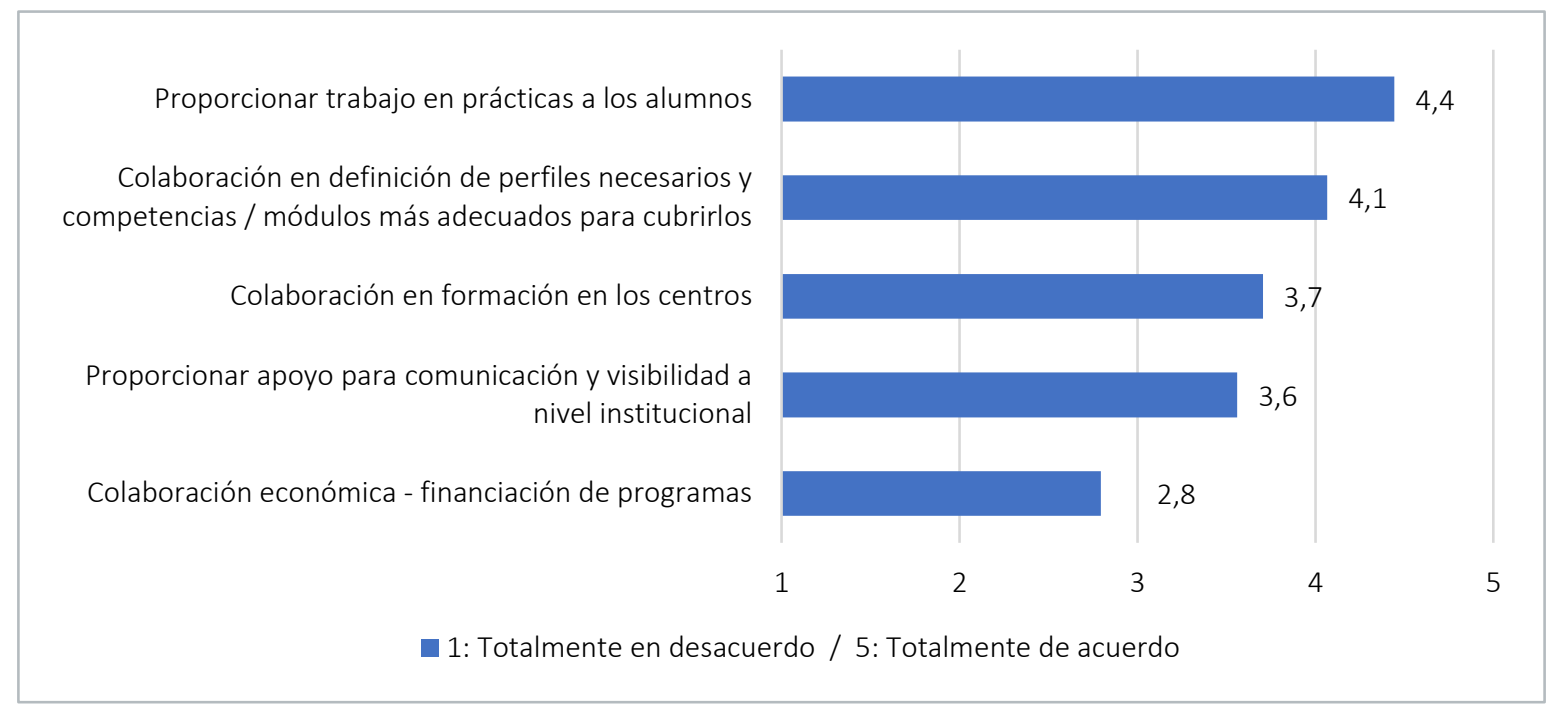

\subsubsection{Ayudas esperadas de los gobiernos para facilitar la empleabilidad de las personas en la empresa}

Las empresas piden a los gobiernos, mayoritariamente, ayudas fiscales para la formación en ellas y becas para trabajos en prácticas. Pero también se espera que se involucre más a las empresas en el futuro de la educación y que se facilite su relación con los centros de formación profesional para que puedan adaptar sus contenidos a las necesidades del mundo laboral (véase la Figura 71).

Figura 71

\section{Ayudas de los gobiernos}

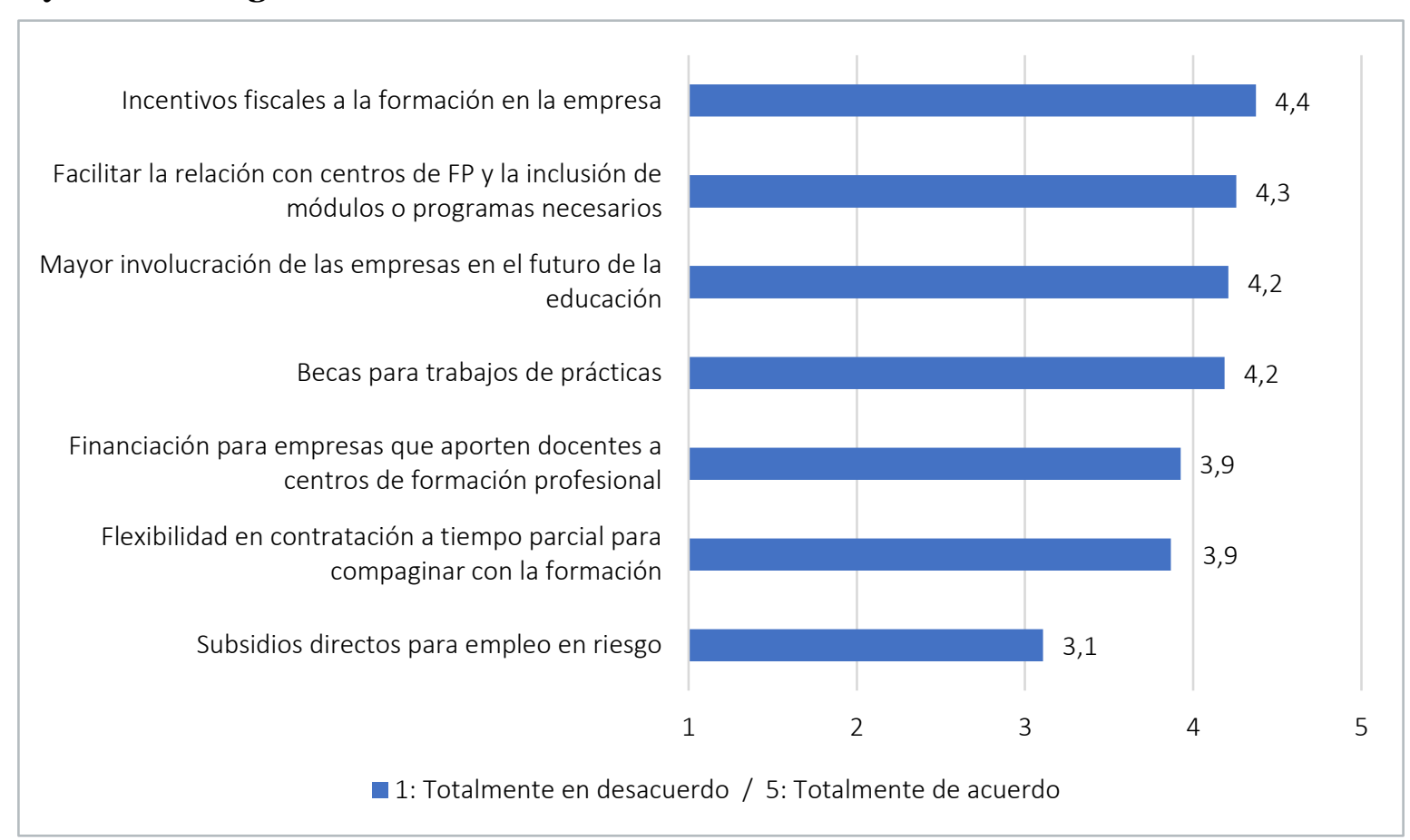




\section{Un diagnóstico de conjunto sobre las competencias profesionales necesarias para el empleo desde la perspectiva de las empresas}

Los resultados de las encuestas se han presentado en los apartados 4 y 5 . Las entrevistas personales a altos directivos de las 53 empresas participantes nos han permitido analizar dichos resultados, entender las motivaciones y preocupaciones de las compañías y realizar un diagnóstico de conjunto que nos permitirá perfilar planes de acción. Para ello, agruparemos las principales conclusiones en tres apartados:

- Cambios en los perfiles profesionales contratados

- Brecha de competencias y evolución de los conocimientos, capacidades y actitudes requeridos por las empresas

- Propuesta de soluciones y actores clave

\subsection{Cambios en los perfiles profesionales contratados}

\subsubsection{Las empresas siguen apostando por perfiles de grado superior}

Los profesionales con nivel de estudios de grado superior siguen ocupando la gran mayoría de los puestos de trabajo en 2018. El $67 \%$ de los puestos de trabajo actuales y el $57 \%$ de los puestos de trabajo ofrecidos en los últimos doce meses en las empresas entrevistadas están ocupados por personas con formación universitaria de grado superior. Los empleados con formación profesional suponen el $17 \%$ de los puestos de trabajo actuales y el $21 \%$ de las contrataciones realizadas en los últimos doce meses en las empresas entrevistadas (véanse las Figuras 33, 34 y 35).

Algunas empresas reconocen que los titulados de grado superior realizan funciones que no se corresponden con su nivel de formación, y que esto puede generar desmotivación en algunas personas. Estas decisiones tienen un efecto negativo en la retención de talento y productividad.

\subsubsection{Las empresas siguen encontrando dificultades para incorporar candidatos procedentes de formación profesional}

Muchas empresas reconocen que la formación profesional es una buena opción para cubrir determinado tipo de puestos, sobre todo en el área de Operaciones, y en varias de las entrevistadas se incorporan estos perfiles con éxito; sin embargo, las compañías siguen encontrando dificultades para incorporar perfiles procedentes de la formación profesional. De hecho, tal como muestra la Figura 9, España tiene un porcentaje de jóvenes con estudios de formación profesional del 24\%, una cifra muy inferior a la media de la UE (36\%) o de países como Austria (59\%), Francia (48\%) o Alemania (51\%).

Son varios los motivos que se mencionan para explicar este bajo porcentaje de perfiles con estudios de formación profesional. En primer lugar, numerosas empresas, sobre todo multinacionales, admiten que prefieren perfiles universitarios de grado superior porque tienen un mayor potencial en su trayectoria profesional dentro de la compañía, y que la promoción a los puestos directivos solo se consigue con titulación superior.

En otras ocasiones, no han podido contratar perfiles de formación profesional, aunque hubiera sido lo deseado para los puestos de trabajo en cuestión, porque los estudios existentes no 
cubren las capacidades que se buscan y su desarrollo. Aunque hay empresas que han conseguido acuerdos con centros de formación profesional para adaptar determinados módulos a sus necesidades específicas, esto no es lo más frecuente. En este tema hay que tener en cuenta, además, el componente geográfico, y se observa poca adaptación de la oferta de contenido de formación profesional a los sectores más representados en algunas zonas geográficas.

Finalmente, se considera que la formación profesional dual es una buena solución, pero no siempre está disponible o funciona, y las empresas, en ocasiones, encuentran el sistema poco flexible para sus necesidades.

\subsubsection{La revolución digital, la internacionalización y las necesidades de los clientes cambian los perfiles profesionales requeridos}

En el apartado 3 se han examinado algunos de los aspectos de la revolución digital y la Industria 4.0, así como su impacto en las competencias y empleos del futuro. Las empresas consideran que tanto la revolución digital como la automatización son dos de las principales causas de los cambios en los perfiles profesionales requeridos. Así, un 72\% de las compañías encuestadas consideran que la revolución digital tiene un impacto alto o muy alto en el cambio de los perfiles requeridos, y un 56\% piensan que el impacto de la automatización es alto o muy alto. La revolución digital afecta a todo tipo de perfiles y supone cambios en la definición de los puestos de trabajo, así como en las tareas y herramientas necesarias para llevar a cabo sus funciones (véase la Figura 38).

Los perfiles de personas con experiencia y conocimientos en el área digital son muy apreciados y es un área de gran dificultad de contratación para las empresas. En algunos sectores existe una gran competencia entre estas por este tipo de perfiles, siendo la retención del talento uno de los principales retos que afrontan (Apascaritei y Elvira, 2018).

Otro de los motivos que, según las empresas, ha generado más cambios en los perfiles profesionales requeridos son las necesidades de los clientes. El 78\% de las empresas encuestadas consideran que el cambio en las necesidades de los clientes ha tenido un impacto alto o muy alto. En ocasiones, las compañías han experimentado cambios en el tipo de clientes, ya sea por diversificación o por variaciones en el mercado. En otros casos, lo que ha variado es la forma de relacionarse con ellos, que requiere herramientas y capacidades diferentes. También se menciona por parte de las empresas un mayor nivel de exigencia por parte de los clientes, que están más informados y cuentan con un mayor nivel de sofisticación; en este sentido, es necesario adaptarse a sus expectativas.

La internacionalización también ha tenido una gran incidencia en los perfiles requeridos. Las empresas mencionan que sus formas de trabajo cada vez son más globales y requieren una interacción constante con equipos de otros países. Esto supone necesidades diferentes no solo a nivel de idiomas, sino también de mentalidad y sensibilidad multicultural, entre otros.

\subsubsection{La automatización comporta un cambio en las capacidades requeridas}

La automatización se identifica como una de las grandes causas de cambio en los perfiles profesionales y, en este caso, el impacto que se observa es mayor para niveles educativos inferiores y para las funciones más relacionadas con el área de Operaciones (véanse las Figuras 39 y 40). Las empresas consideran, en términos generales, que la automatización provocará la desaparición de algunos puestos de trabajo. 
Numerosas compañías muestran una enorme preocupación por el cambio de competencias que conlleva la tecnología. Consideran que la automatización empujará a que las personas se dediquen a tareas de mayor valor añadido. Habrá nuevas oportunidades profesionales, pero se necesita mejor formación para ello. Por tanto, el cambio tecnológico genera una importante brecha en términos de capacidades.

\subsection{Brecha de competencias y evolución de los conocimientos, capacidades y actitudes requeridos por las empresas}

\subsubsection{El $72 \%$ de las empresas encuestadas encuentran problemas para cubrir los puestos de trabajo}

Las empresas reconocen encontrar problemas para cubrir determinado tipo de puestos. Así, el $72 \%$ de las empresas encuestadas admiten encontrar bastantes o muchas dificultades (véase la Figura 41). En la mayoría de los casos, estos problemas se relacionan con la búsqueda de perfiles de tipo tecnológico o digital.

La mayoría de las compañías entrevistadas tienen una gran visibilidad y ofrecen planes de carrera y desarrollo profesional atractivos para los jóvenes. Por tanto, consideran que sus problemas para encontrar los perfiles requeridos son menores que los de las pymes, que conforman la gran mayoría del tejido empresarial español.

\subsubsection{Existe una importante brecha de conocimientos en tecnología y digitalización}

En determinados puestos de trabajo, las empresas encuentran dificultades para conseguir talento en el mercado, en particular en relación con las competencias vinculadas a la tecnología. Consideran que ciertos conocimientos en este ámbito deberían ser transversales en cualquier titulación.

Para cubrir sus necesidades actuales, el $68 \%$ de las empresas consideran que los perfiles de educación superior tienen un nivel de conocimientos relacionados con nuevas tecnologías insuficiente (véase la Figura 44). Por su parte, un $48 \%$ consideran insuficiente el nivel de conocimientos tecnológicos de los perfiles con estudios de formación profesional (véase la Figura 47).

Es necesario potenciar el conocimiento y atractivo de las carreras STEM, en las que España está por debajo del resto de países europeos. Se considera que hay un buen nivel en ingeniería, pero, en ocasiones, es necesario recurrir a candidatos graduados en otros países porque no hay suficiente disponibilidad. Esto genera un problema grave para la competitividad de las empresas.

"El sistema formativo europeo no es capaz de producir la demanda de ingenieros que las empresas tecnológicas necesitamos".

Director de Recursos Humanos de una empresa multinacional.

Numerosas empresas entrevistadas argumentan que hay carencia de mujeres profesionales en áreas más tecnológicas, un fenómeno que también se detecta en los módulos de formación profesional de contenido más técnico. Las compañías consideran necesario concienciar, desde niveles tempranos de la educación, sobre las opciones y oportunidades que estos puestos suponen para las mujeres. 
Las empresas están realizando importantes esfuerzos de formación interna para cubrir dichas carencias, así como las necesidades específicas de conocimientos de sus respectivos sectores. Algunas no han encontrado módulos de formación profesional que cubran la especialidad que necesitan, por lo que han tenido que desarrollarlos, por su cuenta o en colaboración con algún centro de formación profesional.

También se ha identificado un claro desajuste con respecto al conocimiento de idiomas en todos los niveles, aunque sobre todo en los inferiores. Esto se considera un factor higiénico por la mayoría de las empresas y, aunque se admite que ha mejorado con las últimas generaciones, es necesario seguir avanzando. (Véanse las Figuras 44 y 47).

\subsubsection{Los conocimientos cambiarán a un ritmo cada vez mayor y las capacidades de aprendizaje y adaptación serán clave}

El cambio en los conocimientos requeridos, sobre todo debido al impacto tecnológico, es importante y existe un déficit claro de conocimientos en el área digital y de nuevas tecnologías. El problema es que los conocimientos seguirán cambiando (y cada vez a un ritmo mayor), por lo que la brecha se seguirá ampliando a no ser que se reaccione de forma ágil. Los conocimientos relacionados con el big data, el marketing digital, la inteligencia artificial o el blockchain, que actualmente ya son relevantes para las empresas, aumentarán claramente en importancia en 2023, tal y como muestran las Figuras 54 y 57.

"La caducidad de los conocimientos cada vez va a ser más rápida. Lo que necesitamos es gente que se adapte".

Director de Talento de una empresa del IBEX.

\subsubsection{La brecha de capacidades es amplia y las empresas necesitan una formación más práctica}

En el área de capacidades, las empresas consideran que el sistema educativo presenta claras carencias. Está orientado a los conocimientos teóricos más que a la práctica y al desarrollo de capacidades importantes en la vida empresarial, como son la comunicación, el trabajo en equipo, la flexibilidad o la resolución de problemas.

Un 52\% de las compañías encuestadas admiten no encontrar la capacidad de comunicación que buscan en el sistema educativo de formación superior, cuando el $91 \%$ de ellas la consideran muy importante. De igual modo, el $56 \%$ no encuentran la capacidad de trabajo en equipo, considerada como muy importante por el 100\% (véase la Figura 45). Falta también, en opinión de las empresas, una visión más práctica en la formación.

En relación con los perfiles de formación profesional, las empresas perciben la misma tendencia que en los de educación superior. Así, el 52\% de las empresas encuestadas admiten no encontrar las capacidades de comunicación que busca en los perfiles de formación profesional, mientras que el $48 \%$ tienen el mismo problema con respecto al trabajo en equipo (véase la Figura 48).

"El 80\% de los recién titulados carece de capacidades de comunicación, venta, generación de impacto o influencia".

Directora de Recursos Humanos de una empresa del IBEX.

"Hay un gap enorme entre lo que necesitamos las empresas y lo que ofrece el sistema educativo".

Director de Recursos Humanos de una empresa del IBEX. 
Finalmente, en un contexto en constante evolución, las compañías buscan personas con la capacidad de adaptarse y mantener un aprendizaje continuo. Esta última es cada día más urgente, aunque, desgraciadamente, no se desarrolla en el sistema educativo (véase la Figura 53).

\subsubsection{Las nuevas formas de trabajo requieren capacidades diferentes, con énfasis en las relacionales}

En general, las empresas tienden a tener estructuras más planas y transversales, lo que afecta a los modos de trabajar, que están incorporando metodologías agile, el trabajo por proyectos y métodos como el design thinking.

Las compañías están rompiendo los silos tradicionales, aunque algunas todavía reconocen trabajar de forma más aislada por áreas de negocio.

Las que trabajan por proyectos y con equipos transversales consideran que estas formas de trabajo generan beneficios como un mayor dinamismo, aprendizaje, visión de conjunto y motivación. Sin embargo, también plantean retos. Se necesitan personas versátiles, y las capacidades requeridas serán diferentes, con mayor énfasis en las relacionales, de trabajo en equipo, comunicación, liderazgo, negociación y con una visión general de la empresa (véanse la Figuras 55 y 58). Esto implicará cambios en la selección de personas, que estará menos basada en titulaciones concretas y más en la capacidad o el potencial de desarrollar un trabajo en un área determinada

Las empresas también piensan que los jóvenes graduados deberían desarrollar capacidades profesionales para trabajar en entornos internacionales

"La organización tradicional jerárquica cambiará. Recursos Humanos tiene que liderar la transformación”.

Director de Recursos Humanos de una empresa multinacional.

\subsubsection{La brecha de actitudes es importante, sobre todo en lo relativo a la adaptabilidad y la resiliencia}

Las compañías encuestadas consideran que la brecha en actitudes es también muy amplia. Un 72\% de ellas no encuentran el nivel de adaptabilidad y resiliencia que buscan en las personas con formación universitaria. Estas capacidades son muy importantes para el 95\% de las empresas. (Véase la Figura 46).

En cuanto a la formación profesional, los resultados son similares: más del 50\% de las empresas no encuentran la adaptabilidad y resiliencia que busca en los jóvenes graduados y el $40 \%$ tienen el mismo problema con el nivel de iniciativa necesario (véase la Figura 49).

\subsubsection{Las nuevas generaciones tienen actitudes ante el trabajo diferentes a las del pasado, en temas clave como el compromiso, la visión a largo plazo o la motivación}

Las empresas entrevistadas consideran, en numerosas ocasiones, que las nuevas generaciones tienen una visión más cortoplacista del mundo laboral y que necesitan altas dosis de motivación. Los conceptos de compromiso y lealtad a la empresa han cambiado (véase la Figura 53). Los jóvenes, en general, tienen menos miedo al cambio que las generaciones anteriores y son más exigentes con lo que las empresas pueden ofrecerles. 
Las compañías deben desarrollar políticas activas para atraer y comprometer a las nuevas generaciones. Reconocen los beneficios de integrar en la plantilla a las nuevas generaciones con las anteriores, y destacan tanto el reto como las sinergias que esto supone.

\subsubsection{Las empresas deben llevar a cabo una importante labor de adaptación a la nueva realidad social}

Los jóvenes valoran cada vez más la flexibilidad y muchas compañías están introduciendo cambios para aportarla.

"Las empresas tienen que esforzarse para dar a los jóvenes trabajo de valor añadido y un sentido de contribuir".

Directora de Talento de una empresa del IBEX.

"Hay que atreverse con la flexibilidad. Da resultados y engagement".

Directora de Recursos Humanos de una empresa multinacional.

\subsection{Propuesta de soluciones y actores clave}

\subsubsection{Las empresas consideran que deben desempeñar un papel más activo en la definición del contenido de los planes de formación}

La colaboración entre empresas y centros educativos es la primera prioridad de acción que contemplan las empresas. Estas consideran que las soluciones para asegurar el futuro del trabajo y los posibles cambios del modelo educativo deben construirse a partir de una relación más estrecha y continuada entre ellas y los centros educativos (véanse las Figuras 63 a 68).

Creen que la Universidad debe actuar de un modo más colaborativo con el mundo empresarial en el diseño de planes de estudio y cursos específicos.

"La universidad tiene bastante calidad, pero es endogámica y está alejada del mundo de la empresa".

Director de Talento de una empresa del IBEX.

Del mismo modo, se pide esta colaboración a los centros de formación profesional, si bien algunas empresas han sido capaces de desarrollar programas adecuados a sus necesidades específicas con algunos de ellos. Sin embargo, esto no siempre es posible y se exige una mayor flexibilidad y adaptación de los programas a las necesidades no ya de compañías concretas, sino también de los sectores más representados en determinadas zonas.

\subsubsection{La universidad y los centros de formación profesional deben complementar su enfoque actual con uno más práctico y orientado a competencias}

Las empresas consideran que la Universidad en España ha mejorado, aunque su orientación es eminentemente teórica, por lo que es necesario complementar la formación con un enfoque orientado a aspectos prácticos (véanse las Figuras 67, 70 y 71). De igual modo, hay que reforzar el aprendizaje y la práctica de competencias, más que de conocimientos, en línea con los sistemas educativos de otros países como, por ejemplo, los del mundo anglosajón. 
También se considera importante que los profesores comprendan mejor la realidad de las empresas. Resulta necesario dignificar la función de los profesores y educadores.

"A nivel de educación de competencias, la Universidad está muy lejos de lo que la sociedad requiere".

Director de Recursos Humanos de una empresa del IBEX.

"Los programas de las universidades no están adaptados a las necesidades reales de las empresas".

Director de Recursos Humanos de una empresa multinacional.

\subsubsection{Es necesaria una labor importante de orientación a los estudiantes para que conozcan la realidad de la empresa}

Se percibe una falta de conocimiento por parte de los jóvenes acerca de la realidad del mundo empresarial y de las posibilidades de los distintos itinerarios formativos. Una orientación temprana y más amplia sobre la empresa sería útil para otorgar visibilidad a áreas no contempladas. Del mismo modo, se considera necesario destacar el atractivo de la formación profesional y prestigiar esta alternativa (véase la Figura 63).

Las compañías consideran que, muchas veces, los jóvenes no toman decisiones informadas con respecto a la elección de su trayectoria educativa y que acceden a determinados estudios sin una motivación clara, lo que en el futuro puede generar descontento, falta de productividad y rotación no deseada. Es necesaria una orientación sobre las distintas trayectorias y posibilidades profesionales, que debe proporcionarse desde la educación secundaria. Esta es una de las razones por la que las empresas también proponen como medida la asignación a los alumnos de tutores con experiencia (véase la Figura 63).

\subsubsection{Los gobiernos deberían impulsar la colaboración entre empresas y centros educativos para la mejora y adaptación del sistema educativo, así como facilitar un marco legal estable y consensuado}

En términos generales, las compañías perciben que la labor de los gobiernos sería más útil si aumentara la flexibilidad del sistema para que las instituciones educativas pudieran dar respuesta a sus necesidades. Consideran que solo con cambios legislativos se avanza poco (véanse las Figuras 64, 65 y 71).

Las empresas dedican importantes recursos a la formación interna para cubrir necesidades específicas de conocimiento de sus sectores, pero también para suplir determinadas carencias del sistema educativo actual. Apuestan por la colaboración con los centros educativos y ofrecen involucrarse en la definición de los contenidos y capacidades que deben desarrollarse.

\subsubsection{Las empresas piensan que el SEPE ${ }^{10}$ debería ayudar a la mejora de la empleabilidad de las personas replanteando sus funciones para apoyar mejor a los candidatos y desarrollar una conexión más estrecha con las empresas}

El papel del SEPE, hoy en día, está cuestionado, y debería evolucionar hacia unos servicios que faciliten la empleabilidad de los trabajadores y su conexión con las empresas.

\footnotetext{
10 Servicio Público de Empleo Estatal, anteriormente INEM.
} 


\section{Un plan de acción para promover la empleabilidad en el futuro}

Las entrevistas personales y encuestas realizadas a las 53 empresas colaboradoras han aportado una visión del empleo y de las competencias profesionales que se requerirán en el futuro.

En general, las empresas hacen una valoración realista sobre el sistema educativo español, destacando sus fortalezas y señalando sus debilidades. Demandan una formación más completa, con un mayor énfasis en las capacidades y actitudes. Asimismo, esperan una mejora en los conocimientos tecnológicos. Para conseguirlo, apuestan por la colaboración entre los distintos actores, con una mayor involucración de las empresas en la definición de los contenidos y competencias necesarios para adecuar el sistema educativo a las necesidades reales del mundo empresarial.

A partir de los resultados de las encuestas y de las entrevistas apuntamos algunas iniciativas que ayudarán a promover la empleabilidad de las personas jóvenes:

- Definir y actualizar periódicamente por parte de las empresas los conocimientos, capacidades y actitudes necesarias para el futuro. En particular, las empresas desearían una mejora de la formación en el ámbito tecnológico. También desearían un mejor desarrollo de capacidades y actitudes críticas en la vida profesional. Es conveniente establecer unos objetivos y unos indicadores que ayuden a evaluar el ritmo de mejora.

- Promover acciones de trabajo conjunto entre la comunidad empresarial y las universidades y centros de formación profesional para adaptar los conocimientos y capacidades impartidos a las necesidades reales de las empresas, adoptando un enfoque más práctico. Identificar los obstáculos que impiden avanzar en esta dirección y establecer planes de acción para superarlos.

- Las empresas desean que los gobiernos faciliten una colaboración directa entre ellas y los centros educativos, de modo que los programas de formación se adapten con mayor flexibilidad a las necesidades cambiantes de las compañías.

- Impulsar la orientación profesional a los estudiantes sobre las posibilidades de los distintos itinerarios formativos. En particular, promover el prestigio y las posibilidades de la formación profesional y dotarla de una mayor visibilidad. En este sentido, es importante ofrecer a los jóvenes una buena descripción de la realidad de las empresas y del trabajo profesional.

- Las empresas, por su parte, deben también afrontar los cambios necesarios para adaptarse a las nuevas formas de trabajo, más transversales y multidisciplinares, y a los retos que suponen los cambios en los perfiles profesionales. Estos cambios exigen un enfoque diferente de las políticas de selección, formación, retención y promoción de talento.

- Necesidad de que las universidades y los centros educativos se relacionen más con las empresas y puedan involucrarse en la formación de los profesionales del futuro, teniendo en cuenta las necesidades del mundo empresarial.

- La mayor cercanía de los centros a las empresas plantea la conveniencia de que aquellos dispongan de una mayor autonomía de gestión dentro de un marco general. Asimismo, conviene evaluar también a los centros teniendo en cuenta los resultados educativos y el potencial de empleabilidad de sus alumnos. La mejora del gobierno y gestión de los centros educativos es una necesidad clara del sistema.

- El SEPE debe replantear sus funciones y evolucionar hacia servicios que faciliten los contactos con las empresas y la empleabilidad de los trabajadores, evaluando periódicamente los resultados obtenidos. 
Anexo 1

Relación de empresas y directivos participantes en este proyecto

\begin{tabular}{|c|c|c|}
\hline Empresa & Participante & Cargo \\
\hline Aena & Diego Blanco & $\begin{array}{l}\text { Jefe División de Formación y Selección de } \\
\text { Convenio }\end{array}$ \\
\hline \multirow{2}{*}{ Airbus } & Elena García & Responsable HR Resource and Development \\
\hline & Antonio Lasaga & Director Recursos Humanos \\
\hline Amadeus & Sabine Hansen & Chief Human Resources Officer \\
\hline \multirow{2}{*}{ Atresmedia } & Lucio Fernández & Director Recursos Humanos \\
\hline & Patricia Pérez & Directora general corporativa \\
\hline Banco Sabadell & Conchita Álvarez & HR Director \\
\hline \multirow{2}{*}{ Banco Santander } & Alfredo Fraile & Director de Estrategia de RR. HH. \\
\hline & Manuel Jiménez & Director de Selección \\
\hline \multirow{3}{*}{ Bankia } & Juan Chozas & Director de Personas \\
\hline & Carlos Hernández & Director Estrategia y Políticas de Personas \\
\hline & Gemma Medrano & Directora de Directivos y Gestión de Personas \\
\hline Bankinter & María Paramés & Directora de Personas, Comunicación y Calidad \\
\hline \multirow{2}{*}{ BASF } & Gustavo Alonso & Director RR. HH. \\
\hline & Rosa Marsal & Responsable Selección y Desarrollo \\
\hline \multirow{2}{*}{ BBVA } & Ricardo Forcano & Director global de Talento y Cultura \\
\hline & Pedro J. Méndez & Director global Gestión de Talento \\
\hline \multirow{3}{*}{ CaixaBank } & Xavier Coll & Director general RR. HH. y Organización \\
\hline & Ramón García & Gerente de Formación \\
\hline & Carmen Gómez & Responsable de Desarrollo y Formación \\
\hline Calvo & Rebeca Filgueira & Directora RR. HH. División Europa \\
\hline \multirow{2}{*}{ Catalana Occidente } & Sergio Carol & Desarrollo Profesional \\
\hline & Pedro Ribes & Director RR. HH. \\
\hline Cellnex Telecom & Rosa Piñol & Resources \& Transformation Director \\
\hline Celsa & Pere Oteo & People \& Organization Chief Officer \\
\hline \multirow[t]{2}{*}{ Danone } & Javier Fernández Santín & $\begin{array}{l}\text { Employer Branding \& Talent Acquisition } \\
\text { Manager }\end{array}$ \\
\hline & Cécile Hesse & Directora de Recursos Humanos \\
\hline \multirow[b]{2}{*}{ Delaviuda } & Emma Madrid & Human Resources Manager \\
\hline & Isabel Sánchez & $\begin{array}{l}\text { Directora general corporativa, de Comunicación } \\
\text { y Personas }\end{array}$ \\
\hline \multirow{2}{*}{ Enagás } & Antonio Manzanera & Atracción y Desarrollo de Talento \\
\hline & Javier Perera & Director general de Recursos \\
\hline \multirow{2}{*}{ Endesa } & Esther Clemente & Directora de Selección y Formación \\
\hline & Marta Cotrina & Responsable de Selección \\
\hline Esteve Pharmaceuticals & Sara Giménez & Partner RR. HH. \& Gestión de Talento \\
\hline
\end{tabular}




\section{Anexo 1 (continuación)}

\begin{tabular}{|c|c|c|}
\hline Empresa & Participante & Cargo \\
\hline \multirow{3}{*}{ Ferrovial } & Alejandra Bartolomé & Talent Manager \\
\hline & Aitor Larrabe & Head of Talent \\
\hline & Marta Ortega & Talent Specialist \\
\hline Ficosa & Luis Cano & Chief HR Officer \\
\hline Fluidra & Juanjo Masoliver & Global HR Director \\
\hline \multirow[b]{2}{*}{ Ford } & Esther Gironella & Human Resources Manager \\
\hline & Enrique Roig & $\begin{array}{l}\text { Gerente de Seguridad, Prevención de Incendios } \\
\text { y Formación }\end{array}$ \\
\hline Fundación ONCE & $\begin{array}{l}\text { Sabina Lobato } \\
\text { Virginia Carcedo }\end{array}$ & $\begin{array}{l}\text { Directora de Formación, Empleo, Proyectos y } \\
\text { Convenios } \\
\text { Directora General INSERTA Empleo }\end{array}$ \\
\hline \multirow[t]{2}{*}{ Grifols } & David Payeras & $\begin{array}{l}\text { Vice President Corporate Human Resources } \\
\text { Development }\end{array}$ \\
\hline & Estíbaliz Vicente & Director, Corporate Recruitment \& Staffing \\
\hline Grupo Antolín & Javier Blanco & Director de Recursos Humanos \\
\hline Grupo Ferrer & Beatriz Vila & HR Director \\
\hline Iberdrola & Javier Azorín & $\begin{array}{l}\text { Responsable de Desarrollo, Selección y } \\
\text { Formación }\end{array}$ \\
\hline \multirow{2}{*}{ Indra } & Manuel Ausaverri & Director de Estrategia, Innovación y Gabinete \\
\hline & Natalia Fernández & Directora de Capital Humano \\
\hline \multirow{2}{*}{ Lilly } & Abel Pérez & Senior HR Director \\
\hline & Laura Podo & Human Resources Manager \\
\hline Logista & Beatriz de Miguel & Group Talent Director \\
\hline \multirow{2}{*}{ MAT Holding } & Carla Araque & Recursos Humanos y Comunicación \\
\hline & Miquel Àngel Catarineu & Director de Recursos Humanos y Comunicación \\
\hline Grupo Miquel y Costas & Jose M. Masifern & Director de Recursos Humanos \\
\hline \multirow{2}{*}{ MSD } & Sara Carbajo & HHRR Business Partner Specialist \\
\hline & Beatriz Martín & Directora Recursos Humanos España y Portugal \\
\hline \multirow[b]{2}{*}{ Mutua Madrileña } & Cristina Esteban & Gerente de Selección y Formación \\
\hline & $\begin{array}{l}\text { Rafael González- } \\
\text { Palenzuela }\end{array}$ & Director de Recursos Humanos \\
\hline \multirow{3}{*}{ Naturgy } & Daniele Conrado & Universidad Corporativa \\
\hline & Carmen Fernández & Directora de Talento Directivo y Cultura \\
\hline & Enrique Tapia & Director de Personas \\
\hline \multirow[b]{2}{*}{ Nestlé } & Luís Miguel García & Director de Recursos Humanos \\
\hline & Francisco Megías & $\begin{array}{l}\text { Responsable de Selección, Desarrollo de } \\
\text { Talento y Formación }\end{array}$ \\
\hline \multirow[t]{2}{*}{ Nissan } & $\begin{array}{l}\text { Gemma } \\
\text { Fernández- Nespral }\end{array}$ & Human Resources Director \\
\hline & Germán Pérez & Talent Management \\
\hline
\end{tabular}




\section{Anexo 1 (continuación)}

\begin{tabular}{|c|c|c|}
\hline Empresa & Participante & Cargo \\
\hline Pescanova & Pedro Casaño & Director corporativo de Personas \\
\hline \multirow{2}{*}{ Prosegur } & Juan Luis Martín & Director corporativo de RR. HH. \\
\hline & Miguel Zancajo & Director global de Talento y Cultura \\
\hline \multirow{3}{*}{ Puig } & Eulalia Alfonso & Chief Human Resources Officer \\
\hline & Raquel Roca & Brands and Fashion HR Director \\
\hline & Álvaro Sanz & Iberia Human Resources Director \\
\hline Red Eléctrica & José Luis Mata & Jefe del Departamento de Gestión de Talento \\
\hline \multirow{2}{*}{ Repsol } & Arturo Gonzalo & Director de RR. HH. \\
\hline & Silvia Sotillo & Professional Development \\
\hline Roca & Xavier Aguilera & Senior Managing Director Human Resources \\
\hline \multirow{2}{*}{ Seat } & Laura Carnicero & Gerente de Formación \\
\hline & Delfina Murillo & Reclutamiento y Servicio de Personal \\
\hline Sener & Marta Valls & Responsable Dirección de Personas Barcelona \\
\hline \multirow{2}{*}{ Siemens } & Katia Becares & Leadership \& Development \\
\hline & Dory Liquete & Talent Acquisition Specialist \\
\hline \multirow{3}{*}{ Suez } & Fernando André & $\begin{array}{l}\text { Human Resources Projects \& Governance } \\
\text { Director }\end{array}$ \\
\hline & Manuel Cermerón & Director de Estrategia y Desarrollo \\
\hline & Lluc Pejó & Gerente Escuela del Agua \\
\hline Telefónica & Rory Simpson & Chief Executive Learning Officer \\
\hline Vodafone & Remedios Orrantia & Human Resources and Property Director \\
\hline \multirow{2}{*}{ Werfen } & Lucía del Moral & VP Corporate Human Resources \\
\hline & Itziar Rabasa & HR Director Iberia \\
\hline \multirow{3}{*}{ Zurich } & Elena Balletbó & HR Senior Specialist \\
\hline & Carlos Esteban & Director de RRHH, Comunicación Interna y RSC \\
\hline & Gemma Herms & Human Resources, Talent Acquisition \\
\hline
\end{tabular}




\section{Anexo 1 (continuación)}

Tabla 1

Distribución de ingresos y empleados de los sectores representados por las empresas participantes, 2017

\begin{tabular}{|l|r|r|r}
\hline Sectores & $\begin{array}{c}\text { Ingresos } \\
\mathbf{2 0 1 7 1} \\
\mathbf{( M E )}\end{array}$ & $\begin{array}{c}\text { Empleados } \\
\text { en todo el } \\
\text { mundo } \\
\mathbf{( 2 0 1 7 )}\end{array}$ & $\begin{array}{c}\text { Empleados } \\
\text { en España } \\
\text { (2017) }\end{array}$ \\
\hline Alimentación y bebidas & 28.448 & 444.218 & 7.442 \\
\hline Automoción y componentes & 27.592 & 392.930 & 22.591 \\
\hline Banca y seguros & 141.443 & 518.642 & 129.320 \\
\hline Construcción, servicios de ingeniería, aeronáutica y espacial & 28.628 & 336.228 & 85.379 \\
\hline Distribución comercial, venta minorista y bienes de consumo & 5.814 & 98.712 & 73.441 \\
\hline Electrónica, tecnología de la información y telecomunicaciones & 67.139 & 661.181 & 66.498 \\
\hline Energía & 121.616 & 88.081 & 43.299 \\
\hline Salud & 1.337 & 5.015 & 692 \\
\hline Logística y transporte & 9.493 & 5.586 & 3.352 \\
\hline Medios de comunicación & 1.052 & 2.089 & 2.089 \\
\hline Químico y farmacia & 10.561 & 249.090 & 12.721 \\
\hline Servicios profesionales & 4.291 & 168.461 & 939 \\
\hline Total & 447.413 & $\mathbf{2 . 9 7 0 . 2 3 3}$ & $\mathbf{4 4 7 . 7 6 3}$ \\
\hline
\end{tabular}

Fuente: Informe Anual e información de las empresas entrevistadas.

${ }^{11}$ Para las empresas no españolas hemos computado su facturación en España en 2017. 


\section{Anexo 2 \\ Propuestas procedentes de las empresas. Algunas experiencias empresariales significativas}

Numerosas empresas, de forma individual o en colaboración con otras, han puesto en marcha iniciativas para tratar de aportar soluciones, aunque sean parciales, al problema del desempleo juvenil. Muchas de ellas hacen referencia a la necesidad de fomentar la penetración de la formación profesional y la formación profesional dual en nuestro país. A continuación mencionamos brevemente algunas de ellas a modo de referencia.

\section{Nestlé}

En 2013, Nestlé comenzó a desarrollar la Iniciativa Europea de Empleo Juvenil con el programa Nestlé needs YOUth. En 3 años, proporcionaron 20.000 oportunidades de empleo para jóvenes europeos y, en el caso de España, han empleado mediante este programa a 1.250 jóvenes, de los que unos 750 pasarán a formar parte de la compañía para cubrir nuevas necesidades de empleo. Los restantes se incorporarán a través de programas de formación profesional dual - vigentes en la oficina central y en las fábricas de Gerona, La Penilla (Cantabria), Viladrau (Gerona) y Pontecesures (Pontevedra)-, de programas internacionales -como el convenio de colaboración establecido con Nestlé Alemania- y de conciertos educativos con universidades e institutos de formación profesional.

En 2017, Nestlé se marcó un nuevo objetivo, consistente en ayudar a 10 millones de jóvenes de todo el mundo a acceder a oportunidades laborales y de desarrollo económico hasta el año 2030. En concreto, Nestlé España se comprometió a promover 1.400 nuevas oportunidades de empleo y formación para jóvenes entre 2017 y 2020.

La empresa también ratificó su compromiso con los jóvenes, siendo una de las primeras compañías en unirse a la Iniciativa Global sobre Empleo Decente para los Jóvenes (OIT). Además, recibió un reconocimiento por estar adscrita a la Estrategia de Emprendimiento y Empleo Joven promovida por el Ministerio de Trabajo, Migraciones y Seguridad Social con el objetivo de favorecer la inserción de los jóvenes en el ámbito laboral y mejorar su situación dentro del mercado de trabajo.

Fuente: información proporcionada por la empresa Nestlé.

\section{BASF}

Ha creado el Programa de Formación Profesional Dual Transnacional, que consiste en la realización del Ciclo Formativo de Grado Superior de Química Industrial en el Institut Comte de Rius de Tarragona, en el que se imparten clases de alemán y se realizan prácticas en BASF en los centros de producción de Tarragona y Ludwigshafen (Alemania).

La duración es de 2 años y 4 meses, de los cuales 9 meses son de prácticas en la empresa, 3 de ellos en Tarragona y 6 en la ciudad alemana de Ludwigshafen. Durante todo el programa se imparten clases en alemán y, una vez terminado, los jóvenes pueden optar a puestos de operadores de planta en ese país.

Por otro lado, BASF colabora con el Observatorio de Formación Profesional Dual, liderado por la Asociación para el Progreso de la Dirección APD, el Centro de Estudios Sagardoy y el Club de Excelencia en Sostenibilidad. 


\section{Anexo 2 (continuación)}

El Observatorio funciona como un foro de discusión sobre las mejores prácticas e iniciativas en formación profesional dual, con el doble objetivo de sensibilizar al tejido empresarial, a la Administración y a las distintas comunidades autónomas para la puesta en marcha de planes de formación profesional dual y políticas públicas de promoción en esta materia.

"El principal acuerdo entre las partes es el compromiso conjunto de desarrollar, analizar e impulsar la colaboración en el diseño e impulso de programas de formación dual".

Fuente: información proporcionada por la empresa BASF.

\section{Fundación Bertelsmann}

Bertelsmann ha sido la empresa impulsora de la Alianza para la Formación Profesional Dual. Esta iniciativa, promovida también por la Fundación Princesa de Girona junto con la CEOE, la CEPYME y la Cámara de Comercio de España, cuenta con la participación de numerosas compañías como Deloitte, Acciona, Agbar, CaixaBank, Bosch, Mercedes-Benz España, Naturgy, Nestlé, Repsol, Seat, Sol Meliá o Siemens, entre otras.

Su misión es conseguir una mayor implantación de la formación profesional dual en España y mejorar la empleabilidad de los jóvenes al mismo tiempo que las empresas obtienen profesionales con una formación acorde a sus necesidades.

Pretende aglutinar las mejores iniciativas y experiencias que se están llevando a cabo para que confluyan, se retroalimenten y se extiendan a más empresas, centros e instituciones de nuestro país.

La Alianza ha definido 4 objetivos más concretos y estratégicos para la expansión de la formación profesional dual en España:

- Construir un modelo de formación profesional dual de calidad.

- Implicar a las pymes en la formación profesional dual.

- Mejorar el marco legal y jurídico existente.

- Aumentar el prestigio social de la formación profesional y, concretamente, de la formación profesional dual.

Como resultado de esta iniciativa, ya se ha lanzado un programa junto a la AEC (Asociación Española de Empresas de Consultoría) y otras compañías para ofrecer 90 plazas de especialización en Java, big data y ciberseguridad.

Por otro lado, han desarrollado el Proyecto de Orientación Profesional Coordinada con el objetivo de que los alumnos dispongan de la información necesaria para tomar una decisión acertada sobre su futuro laboral. La empresa considera que una orientación de calidad minimiza los efectos del abandono escolar, mejora la empleabilidad y la permeabilidad entre el sistema educativo y el mundo empresarial.

Para ello, es necesario que el proceso de orientación incluya a todos los actores relevantes del entorno de los jóvenes. Bertelsmann está desarrollando diversos proyectos piloto, comenzando por 30 centros de Cataluña, Andalucía y Madrid. Pretenden diseñar una metodología extensible al resto de territorios y centros.

Fuente: información proporcionada por la Fundación Bertelsmann. 


\section{Anexo 3}

\section{Encuesta. Desarrollo de las competencias profesionales del futuro}

\section{Perfiles profesionales en su empresa y evolución}

1. ¿Qué perfiles contratan en su empresa para cada uno de los siguientes niveles educativos?

\begin{tabular}{|c|c|c|c|c|c|c|}
\hline & \multicolumn{2}{|c|}{$\begin{array}{l}\text { Comercial, } \\
\text { Marketing }\end{array}$} & \multicolumn{2}{|c|}{$\begin{array}{l}\text { Operaciones, } \\
\text { Tecnologia, I+D }\end{array}$} & \multicolumn{2}{|c|}{$\begin{array}{l}\text { Servicios Corporativos } \\
\text { (financiero, } \\
\text { administración...) }\end{array}$} \\
\hline & $\begin{array}{c}\text { Total } \\
\text { empleados }\end{array}$ & $\begin{array}{l}\text { Contratación } \\
\text { en el último } \\
\text { año }\end{array}$ & $\begin{array}{c}\text { Total } \\
\text { empleados }\end{array}$ & $\begin{array}{l}\text { Contratación } \\
\text { en el último } \\
\text { año }\end{array}$ & $\begin{array}{l}\text { Total } \\
\text { empleados }\end{array}$ & $\begin{array}{l}\text { Contratación } \\
\text { en el último } \\
\text { año }\end{array}$ \\
\hline \multicolumn{7}{|l|}{ Grado superior ${ }^{12}$} \\
\hline \multicolumn{7}{|l|}{ Grado medio ${ }^{13}$} \\
\hline \multicolumn{7}{|l|}{ Formación profesional } \\
\hline Educación obligatoria & & & & & & \\
\hline
\end{tabular}

2. Durante la última década, los avances tecnológicos, la mayor internacionalización de las empresas, o los nuevos modelos de negocio, entre otros, han comportado un cambio en las necesidades de las empresas respecto a los perfiles de personas que necesitan. ¿A qué se debe el cambio de perfil en su empresa? 1 (nada de acuerdo) - 5 (totalmente de acuerdo)

\begin{tabular}{|l|l|l|l|l|}
\hline & 1 & 2 & 3 & 5 \\
\hline Revolución digital & & & \\
\hline Automatización (IA) & & & \\
\hline Necesidades de los clientes & & & \\
\hline Internacionalización & & & \\
\hline Mayor rivalidad & & & \\
\hline Otros & & & \\
\hline
\end{tabular}

\footnotetext{
12 Actual: grado + máster. Anterior: licenciatura, Ingeniería / Arquitectura Superior

${ }^{13}$ Actual: grado. Anterior: diplomatura, Ingeniería / Arquitectura Técnica
} 


\section{Anexo 3 (continuación)}

3. ¿Cómo ha afectado el cambio del perfil que necesitan en los últimos años según el departamento y el nivel formativo? 1 (poco) -5 (mucho)

\begin{tabular}{|c|c|c|c|c|c|c|c|c|c|c|c|c|c|c|c|}
\hline & \multicolumn{5}{|c|}{$\begin{array}{l}\text { Comercial, } \\
\text { Marketing }\end{array}$} & \multicolumn{5}{|c|}{$\begin{array}{l}\text { Operaciones, } \\
\text { Tecnologia, I+D }\end{array}$} & \multicolumn{5}{|c|}{$\begin{array}{l}\text { Servicios Corporativos } \\
\text { (financiero, } \\
\text { administración...) }\end{array}$} \\
\hline & 1 & 2 & 3 & 4 & 5 & 1 & 2 & 3 & 4 & 5 & 1 & 2 & 3 & 4 & 5 \\
\hline \multicolumn{16}{|l|}{ Grado superior } \\
\hline \multicolumn{16}{|l|}{ Grado medio } \\
\hline \multicolumn{16}{|l|}{ Formación profesional } \\
\hline Educación obligatoria & & & & & & & & & & & & & & & \\
\hline
\end{tabular}




\section{Anexo 3 (continuación)}

4. ¿Cómo cree que cambiará este perfil en los próximos años? Por favor, indique qué conocimientos, capacidades o actitudes específicos se requerirán en cada nivel. 1 (poco) - 5 (mucho)

\begin{tabular}{|c|c|c|c|c|c|c|c|c|c|c|c|}
\hline & \multicolumn{11}{|c|}{ Grado superior y grado medio } \\
\hline & & \multicolumn{5}{|c|}{2018} & \multicolumn{5}{|c|}{2023} \\
\hline & & 1 & 2 & 3 & 4 & 5 & 1 & 2 & 3 & 4 & 5 \\
\hline \multirow{7}{*}{ Conocimientos } & Marketing digital & & & & & & & & & & \\
\hline & Idiomas & & & & & & & & & & \\
\hline & Finanzas & & & & & & & & & & \\
\hline & Big data & & & & & & & & & & \\
\hline & Inteligencia artificial & & & & & & & & & & \\
\hline & Blockchain & & & & & & & & & & \\
\hline & Otros & & & & & & & & & & \\
\hline \multirow{6}{*}{ Capacidades } & $\begin{array}{l}\text { Capacidad de } \\
\text { comunicación }\end{array}$ & & & & & & & & & & \\
\hline & Negociación & & & & & & & & & & \\
\hline & Orientación al cliente & & & & & & & & & & \\
\hline & Trabajo en equipo & & & & & & & & & & \\
\hline & Capacidad de ejecución & & & & & & & & & & \\
\hline & Otros & & & & & & & & & & \\
\hline \multirow{8}{*}{ Actitudes } & Iniciativa & & & & & & & & & & \\
\hline & Adaptabilidad, resiliencia & & & & & & & & & & \\
\hline & Sentido emprendedor & & & & & & & & & & \\
\hline & Sensibilidad multicultural & & & & & & & & & & \\
\hline & Respeto & & & & & & & & & & \\
\hline & Valores éticos & & & & & & & & & & \\
\hline & Pensamiento creativo & & & & & & & & & & \\
\hline & Otros & & & & & & & & & & \\
\hline
\end{tabular}




\section{Anexo 3 (continuación)}

\begin{tabular}{|c|c|c|c|c|c|c|c|c|c|c|c|}
\hline & \multicolumn{11}{|c|}{ Formación profesional } \\
\hline & & \multicolumn{5}{|c|}{2018} & \multicolumn{5}{|c|}{2023} \\
\hline & & 1 & 2 & 3 & 4 & 5 & 1 & 2 & 3 & 4 & 5 \\
\hline \multirow{7}{*}{ Conocimientos } & Marketing digital & & & & & & & & & & \\
\hline & Idiomas & & & & & & & & & & \\
\hline & Finanzas & & & & & & & & & & \\
\hline & Big data & & & & & & & & & & \\
\hline & Inteligencia artificial & & & & & & & & & & \\
\hline & Blockchain & & & & & & & & & & \\
\hline & Otros & & & & & & & & & & \\
\hline \multirow{6}{*}{ Capacidades } & $\begin{array}{l}\text { Capacidad de } \\
\text { comunicación }\end{array}$ & & & & & & & & & & \\
\hline & Negociación & & & & & & & & & & \\
\hline & Orientación al cliente & & & & & & & & & & \\
\hline & Trabajo en equipo & & & & & & & & & & \\
\hline & Capacidad de ejecución & & & & & & & & & & \\
\hline & Otros & & & & & & & & & & \\
\hline \multirow{8}{*}{ Actitudes } & Iniciativa & & & & & & & & & & \\
\hline & Adaptabilidad, resiliencia & & & & & & & & & & \\
\hline & Sentido emprendedor & & & & & & & & & & \\
\hline & Sensibilidad multicultural & & & & & & & & & & \\
\hline & Respeto & & & & & & & & & & \\
\hline & Valores éticos & & & & & & & & & & \\
\hline & Pensamiento creativo & & & & & & & & & & \\
\hline & Otros & & & & & & & & & & \\
\hline
\end{tabular}




\section{Anexo 3 (continuación)}

\begin{tabular}{|c|c|c|c|c|c|c|c|c|c|c|c|}
\hline & \multicolumn{11}{|c|}{ Educación obligatoria } \\
\hline & & \multicolumn{5}{|c|}{2018} & \multicolumn{5}{|c|}{2023} \\
\hline & & 1 & 2 & 3 & 4 & 5 & 1 & 2 & 3 & 4 & 5 \\
\hline \multirow{7}{*}{ Conocimientos } & Marketing digital & & & & & & & & & & \\
\hline & Idiomas & & & & & & & & & & \\
\hline & Finanzas & & & & & & & & & & \\
\hline & Big data & & & & & & & & & & \\
\hline & Inteligencia artificial & & & & & & & & & & \\
\hline & Blockchain & & & & & & & & & & \\
\hline & Otros & & & & & & & & & & \\
\hline \multirow{6}{*}{ Capacidades } & $\begin{array}{l}\text { Capacidad de } \\
\text { comunicación }\end{array}$ & & & & & & & & & & \\
\hline & Negociación & & & & & & & & & & \\
\hline & Orientación al cliente & & & & & & & & & & \\
\hline & Trabajo en equipo & & & & & & & & & & \\
\hline & Capacidad de ejecución & & & & & & & & & & \\
\hline & Otros & & & & & & & & & & \\
\hline \multirow{8}{*}{ Actitudes } & Iniciativa & & & & & & & & & & \\
\hline & Adaptabilidad, resiliencia & & & & & & & & & & \\
\hline & Sentido emprendedor & & & & & & & & & & \\
\hline & Sensibilidad multicultural & & & & & & & & & & \\
\hline & Respeto & & & & & & & & & & \\
\hline & Valores éticos & & & & & & & & & & \\
\hline & Pensamiento creativo & & & & & & & & & & \\
\hline & Otros & & & & & & & & & & \\
\hline
\end{tabular}




\section{Anexo 3 (continuación)}

5. La automatización y la inteligencia artificial están cambiando la naturaleza del trabajo. Almacenes robotizados, cadenas de producción automáticas o robots en centros de atención al cliente son algunos de los ejemplos de cómo han cambiado las tareas que las personas desarrollan en sus puestos de trabajo. En su empresa, ¿cuál será el grado de automatización de estas funciones en 5 años? 1 (nula) - 5 (completa)

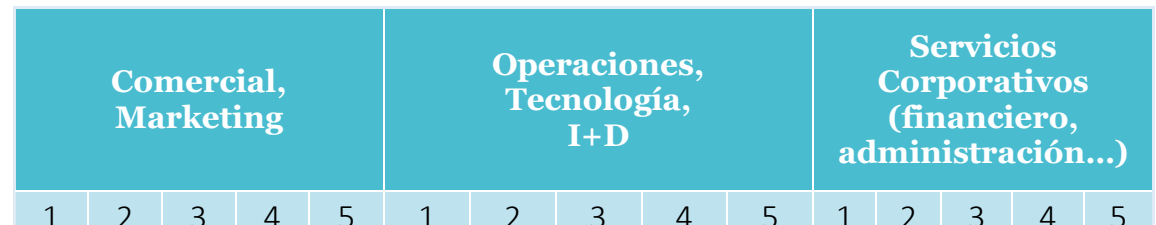

\begin{tabular}{|l|l|l|l|l|l|l|l|l|l|l|l|}
\hline Grado superior & & & \\
\hline Grado medio & & & \\
\hline Formación profesional & & & \\
\hline Educación obligatoria & & & \\
\hline
\end{tabular}




\section{Anexo 3 (continuación)}

\section{Ajuste/desajuste de conocimientos, capacidades y actitudes}

6. ¿Considera que su empresa tiene dificultades actualmente para cubrir los puestos de trabajo debido a los cambios de perfiles?

\begin{tabular}{|l|l|l|l|}
\hline Muy pocas & Pocas & Bastantes \\
\hline & & \\
\hline
\end{tabular}

7. ¿De dónde proceden los empleados de su empresa para cada categoría profesional?

\begin{tabular}{|c|c|c|c|c|}
\hline & $\begin{array}{c}\text { Centros } \\
\text { universitarios }\end{array}$ & $\begin{array}{l}\text { Formación } \\
\text { profesional }\end{array}$ & $\begin{array}{l}\text { Formación } \\
\text { profesional } \\
\text { dual }\end{array}$ & Otros \\
\hline \multicolumn{5}{|l|}{ Grado superior } \\
\hline \multicolumn{5}{|l|}{ Grado medio } \\
\hline \multicolumn{5}{|l|}{ Formación profesional } \\
\hline Educación obligatoria & & & & \\
\hline
\end{tabular}

8. ¿Cuál es su grado de satisfacción con la calidad de la formación de las personas que contratan? 1 (nada satisfecho) - 5 (muy satisfecho)

\begin{tabular}{|l|l|l|l|l|}
\hline & 1 & 2 & 3 & 4 \\
\hline Grado superior & & & 5 \\
\hline Grado medio & & & \\
\hline Formación profesional & & & \\
\hline Educación obligatoria & & & \\
\hline
\end{tabular}




\section{Anexo 3 (continuación)}

9. ¿En qué nivel o puestos encuentra un mayor desajuste entre lo que necesita su empresa y lo que ofrece el sistema educativo? 1 (desajuste bajo) - 5 (desajuste alto).

\begin{tabular}{|l|l|l|l|l|}
\hline & 1 & 2 & 3 & 4 \\
\hline Grado superior & & & \\
\hline Grado medio & & & \\
\hline Formación profesional & & & \\
\hline Educación obligatoria & & & \\
\hline
\end{tabular}

10. En caso de que exista un desajuste, ¿cree que se debe más a la falta de conocimientos, capacidades o actitudes? Por favor, especifique en cada nivel los conocimientos, capacidades y actitudes que debería ofrecer y no ofrece el sistema educativo.

\begin{tabular}{|l|l|}
\hline & Conocimientos \\
\hline Grado superior y & \\
\hline grado medio & \\
\hline Formación & \\
\hline profesional & \\
\hline
\end{tabular}


Anexo 3 (continuación)

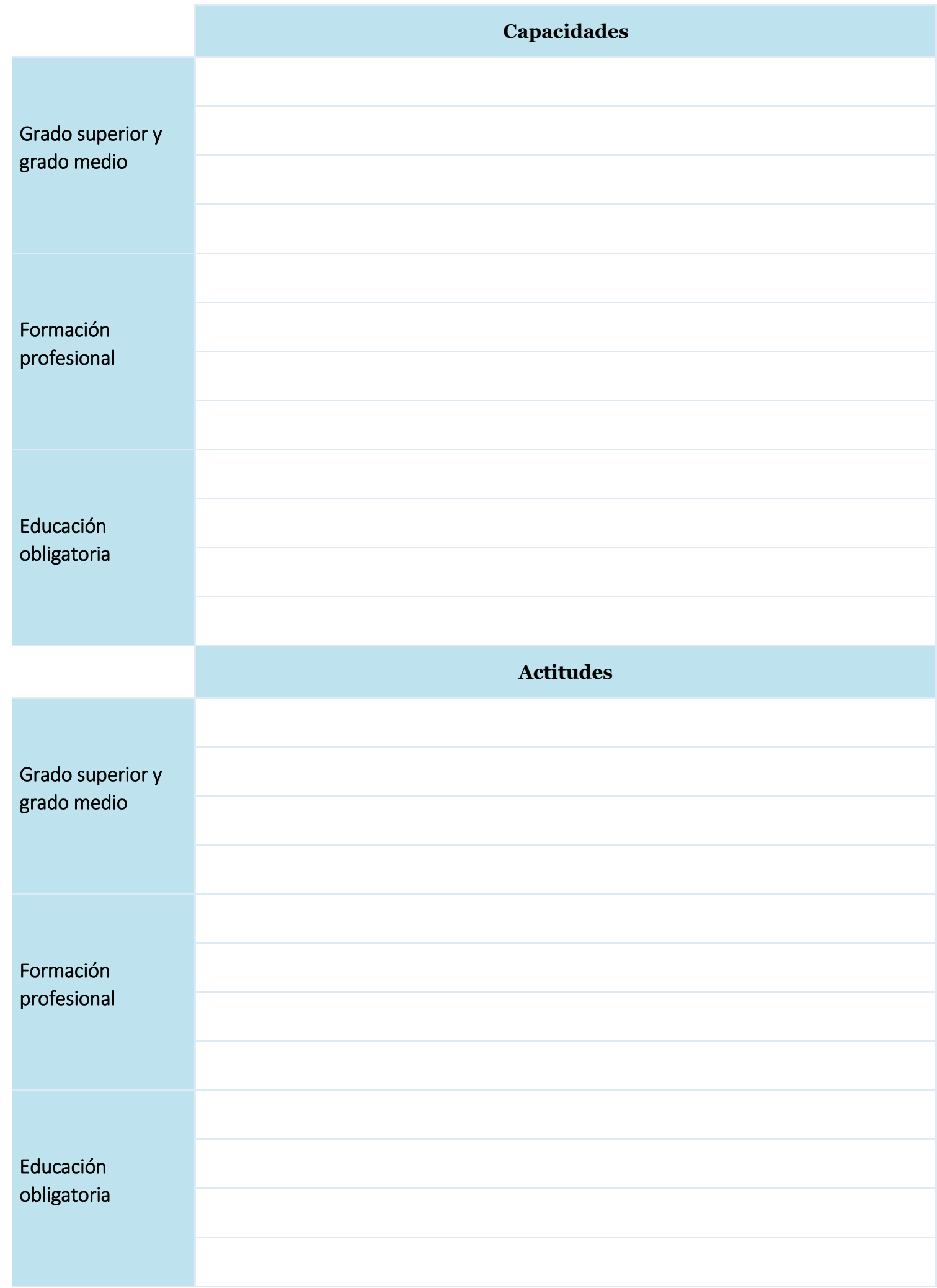




\section{Anexo 3 (continuación)}

\section{Propuesta de soluciones}

11. ¿Cree que la solución para un mejor encaje de los perfiles demandados y encontrados debería venir por alguna de las siguientes vías? 1 (totalmente en desacuerdo) - 5 (totalmente de acuerdo)

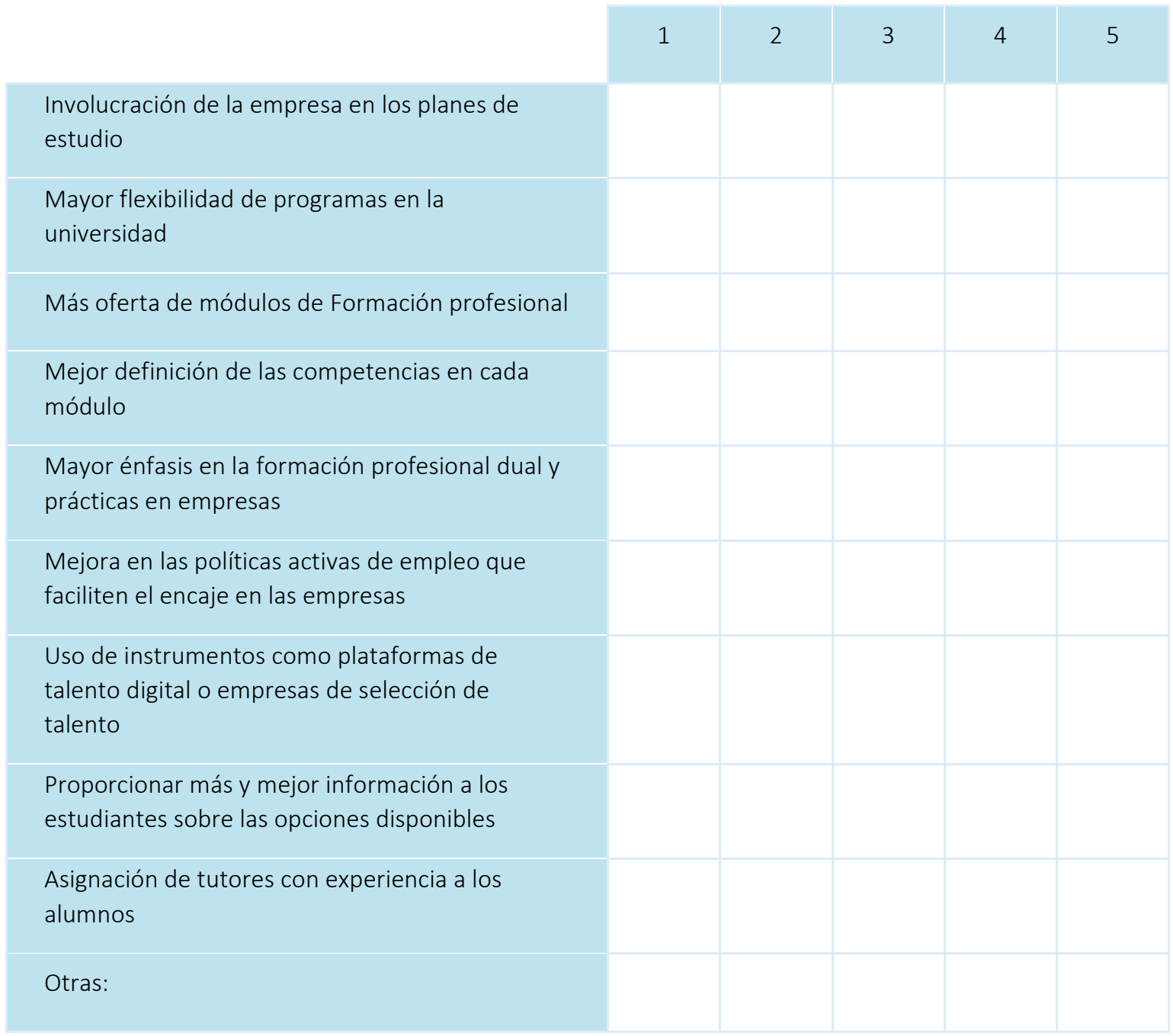




\section{Anexo 3 (continuación)}

12. ¿Quiénes cree que son los actores clave para asegurar el futuro del trabajo y cuál es el papel de cada uno en este proceso? 1 (totalmente en desacuerdo) - 5 (totalmente de acuerdo)

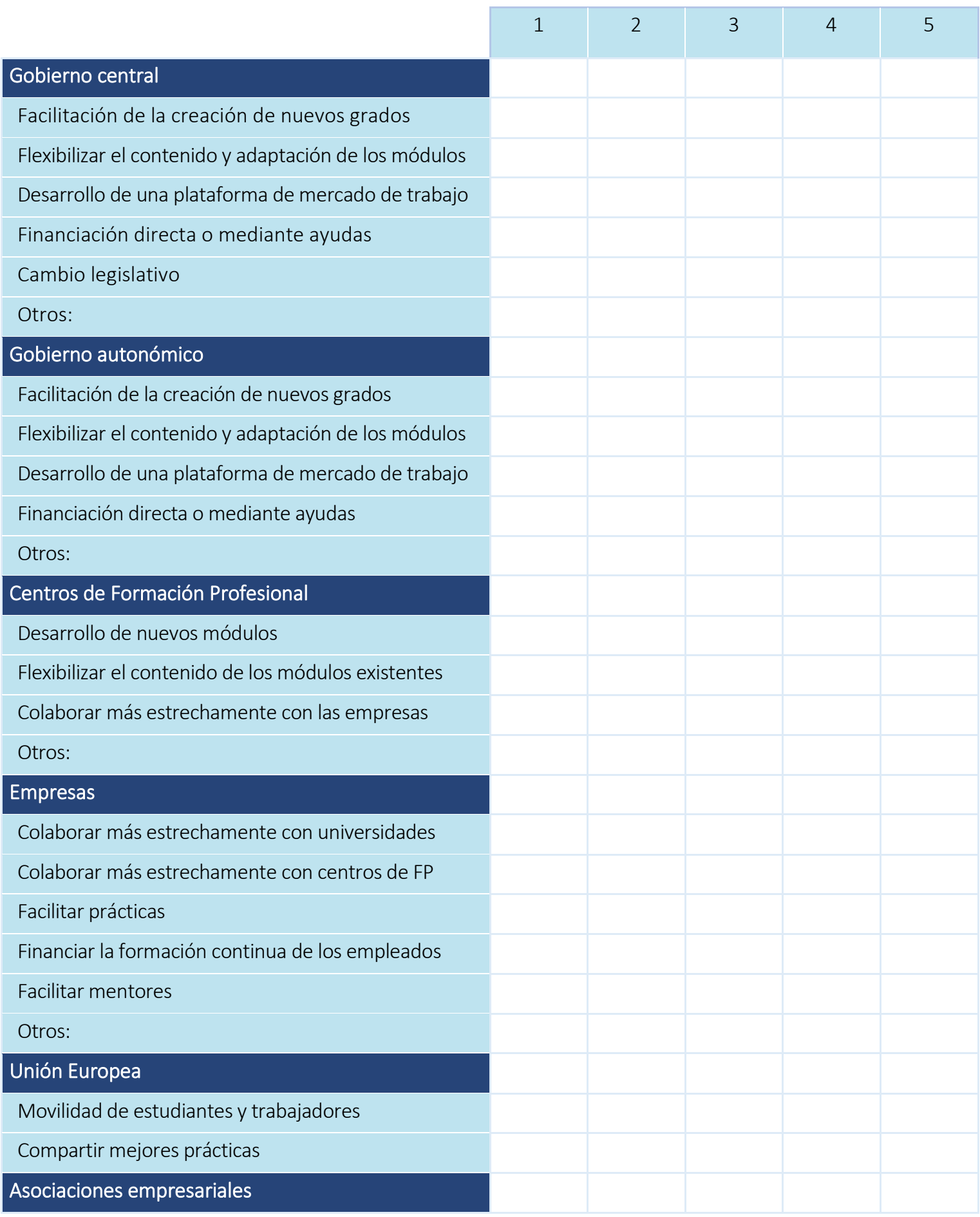




\section{Anexo 3 (continuación)}

\section{Posible implicación de su empresa}

13. Como empresa, ¿̇tiene alguna relación continua con universidades o centros de formación profesional para colaborar en proyectos formativos? 1 (relación baja) - 5 (relación alta)

\begin{tabular}{|l|l|l|l|l|l|}
\hline UNIVERSIDADES & 1 & 2 & 3 & 4 & 5 \\
\hline Diseño de programas y cursos & & & & \\
\hline Colaboración con profesores & & & \\
\hline Contratación de alumnos & & & \\
\hline Relación institucional & & & \\
\hline Otras: & & \\
\hline
\end{tabular}

\begin{tabular}{|l|l|l|l|l|l|}
\hline CENTROS DE FORMACIÓN PROFESIONAL & 1 & 2 & 3 & 4 & 5 \\
\hline Diseño de programas y cursos & & & \\
\hline Colaboración con profesores & & \\
\hline Contratación de alumnos & & \\
\hline Relación institucional & & \\
\hline Otras:
\end{tabular}

14. Indique los centros con los que colabora activamente. ¿Con cuáles tiene una mejor experiencia? ¿’Por qué?

15. ¿Puede describir alguna experiencia positiva que haya tenido en la formación, contratación o retención de personas jóvenes? 


\section{Anexo 3 (continuación)}

16. Otras áreas posibles de colaboración de su empresa con centros de formación en el futuro. 1 (nada de acuerdo) - 5 (totalmente de acuerdo).

\begin{tabular}{|c|c|c|c|c|c|}
\hline \multirow{2}{*}{$\begin{array}{l}\text { Colaboración en definición de perfiles necesarios y } \\
\text { competencias/módulos más adecuados para } \\
\text { cubrirlos }\end{array}$} & 1 & 2 & 3 & 4 & 5 \\
\hline & & & & & \\
\hline \multicolumn{6}{|l|}{ Colaboración en formación en los centros } \\
\hline \multicolumn{6}{|l|}{ Proporcionar trabajo en prácticas a alumnos } \\
\hline \multicolumn{6}{|l|}{$\begin{array}{l}\text { Colaboración económica - financiación de } \\
\text { programas }\end{array}$} \\
\hline \multicolumn{6}{|l|}{$\begin{array}{l}\text { Proporcionar apoyo para comunicación y visibilidad } \\
\text { a nivel institucional }\end{array}$} \\
\hline Otras: & & & & & \\
\hline
\end{tabular}

17. ¿Qué tipo de ayuda le gustaría recibir del gobierno correspondiente para facilitar el desarrollo de competencias profesionales y empleabilidad de las personas en su empresa? 1 (totalmente en desacuerdo) - 5 (totalmente de acuerdo)

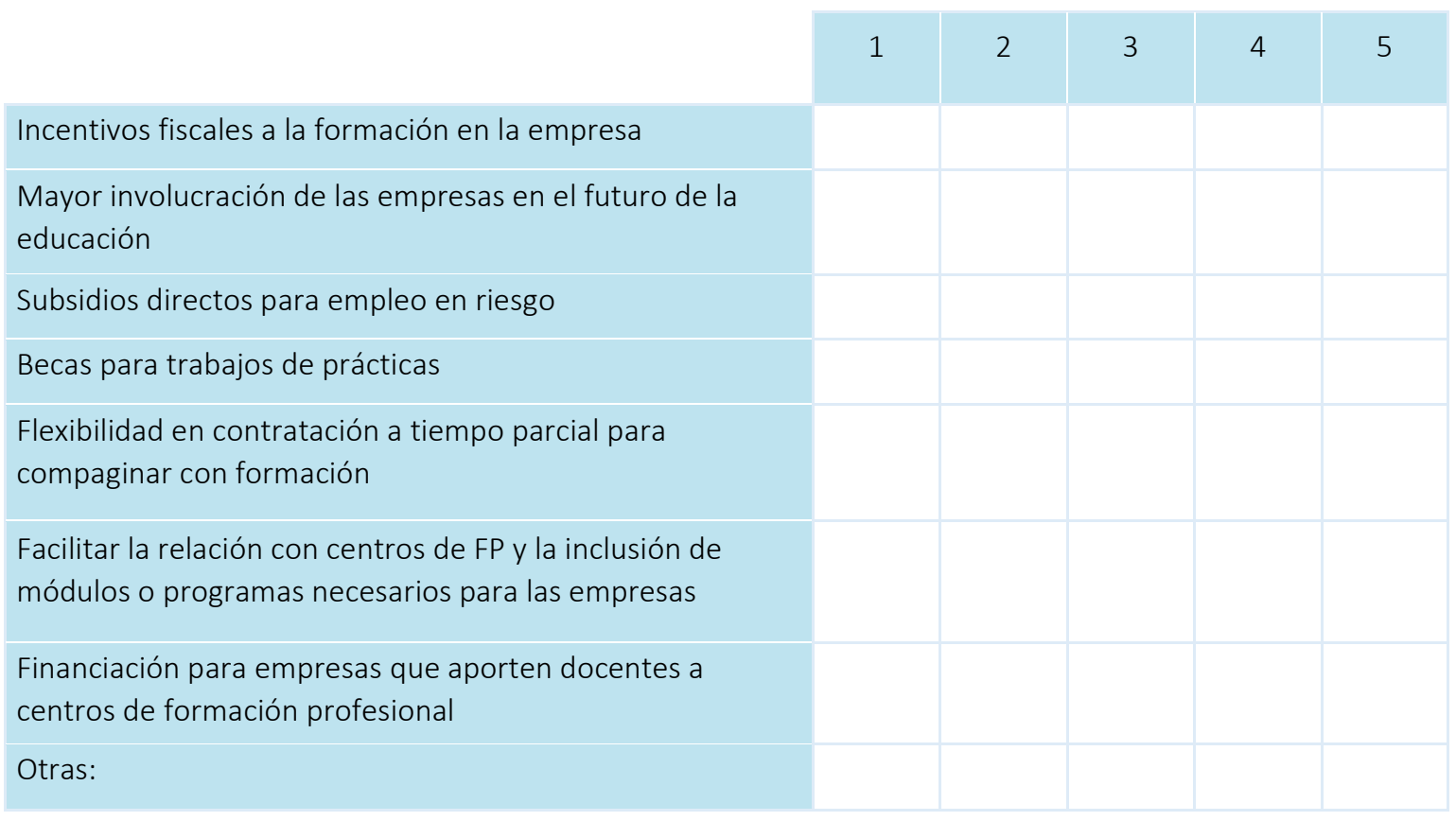




\section{Bibliografía}

Acemoglu, D., y P. Restrepo (2017), "Robots and Jobs: Evidence from US labor Markets", National Bureau of Economic Research, Working Paper n.ㅇ 23285.

Apascaritei, P. y M. Elvira (2018), Agilidad Estratégica a través del Capital Humano, IESE y Meta4, Barcelona.

Autor, D. y D. Dorn (2013), "The Growth of Low-Skill Service Jobs and the Polarization of the US Labor Market", American Economic Review, vol. 103(5), pp. 1553-1597.

Autor, D., D. Dorn, y G. Hanson (2013), "The China Syndrome: Local Labor Market Effects of Import Competition in the United States", American Economic Review, vol. 103(6), pp. 2121-2168.

Autor, D., y M. Handel (2013), "Putting Tasks to the Test: Human Capital, Job Tasks, and Wages", Journal of Labor Economics, vol. 31(2), pp. 59-96.

Autor, D. (2015), "Why Are There Still So Many Jobs? The History and Future of Workplace Automation", Journal of Economic Perspectives, vol. 29(3), pp. 3-30.

Banco de España (2018a), Boletín Económico 2/2018, Madrid.

Banco de España (2018b), Informe Anual 2017, Madrid.

Bentolila, S., J. J. Dolado, y J. F. Jimeno (2008), "Does Immigration Affect the Phillips Curve? Some Evidence for Spain", Banco de España, Working Paper n.o 0814.

Bentolila, S., J. I. García-Pérez, y M. Jansen (2017), "Are the Spanish Long-Term Unemployed Unemployable?", Journal of the Spanish Economic Association, SERIEs, vol. 8(1), pp. 1-41.

Canals, J. (2012), "Rethinking Global Leadership Development: Designing New Paradigms". En J. Canals, Leadership Development in a Global World, Palgrave Macmillan, Houndmills.

Cardona, P., y P. García-Lombardía (2005), Cómo desarrollar las competencias de liderazgo, EUNSA, Pamplona.

CEOE (2017), "La educación importa: libro blanco de los empresarios españoles", Madrid.

Círculo de Empresarios (2018), "El Barómetro de los Círculos", Madrid.

Consejo Económico y Social (2015), “Informe 03/2015. Competencias profesionales y empleabilidad", Madrid.

Dolado, J., et al. (2013), "Youth Labour Market Performance in Spain and its Determinants: A Micro-Level Perspective", OECD Economics Department Working Papers, n.․1039, OECD Publishing, París.

Eurostat (2018a), Early Leavers from Education and Training.

Eurostat (2018b), Employment Statistics.

Eurostat (2019), Unemployment Statistics.

Fundación ATRESMEDIA, Fundación MAPFRE, e IESE (2018), Reflexiones sobre la Formación Profesional de Grado Medio y Superior en España, Madrid. 


\section{Bibliografía (continuación)}

Fundación Conocimiento y Desarrollo (2017), "Informe CYD 2017".

Gallup (2018), The Gig Economy and Alternative Work Arrangements.

Goos, M., A. Manning, y A. Salomons (2014), “Explaining Job Polarization: Routine-Biased Technological Change and Offshoring", American Economic Review, vol. 104(8), pp.2509-2526.

Gortázar, L. (2018), "Transformación digital y consecuencias para el empleo en España: una revisión de la investigación reciente", Working Papers 2018/04, FEDEA.

Harris, K., A. Kimson, y A. Schwedel, A. (2018), "Labor 2030: The Collision of Demographics, Automation and Inequality", Bain \& Company.

Instituto Nacional de Estadística (2018a), Encuesta de Población Activa.

Instituto Nacional de Estadística (2018b), Proyecciones de población.

Instituto Nacional de Estadística (2019), Encuesta de Población Activa.

Jansen, M., y D. Troncoso-Ponce (2018), El impacto de los contratos para la formación y el aprendizaje en la inserción laboral de los jóvenes, Fedea y J.P. Morgan, Madrid.

McKinsey Global Institute (2016), "Independent Work: Choice, Necessity, and the Gig Economy", McKinsey\&Company.

McKinsey Global Institute (2018), "Skill Shift Automation and the Future of the Workforce", McKinsey\&Company.

Nedelkoska, L., y G. Quintini (2018), “Automation, Skills Use and Training”, OECD Social, Employment and Migration Working Papers, n. 202, OECD Publishing, París.

OCDE (2016), Education at a Glance 2016: OECD Indicators, OECD Publishing, París.

OCDE (2017a), Economic Policy Reforms 2017: Going for Growth, OECD Publishing, París.

OCDE (2017b), OECD Employment Outlook 2017, OECD Publishing, París.

OCDE (2018a), Education at a Glance 2018: OECD Indicators, OECD Publishing, París

OCDE (2018b), Getting Skills Right, OECD Publishing, París.

OCDE (2018c), Job Creation and Local Economic Development 2018: Preparing for the Future of Work, OECD Publishing, París.

OCDE (2018d), OECD Labour Force Statistics, OECD Publishing, París.

OCDE (2018e), OECD Productivity Statistics: GDP per capita and productivity growth, OECD Publishing, París.

Randstad Research (2016), "La digitalización: ¿crea o destruye empleo?”.

Subdirección General de Estadística y Estudios del Ministerio de Educación y Formación Profesional (2018), Estadísticas de las Enseñanzas no universitarias. 


\section{Bibliografía (continuación)}

Subsecretaría de Trabajo, Migraciones y Seguridad Social (2018a), "Jóvenes y mercado de trabajo", ก. 016.

Subsecretaría de Trabajo, Migraciones y Seguridad Social (2018b), "Jóvenes y mercado de trabajo", ก. 017 .

World Economic Forum (2016), "The Future of Jobs Report 2016".

World Economic Forum (2018a), "The Future of Jobs Report 2018".

World Economic Forum (2018b), "The Global Competitiveness Report". 





\section{www.iese.edu}

Barcelona

Madrid

Munich

New York

São Paulo 